FEDERAL RESERVE BANK OF SAN FRANCISCO

WORKING PAPER SERIES

\title{
A Risk-based Theory of Exchange Rate Stabilization
}

\author{
Tarek A. Hassan \\ Boston University \\ NBER and CEPR \\ Thomas M. Mertens \\ Federal Reserve Bank of San Francisco \\ Tony Zhang \\ Boston University \\ May 2020 \\ Working Paper 2016-15 \\ https://www.frbsf.org/economic-research/publications/working-papers/2016/15/
}

\section{Suggested citation:}

Hassan, Tarek A., Thomas M. Mertens, Tony Zhang. 2020. “A Risk-based Theory of Exchange Rate Stabilization.” Federal Reserve Bank of San Francisco Working Paper 201615. https://doi.org/10.24148/wp2016-15

The views in this paper are solely the responsibility of the authors and should not be interpreted as reflecting the views of the Federal Reserve Bank of San Francisco or the Board of Governors of the Federal Reserve System. 


\title{
A Risk-based Theory of Exchange Rate Stabilization*
}

\author{
Tarek A. Hassan ${ }^{\dagger} \quad$ Thomas M. Mertens ${ }^{\ddagger} \quad$ Tony Zhang ${ }^{\S}$
}

May 2020

\begin{abstract}
We develop a novel, risk-based theory of the effects of exchange rate stabilization. In our model, the choice of exchange rate regime allows policymakers to make their currency, and by extension, the firms in their country, a safer investment for international investors. Policies that induce a country's currency to appreciate when the marginal utility of international investors is high lower the required rate of return on the country's currency and increase the world-market value of domestic firms. Applying this logic to exchange rate stabilizations, we find a small economy stabilizing its bilateral exchange rate relative to a larger economy can increase domestic capital accumulation, domestic wages, and even its share in world wealth. In the absence of policy coordination, small countries optimally choose to stabilize their exchange rates relative to the currency of the largest economy in the world, which endogenously emerges as the world's "anchor currency." Larger economies instead optimally choose to float their exchange rates. The model therefore predicts an equilibrium pattern of exchange rate arrangements that is remarkably similar to the one in the data.
\end{abstract}

JEL classification: E4, E5, F3, F4, G11, G15

Keywords: fixed exchange rate, managed float, exchange rate stabilization, uncovered interest parity, currency returns

*Previous versions of this paper were circulated under the title "Currency Manipulation." We thank Mark Aguiar, Fernando Alvarez, Adrien Auclert, Oleg Itskhoki, Federico Gavazzoni, Loukas Karabarbounis, Robert Kollmann, Matteo Maggiori, Brent Neiman, Stavros Panageas, Jesse Schreger, Batchimeg Sambalaibat, Vania Stavrakeva, and Ivan Werning for helpful comments. We also thank seminar participants at the University of Chicago, Princeton, Toulouse, Oslo, the Federal Reserve Banks of Chicago, New York, and San Francisco, the Board of Governors, the annual meetings of the SED, EFA, and AEA, Chicago IFM conference, Chicago CWIE, the CEPR and SAFE AP Workshops, the Cowles Foundation, and the NBER Summer Institute, IFM, and Asset Pricing program meetings. Hassan is grateful to the Fama-Miller Center at the University of Chicago for providing financial support. The views expressed here are solely those of the authors and do not necessarily represent those of the Federal Reserve Bank of San Francisco or the Federal Reserve System.

†Boston University, NBER, and CEPR; Postal Address: 270 Bay State Road, Boston, MA 02215, USA; E-mail: thassan@bu.edu.

${ }^{\ddagger}$ Federal Reserve Bank of San Francisco; Postal Address: 101 Market Street Mail Stop 1130, San Francisco, CA 94105, USA; E-mail: thomas.mertens@sf.frb.org.

$\S$ Boston University, Questrom School of Business; Postal Address: 595 Commonwealth Avenue, Boston, MA 02215, USA; E-mail: tzhang0@bu.edu. 
Two thirds of all countries in the world stabilize their currency relative to the US dollar 1 Such stabilizations take on many different forms, including pegs, moving bands, stabilized arrangements, and managed floats. Their common feature is that they set an upper bound for the volatility of the real or nominal exchange rate, without necessarily manipulating its mean. Why do so many countries stabilize their exchange rates relative to the US dollar?

In this paper, we develop a novel, risk-based theory of the effects of currency manipulation in general, and currency stabilization in particular. In this model, the choice of exchange rate regime affects economic outcomes because it allows policymakers to make their currency, and by extension, the firms based in their country, a safer investment from the perspective of international investors. Policies that induce a country's currency to retain value or even appreciate when the marginal utility of international investors is high (in "bad times") lower the required rate of return on the country's currency and thus also lower domestic interest rates and increase the world-market value of domestic firms. Policies that change the variances and covariances of real exchange rates can thus, via their effect on interest rates and asset returns, affect the allocation of capital across countries.

This approach, linking a country's exchange rate regime to the value of domestic firms, yields three main insights. First, in canonical models of exchange rate determination, a direct link exists between the stochastic properties of a country's exchange rate, the expected return on its currency, and the world-market value of firms producing country-specific (or nontraded) goods. The safer a country's currency is from the perspective of international investors, the higher the world-market value of its firms, and the higher domestic investment and wages. Second, the choice of target currency is key to the effects of any exchange rate stabilization. A country that stabilizes its exchange rate relative to a "safe" currency that appreciates when marginal utility is high inherits some or all of the stochastic properties of that target currency. Through its effect on risk premia, a stabilization relative to the safest currency in the world thus offers a maximal boost to the value of domestic firms and to domestic investment and wages. Third, stabilizations are generally cheaper to implement for smaller countries whose actions have little or no effect on the price of traded goods in world markets.

Taken together, these insights shed new light on otherwise puzzling features of exchange rate arrangements we see in the data today. Since the demise of the Bretton-Woods system of fixed exchange rates in 1975, individual countries have been largely free to choose their own exchange rate regime. Despite this lack of centralized coordination, recent research by Ilzetzki, Reinhart,

\footnotetext{
${ }^{1}$ According to a comprehensive analysis by Ilzetzki, Reinhart, and Rogoff $[$ (2018). See Table 1 for a summary.
} 
and Rogoff (2018) has shown surprising regularity in the choices made by individual countries. Table 1 shows three stylized facts from their data. First, small economies tend to stabilize, whereas only the largest economies in the world float their exchange rate. Second, the smaller the economy, the stricter the stabilizations tend to be - small economies such as Hong Kong, and Iceland tend to maintain hard pegs, while intermediate size economies, such as Mexico or Thailand allow more flexibility in their stabilizations. Third, there is remarkable agreement in the choice of target country: The vast majority of stabilizations target the currency of the largest economy in the world, the US dollar, making it the "anchor" currency of the world monetary system. Almost all exceptions to this rule instead target the currency of the largest market in the world, the euro.

Figure 1 adds to this list a fourth, less well-known, set of stylized facts that will be key to our interpretation below: Small and medium-sized economies that stabilize their exchange rates have lower interest rates, their currencies pay lower returns to international investors, and their firms use relatively more capital than those that do not. Holding constant the size of a country's economy, a one percentage point decrease in the allowed annual standard deviation of its nominal exchange rate relative to the US dollar is statistically significantly associated with a 0.4 percentage point decrease in its risk-free interest rate (Panel a), 0.4 pp lower average returns the currency pays to international investors (Panel b), and a 1.6\% increase in the capital intensity of production in the country (Panel c).2 In other words, going from a soft stabilization that allows a five percent annual standard deviation to the US dollar (such as Mexico's managed float), to a much tighter stabilization allowing only variations of two percent (such as Thailand's moving band) is associated with about a $4.8 \%$ increase in the domestic capital-to-output ratio.

We argue this apparent effect of stabilizations on interest rates and capital intensity, and the patterns in countries' choices of exchange rate regime and anchor currency mentioned above, arise naturally from optimal non-cooperative behavior in a parsimonious model where currency risk premia affect the allocation of capital across countries. In other words, we argue the US dollar may be the anchor of the world monetary system because smaller countries are optimally trying to attract international investment by reducing the risk associated with their currencies.

Our work builds on a growing literature that links highly persistent differences in interest rates, currency returns, and capital intensity across countries to the stochastic properties of their currencies (Lustig and Verdelhan, 2007; Lustig, Roussanov, and Verdelhan, 2011; Hassan and

${ }^{2}$ The data are monthly for 38 countries, 1983-2010. For ease of replicability, we simply merge the replication datasets of Ilzetzki et al. (2018) and Hassan and Mano (2019). Panel (c) uses annual data from the Penn World tables. See the caption of Figure 1 for details. 
Mano, 2019; Hassan, Mertens, and Zhang, 2016). This literature has explored various potential drivers of heterogeneity in the stochastic properties of countries' exchange rates, ranging from differences in country size (Martin, 2012, Hassan, 2013) and financial development (Maggiori, 2017) to trade centrality (Richmond, 2019) and differential resilience to disaster risk (Farhi and Gabaix, 2015; Colacito et al., 2018) [3 The common theme across these "risk-based" theories is that whatever makes countries different from each other results in differential sensitivities of their exchange rates to various shocks, so that some currencies (typically the US dollar) tend to appreciate systematically when marginal utility is high.

In this paper, we go one step further and argue the stochastic properties of exchange rates are themselves subject policy intervention. To formalize this idea, we solve for the effect of currency manipulation on risk premia within an otherwise standard model of exchange rate determination. In the model, households consume a freely traded good and a country-specific nontraded good. The nontraded good is produced by domestic firms, the shares of which are the only assets traded in an international stock market. In equilibrium, the real exchange rate may fluctuate in response to country-specific shocks to productivity, preferences, or money supply.

As a stand-in for the various potential sources of heterogeneity in the stochastic properties of countries' exchange rates mentioned above, we allow countries to differ in size. That is, we assume all shocks are common within countries, and some countries account for a larger share of world GDP than others. In the absence of policy intervention, this heterogeneity in country size endogenously generates differences in interest rates, because shocks that raise the price of consumption in a larger country spill over more into the world-market price of traded goods. As a result, the currencies of larger countries tend to appreciate when the marginal utility of international investors is high. Larger countries therefore have lower risk-free interest rates, more valuable firms, and higher capital-output ratios in equilibrium.

Within this standard economic environment, we study the effects of policies that lower the variance of one "stabilizing" country's real exchange rate relative to a "target" country's currency, while leaving the mean of the exchange rate unaffected. To this end, we assume each country has a central bank that issues and controls the supply of domestic currency, and that the nominal price of the traded good is sticky in that domestic currency, giving the central bank the means to affect allocations and the real exchange rate.

\footnotetext{
${ }^{3}$ Other papers in this literature have studied heterogeneity in the volatility of shocks affecting the nontraded sector (Tran, 2013), factor endowments (Ready, Roussanov, and Ward, 2017; Powers, 2015), and risk aversion in combination with country size (Govillot, Rey, and Gourinchas, 2010). Also see Gourinchas and Rey (2007), Campbell, Serfaty-De Medeiros, and Viceira (2010), Menkhoff et al. (2012), David, Henriksen, and Simonovska (2016), and Verdelhan (2017).
} 
Because nontraded goods cannot be shipped internationally, stabilizing the real exchange rate requires driving a wedge between the domestic and world-market prices of traded goods. For example, when the target country appreciates, the stabilizing country must artificially raise the domestic relative price of traded goods to increase the price of the domestic consumption bundle and match the appreciation. We show these stabilizing wedges between the domestic and international prices of traded goods arise naturally from a simple nominal stabilization regime where the central bank exchanges domestic for foreign currency at a predetermined rate. In this sense, a nominal stabilization implements a real stabilization.

We first consider the case in which the stabilizing country is small and thus only affects its own price of consumption. A small country that stabilizes its exchange rate relative to a larger country inherits the stochastic properties of the larger country's exchange rate, so that the stabilized exchange rate now also tends to appreciate when marginal utility is high (that is, it retains value in "bad times"). A safer currency, in turn, comes with a lower domestic interest rates, a higher world-market value of domestic firms, and increased capital accumulation - the relation shown in Figure 1.

By raising the domestic price of traded goods whenever the target country appreciates, the stabilizing country effectively reduces domestic consumption and thus exports additional traded goods in these states of the world. If the target country is large, these states tend to be those in which the world-market price of traded goods is high, so that the stabilizing country effectively sells traded goods when they are expensive and buys them when they are cheap. Stabilizing relative to a larger target country thus generates an insurance premium in the form of additional seigniorage. (Effectively, a stabilizing country provides more insurance to the target country than it would under freely floating exchange rates, and thus increases the volatility of its own consumption.) If the target country is sufficiently large, this insurance premium may be so large that the stabilization generates a positive net present value of revenues. In this sense, stabilizations relative to a larger country increase, rather than deplete, the central bank's resources.

However, this revenue-generating effect diminishes when the stabilizing country itself becomes larger, because the stabilization increases the variation in the stabilizing country's own demand for traded goods and therefore its price impact. When the stabilizing country is large enough to affect the world-market price of traded goods, the stabilization thus induces an unfavorable change in the state-contingent prices of traded goods. The larger the stabilizing country, the more resources are required to maintain a stable exchange rate.

Although the allocation is Pareto efficient if all central banks float their exchange rates, the 
model nevertheless produces a consistent rationale for currency stabilization. The reason is our assumption that households can transact in an international stock market, but cannot insure against the imposition of currency stabilization ex-ante. Because of this restriction on the asset space, changes in the value of an asset that even a small country has pricing power over (the relative value of its own firms) can translate into shifts in relative wealth across countries. In particular, a small country that announces a stabilization relative to a larger country not only raises the world-market value of its firms, but also increases its households' share in world wealth. We show this valuation effect can be large enough to compensate for all domestic distortions caused by the stabilization.

The model therefore predicts an equilibrium pattern of exchange rate arrangements remarkably similar to that in the data: In the absence of policy coordination, it is optimal for a small country to stabilize its exchange rate; larger countries optimally adopt "softer" stabilizations (due to the rising costs of implementing the stabilization); and the countries with the largest economies find it optimal to float. The optimal target currency for all stabilizations is the currency of the largest country in the world, endogenously rendering this currency the "anchor" currency of the world.

Because the allocation of resources under freely floating exchange rates is Pareto efficient, any utility gain accruing to a stabilizing country must come at the expense of households in another country. Interestingly, these costs of stabilization are typically not borne by the target country, but instead by other economies that float their exchange rate but are not the target of the stabilization. The reason is that all countries with floating exchange rates suffer from the valuation effect and some distortion of their consumption plans, whereas only the target country receives something in return: targeted consumption insurance, courtesy of the fact that stabilizing countries export additional traded goods whenever the target country appreciates. In this sense, the model also reflects the general intuition that being at the center of the world monetary system provides a benefit, and that the target country does not wish to retaliate.

In various extensions, we show this broad set of conclusions arises regardless of whether variation in exchange rates is driven primarily by supply or demand shocks, regardless of whether the stabilization regime is fully credible, and that the positive conclusions of our analysis also extend to a model with segmented financial markets.

We make four main caveats to our interpretation. First, we focus on differences in country size only in the interest of parsimony. Variations of the model where differences in interest rates also result from differences in financial development or some of the other microfoundations men- 
tioned above should yield similar interpretations - with the US dollar and the euro emerging as the safest currencies in the world. Second, although we solve for optimal stabilizations, we do not attempt to answer the broader question of whether other, more complicated patterns of currency manipulation might produce superior results. Third, as in most models with standard preferences, risk premia are quantitatively small in our framework, so that a quantitative application would need additional ingredients. Finally, in our model, currency manipulation manifests itself as a wedge between the domestic and world-market prices of traded goods. In richer models, currency manipulations could also operate by changing allocations within countries, such as the sectoral allocation of labor or the distribution of wealth across households.

Our paper makes two main contributions to the existing literature: First, we highlight a novel link between exchange rate regimes, currency risk premia, and capital accumulation that can and should operate in a wide range of conventional models of exchange rate determination. Second, we offer a novel rationale for the prevalence of exchange rate stabilizations among small and medium-sized economies and the first formal model that can rationalize the multilateral patterns in exchange rate arrangements outlined above.

A large literature studies the effects of nominal stabilizations in two-country New Keynesian models, where they affect the level of production by altering markups (e.g., Kollmann, 2002; Devereux and Engel, 2003; Fornaro, 2015). A Another, largely empirical, literature argues that stabilizations may promote bilateral trade or serve to import monetary policy credibility $5^{5}$ More closely related to our own work, Fanelli and Straub (2019) and Gabaix and Maggiori (2015) argue real exchange rate interventions can alter the distribution of wealth across agents under segmented markets. Our work complements these other approaches in that the effect of currency stabilization on risk premia may operate in parallel to all of these other mechanisms. To our knowledge, none of these existing approaches have been used to formally model the optimal choice of target currency, nor the emergence of a single anchor currency or any of the other stylized facts outlined above.

In this sense, our work also relates to a recent literature that argues for a special role of the US dollar in world financial markets. Branches of this literature have focused on the emergence of a dominant currency for debt issuance Chahrour and Valchev, 2019; Farhi and Maggiori, 2017;

\footnotetext{
${ }^{4}$ One strand of this literature analyzes optimal monetary policy in small open economies with fixed exchange rates (Kollmann, 2002, Parrado and Velasco, 2002, Gali and Monacelli, 2005, Auclert and Rognlie, 2014), whereas another deals with the choice of the exchange rate regime in the presence of nominal rigidities (Helpman and Razin, 1987; Bacchetta and van Wincoop, 2000; Corsetti, Dedola, and Leduc, 2010, Schmitt-Grohé and Uribe, 2012 Bergin and Corsetti, 2015) or collateral constraints (Ottonello, 2015: Fornaro, 2015).

${ }^{5}$ See Hooper and Kohlhagen (1978), Kenen and Rodrik (1986), and Frankel and Rose (2002).
} 
He, Krishnamurthy, and Milbradt, 2019, Gopinath and Stein, 2019) and on the transmission of monetary shocks (Boz et al., 2020; Miranda-Agrippino and Rey, 2015, Zhang, 2019).

More broadly, our paper also relates to a large literature on capital controls ${ }^{6}$ Similar to Costinot, Lorenzoni, and Werning (2014), who model capital controls as a manipulation of intertemporal prices, we show that currency stabilizations may be thought of as a manipulation of state-contingent prices. The key difference is that capital controls affect allocations through market power and rents, whereas currency stabilization affects allocations through risk premia, even when the country manipulating its exchange rate has no effect on world market prices.

\section{Effects of Currency Manipulation in Reduced Form}

We begin by deriving the main insights of our analysis in their most general form. Consider a world economy in which international assets are priced by a unique stochastic discount factor that depends only on the realization of a world-wide shock, $\lambda_{T}$. Households consume a countryspecific final good, the price of which (accounted for in some common unit) depends on this world-wide shock and a country-specific shock, $x^{n}$,

$$
p^{n}=a \lambda_{T}+b x^{n},
$$

where $\lambda_{T} \sim N\left(0, \sigma_{\lambda_{T}}^{2}\right)$ and $x^{n} \sim N\left(0, \sigma_{x}^{2}\right)$ are normally distributed, not necessarily independent, shocks and $a$ and $b$ are constants greater than zero. As we show in later sections, this structure arises naturally from a microfounded model where the country-specific shock interchangeably may stem from a supply, demand, or monetary shock; in other words, it is a stand-in for any factor that affects the price of consumption in one country more than in others. The higher $x^{n}$, the higher the price of domestic consumption.

The real exchange rate between two countries is the relative price of their respective final goods. In logs,

$$
s^{f, h}=p^{f}-p^{h} .
$$

The risk-based view of differences in currency returns applies some elementary asset pricing to this expression. Using the Euler equation of an international investor, one can show the log

\footnotetext{
${ }^{6}$ See, for example, Calvo and Mendoza (2000), Jeanne and Korinek $(2010)$, Bianchi (2011), Farhi and Werning (2014, 2013), Schmitt-Grohé and Uribe (2012), Korinek (2013), Korinek and Simsek (2016), and Bocola and Lorenzoni (2020).
} 
expected return to borrowing in country $h$ and to lending in country $f$ is

$$
r^{f}+\Delta \mathbb{E} s^{f, h}-r^{h}=\operatorname{cov}\left(\lambda_{T}, p^{h}-p^{f}\right)
$$

where $r^{n}$ is the risk-free interest rate in country $n$ and the log stochastic discount factor is equated to $\lambda_{T}$ for simplicity.7 This statement means a currency that tends to appreciate when $\lambda_{T}$ is high pays a lower expected return and, if $\Delta \mathbb{E} s^{f, h}=0$, also has a lower risk-free interest rate. That is, a currency that appreciates in bad times (when consumption goods are expensive everywhere) provides a hedge against worldwide consumption risk and pays lower returns in equilibrium.

Equations (1) and (2) are the main ingredients of risk-based models of unconditional differences in interest rates across countries, where different approaches model differences in the stochastic properties of $p^{n}$ as the result of heterogeneity in country size, the volatility of shocks, trade centrality, financial development, factor endowments, etc.

We make a simple point relative to this literature: If this risk-based view of currency returns has merit, policies that alter the covariance between a country's exchange rate and $\lambda_{T}$ can alter interest rates, currency returns, and the allocation of capital across countries. In particular, a country that adopts a policy that systematically increases the price of domestic consumption when $\lambda_{T}$ is high can lower its risk-free interest rate relative to all other countries in the world.

As an example, consider a "manipulating" country (indexed by $m$ ) that levies a tax on domestic consumption of traded goods that is proportional to the realization of $\lambda_{T}$, such that

$$
p^{m}=a \lambda_{T}+b x^{m}+\pi \lambda_{T},
$$

where $\pi$ is some positive constant. The taxation scheme increases the tendency of $p^{m}$ to appreciate when $\lambda_{T}$ is high and thus, according to (2), lowers its interest rate relative to all other countries in the world by $\pi \sigma_{\lambda_{T}}^{2}$.

If interest rates play a role in allocating capital across countries (as is the case in our fully specified model), manipulations of the stochastic properties of exchange rates can thus divert capital investment to the country that conducts the manipulation, and, more broadly, alter the equilibrium allocation of capital across countries. The remainder of this paper fleshes out this argument in the context of a general equilibrium model and applies it to one of the most pervasive policies in international financial markets: currency stabilization.

${ }^{7} \Delta \mathbb{E} s^{f, h}$ is defined as the logarithm of the ratio of the countries' expected real price changes. See Appendix B for a formal derivation. 


\section{Stabilizing the Real Exchange Rate}

We begin by studying the effect of stabilizing the real exchange rate in a parsimonious environment, where money is neutral and the allocation of capital across countries, as well as the stochastic properties of real exchange rates, is determined solely as a function of productivity shocks (Backus and Smith, 1993). Within this canonical international real business cycle model, one country, labeled the stabilizing country, deviates from the competitive equilibrium by stabilizing its real exchange rate relative to a target country.

Our purpose in beginning our analysis in this parsimonious environment is to lay bare the main mechanisms as clearly and concisely as possible and to contrast them with the existing literature. We emphasize that none of our main insights depend on monetary neutrality or any of the well-known empirical shortcomings of the international real business cycle model. Instead, the intuition from this baseline model continues to apply when we add sticky prices and stabilizations of the nominal exchange rate in section 3 , study floating bands and partially credible stabilizations in section 4, and when we study more general economic environments where exchange rates are driven by monetary or preference shocks in section 5 .

\subsection{Economic Environment}

Two discrete time periods exist: $t=1,2$. There exists a unit measure of households $i \in$ $[0,1]$, partitioned into three subsets $\Theta^{n}$ of measure $\theta^{n}$. Each subset represents the constituent households of a country. We label these countries $n=\{m, t, o\}$ for the stabilizing (manipulating), target, and outside country, respectively. Households make an investment decision in the first period. All consumption occurs in the second period.

Households derive utility from consuming an index composed of a country-specific nontraded good, $C_{N, 2}$, and a freely traded good, $C_{T, 2}$ in each state $\omega$, where

$$
C_{2}(i, \omega)=C_{T, 2}(i, \omega)^{\tau} C_{N, 2}(i, \omega)^{1-\tau}
$$

and $\tau \in(0,1)$. Each household exhibits constant relative risk aversion according to

$$
U(i)=\frac{1}{1-\gamma} \mathbb{E}\left[\left(C_{2}(i, \omega)\right)^{1-\gamma}\right]
$$

where $\gamma>0$ is the coefficient of relative risk aversion.

At the start of the first period, each household owns a firm that produces the local, country- 
specific, nontraded good using a Cobb-Douglas production technology that employs capital and labor. Each household supplies one unit of labor inelastically to its own firm and, in addition, owns one unit of capital, which it can sell to its own firm or to any other firm in the world. Each firm's output of nontraded goods is

$$
Y_{N, 2}(i, \omega)=\exp \left(\eta^{n}\right)(K(i))^{\nu}
$$

where $0<\nu<1$ is the capital share in production, $K(i)$ is the (per capita) stock of capital, and $\eta^{n}$ is a country-specific productivity shock realized at the start of the second period,

$$
\eta^{n} \sim N\left(-\frac{1}{2} \sigma_{N}^{2}, \sigma_{N}^{2}\right) .
$$

Capital can be freely shipped in the first period, at the end of which it is invested for use in the production of nontraded goods in the second period. In the second period, each household is also endowed with one unit of the traded consumption good.

At the end of the first period, firms trade units of capital and households trade claims to the output of their firms (stocks) in an international stock market. Throughout, we use the traded consumption good as the numéraire, such that all prices and returns are accounted for in the same units. To simplify the derivation, we also assume households receive a country-specific transfer in the first period, $\kappa^{n}$, which equates the marginal utility of wealth in the first period across all households in the world. Finally, because all households and firms within a given country are identical and consumption only occurs in the second period, we henceforth drop the household index $i$ as well as the time subscript $t$ whenever appropriate and write the per-capita capital stock, output, and consumption of traded and nontraded goods in country $n$ as $K^{n}, Y_{N, 2}^{n}$, $C_{T}^{n}$, and $C_{N}^{n}$, respectively.

In sum, the economic environment of our baseline model is identical to that of a standard international real business cycle model. Our only, somewhat subtle, departure from this frictionless benchmark is that we confine households to trading stocks in international markets, and do not allow them to trade a full set of state-contingent claims. We prefer adding this modest restriction on the asset space both for realism and because it gives rise to a model-consistent rationale for stabilization which we discuss in detail in section 2.5.

In the meantime, however, note that because households can trade a unique set of stocks for each country and shock, financial markets are complete within the second period. $8^{8}$ As a

\footnotetext{
${ }^{8}$ In the terminology of (Coeurdacier and Rey, 2013), financial markets are "first-order complete" in the sense
} 
result, the allocation of goods across households (given a distribution of wealth) is efficient in the absence of government interventions and coincides with the solution to the Social Planner's problem with unit Pareto weights. Consequently, all the positive predictions of our baseline model are invariant to whether or not we impose the aforementioned restriction on the asset space. 9

Currency Stabilization We define a real exchange rate stabilization as any policy that decreases fluctuations of the stabilizing country's log real exchange rate with the target country by a fraction $\zeta \in(0,1]$ relative to the freely floating regime, without distorting the conditional mean of the log real exchange rate. Denoting the real exchange rate that would arise under freely floating exchange rates with an asterisk, a stabilization is thus a policy such that

$$
\operatorname{var}\left(s^{t, m}\right)=(1-\zeta)^{2} \operatorname{var}\left(s^{t, m *}\right)
$$

and

$$
\mathbb{E}\left[s^{t, m} \mid\left\{K^{n}\right\}\right]=\mathbb{E}\left[s^{t, m *} \mid\left\{K^{n}\right\}\right] .
$$

We refer to $\zeta \in(0,1]$ as a stabilized real exchange rate and $\zeta=1$ as a "hard" peg.

The stabilizing country's government has two policy instruments available to achieve (P1) and (P2): It has the ability to pay a lump-sum transfer, $\bar{Z}$, to each household in its country in the first period and to levy a state-contingent tax on the domestic consumption of traded goods in the second period $(Z(\omega)$ ). (In our preferred interpretation, these parts will be taken over by intervention in currency markets and seigniorage. Because showing this correspondence requires additional model ingredients, we prefer to first derive results in this more general form.)

The per-capita cost of implementing exchange rate stabilization is thus

$$
\Delta R e s=\bar{Z}-\mathbb{E}\left[\left(\frac{\Lambda_{T}(\omega)}{\Lambda_{T, 1}}\right)(Z(\omega)-1) C_{T}^{m}(\omega)\right]
$$

where $\Lambda_{T}(\omega)$ represents the (world market) shadow price of one unit of traded consumption in state $\omega$ of the second period and $\Lambda_{T, 1}=\mathbb{E}\left[\Lambda_{T}(\omega)\right]$ is the marginal utility of wealth in the first period.

We begin by assuming the government can finance this cost using an independent supply of that the payoffs of the available assets span all states of the world in the log-linear solution to the competitive equilibrium.

${ }^{9}$ See Appendix C.4 for details. 
traded goods (currency reserves) that absorbs any surpluses or deficits generated by the taxation scheme $(\Delta R e s)$. We prefer this specification mainly because it simplifies the exposition and also allows us to cleanly separate the effects of stabilizations from the (well-studied) effects of over- or under-valuations of the real exchange rate. However, we stress that none of the positive predictions of the model depend on this assumption. When we analyze the welfare effects of exchange rate stabilization in section 2.5, we set $\Delta R e s=0$, so that the cost of the stabilization is fully borne by the households in the stabilizing country. In this case, any stabilization also distorts the level of the real exchange rate, and thus violates (P2).

Interestingly, we also show below that, under a range of relevant parameters, the cost of currency stabilization is negative, so that many exchange rate stabilizations (achieving both (P1) and ( $(\bar{P} 2)$ are implementable even if the government has no access to currency reserves.

The market clearing conditions for traded, nontraded, and capital goods are

$$
\begin{gathered}
\int_{i \in[0,1]} C_{T, 2}(i, \omega) d i=1+\theta^{m} \Delta R e s \\
\int_{i \in \theta^{n}} C_{N, 2}(i, \omega) d i=\theta^{n} Y_{N, 2}^{n}(\omega)
\end{gathered}
$$

and

$$
\sum_{n} \theta^{n} K^{n}=1
$$

The economy is in an equilibrium when all households maximize utility taking prices and taxes as given, firms maximize profits, and goods markets clear.

\subsection{Solving the Model}

Appendix C.1 formally derives the conditions of optimality characterizing the equilibrium allocation. The first-order conditions with respect to $C_{T}^{n}$ equate the shadow price of traded consumption across the target and outside countries:

$$
\tau\left(C^{n}(\omega)\right)^{1-\gamma}\left(C_{T}^{n}(\omega)\right)^{-1}=\Lambda_{T}(\omega), n=o, t
$$

In the stabilizing country, the state-contingent tax that implements the currency stabilization appears as a wedge on that shadow price

$$
\tau\left(C^{m}(\omega)\right)^{1-\gamma}\left(C_{T}^{m}(\omega)\right)^{-1}=Z(\omega) \Lambda_{T}(\omega) .
$$


In all countries, marginal utilities with respect to $C_{N, 2}^{n}$ define the shadow prices of nontraded goods

$$
(1-\tau)\left(C^{n}(\omega)\right)^{1-\gamma}\left(C_{N}^{n}(\omega)\right)^{-1}=\Lambda_{N}^{n}(\omega)
$$

In addition, households' portfolio problem and the firm's capital demand function jointly imply

$$
K^{n}=\frac{\nu}{\Lambda_{T, 1} Q_{K}} \mathbb{E}\left[\Lambda_{N}^{n}(\omega) Y_{N}^{n}(\omega)\right],
$$

where $Q_{K}$ denotes the first-period price of a unit of capital. This Euler equation defines the level of capital accumulation in country $n$ as a function of first-period prices and the expected (utility) value of its nontraded goods, $\mathbb{E}\left[\Lambda_{N}^{n}(\omega) Y_{N}^{n}(\omega)\right]$. This latter term will differ across countries and reflect any precautionary motives for capital accumulation, including those that arise as a function of the stochastic properties of the country's exchange rate. ${ }^{10}$

Finally, the (redundant) first-order conditions with respect to the consumption index $C^{n}$ pin down the shadow prices of overall consumption in each country:

$$
\left(C^{n}(\omega)\right)^{-\gamma}=\Lambda^{n}(\omega)
$$

so that $P^{n}(\omega)=\Lambda^{n}(\omega) / \Lambda_{T}(\omega)$ is the price of the consumption bundle country $n$. The real exchange rate between two countries $h$ and $f$ equals the ratio of these prices,

$$
S^{f, h}(\omega)=P^{f}(\omega) / P^{h}(\omega)
$$

In equilibrium, the resource constraints (7)-(9) and the conditions of optimality (10)-(13) jointly determine the endogenous variables $\left\{C_{N}^{n}(\omega), C_{T}^{n}(\omega), K^{n}, \Lambda_{N}^{n}(\omega)\right\}_{n \in\{p, t, o\}}, \Lambda_{T}(\omega)$, and $Q_{K}$. To study the model in closed form, we log-linearize around the deterministic solution — the point at which the variances of shocks are zero $\left(\sigma_{N, n}=0\right)$ and all firms have a capital stock fixed at the deterministic steady-state level. To simplify the exposition, we thus ignore the feedback effect of differential capital accumulation on the size of risk premia, studying the incentives to accumulate different levels of capital across countries, while holding the capital stock fixed. Appendix F.3 shows that all propositions in this section continue to hold when we allow for this feedback effect. Throughout, lowercase variables continue to refer to natural logs and we suppress dependence on the state $\omega$ where appropriate.

\footnotetext{
${ }^{10}$ Because households freely trade stocks and capital across borders, 13 holds in all countries, including in the stabilizing country, even though the government's intervention drives a wedge between $\Lambda_{T}$ and the marginal utility of traded consumption in the stabilizing country. See Appendix C.1 for a formal derivation.
} 


\subsection{The Freely Floating Regime}

We begin by showing that, in the absence of currency manipulation, the model predicts that large countries should have lower real interest rates (Hassan, 2013) and accumulate higher capitaloutput ratios (Hassan et al., 2016). If $\zeta=0$, equilibrium consumption of traded goods is given by

$$
c_{T}^{n *}=\frac{(1-\tau)(\gamma-1)}{(1-\tau)+\gamma \tau}\left(\bar{y}_{N}-y_{N}^{n}\right),
$$

where $\bar{y}_{N}=\sum_{n} \theta^{n} y_{N}^{n}$ is the average log per-capita output of nontraded goods across countries. The expression shows that households use shipments of traded goods to insure themselves against shocks to the output of nontraded goods. If $\gamma>1$, households receive additional traded goods whenever they have a lower-than-average output of nontraded goods, and vice versa 11

This risk-sharing behavior generates a shadow price of traded goods of the form,

$$
\lambda_{T}^{*}=-(\gamma-1)(1-\tau) \sum_{n} \theta^{n} y_{N}^{n},
$$

where each country's weight is proportional to its size: shocks to the productivity of larger countries affect a larger measure of households and thus tend to spill over to the rest of the world in the form of higher shadow prices of traded goods. If $\gamma>1$, the shadow price of traded goods falls with the average output of nontraded goods across countries. Thus, $\lambda_{T}$ tends to be low in good states of the world when countries, on average, experience positive productivity shocks.

The real exchange rate between two countries $f$ and $h$ is

$$
s^{f, h *}=p^{f *}-p^{h *}=\frac{\gamma(1-\tau)}{(1-\tau)+\gamma \tau}\left(y_{N}^{h}-y_{N}^{f}\right),
$$

showing that the country with the lower per-capita output of nontraded goods appreciates because its consumption index is relatively more expensive. (The literature often criticizes this somewhat counter-intuitive link between low output and appreciation in the real business cycle model. However, none of our conclusions depend on this link. Instead, the crucial ingredient is that whatever shock causes a country's real exchange rate to appreciate also prompts this coun-

\footnotetext{
${ }^{11}$ The condition $\gamma>1$ (more generally, $\gamma$ multiplied by the elasticity of substitution between traded and nontraded goods $>1$ ) ensures that the cross-partial of marginal utility from traded consumption with respect to the nontraded good is negative; that is, the relative price of a country's nontraded good falls when its supply increases. Because most empirical applications of international asset pricing models find a relative risk aversion significantly larger than 1 and an elasticity of substitution around 1, most authors assume this condition holds (see Coeurdacier (2009) for a detailed discussion). We show in section 5 that this condition is not needed if variation in exchange rates is driven predominantly by monetary or preference shocks.
} 
try to demand higher imports of traded goods - a feature shared near universally by a broad class of supply- and demand-based models of exchange rate determination, as we show formally in section 5.)

Inspecting $\lambda_{T}^{*}$ and $s^{f, h *}$ shows that currencies of larger countries are "safer" in the sense that they tend to appreciate when the shadow price of traded goods is high: Whenever a country suffers a low productivity shock, its real exchange rate appreciates. For a given percentage decline in productivity, this appreciation occurs independently of how large the country is (note $s^{f, h *}$ is independent of $\theta$ ). However, a shock to a larger country has a larger impact on the shadow price of traded goods $\left(\lambda_{T}\right)$. It then immediately follows from (2) that larger countries have safer currencies and thus a lower risk-free rate:

$$
r^{f *}+\Delta \mathbb{E} s^{f, h *}-r^{h *}=\operatorname{cov}\left(\lambda_{T}^{*}, p^{h *}-p^{f *}\right)=\frac{(\gamma-1) \gamma(1-\tau)^{2}}{1+(\gamma-1) \tau}\left(\theta^{h}-\theta^{f}\right) \sigma_{N}^{2}
$$

To see that these differences in interest rates across countries translate into differential incentives to accumulate capital, we can rearrange the Euler equation for capital accumulation (13) and derive an expression that links differences in capital to differences in interest rates ${ }^{12}$

$$
k^{f *}-k^{h *}=\frac{\gamma}{\tau(\gamma-1)^{2}}\left(r^{h *}-\Delta \mathbb{E} s^{f, h *}-r^{f *}\right)
$$

Firms based in larger countries thus have a lower cost of capital, which increases their value in world markets and prompts them to invest more. It is efficient to accumulate more capital in the larger country because a larger capital stock in a larger country represents a good hedge against global consumption risk: Households around the world fear states of the world in which the large country receives a bad shock. Although households cannot affect the realization of such shocks, they can partially insure themselves against low output in large countries by accumulating more capital in these countries. This precautionary behavior raises expected output in these countries and dampens the negative effects of a low productivity shock.

\subsection{Effects of Currency Stabilization}

Under freely floating exchange rates, larger (safer) countries thus have lower risk-free rates and higher capital-output ratios ${ }^{13}$ With this result in mind, we now analyze how a country can

\footnotetext{
${ }^{12}$ For a derivation, see Appendix C.5

${ }^{13} \mathrm{~A}$ series of papers (cited above) have shown that these predictions are indeed borne out in aggregate data. In addition, recent work by Richers (2019) uses detailed firm-level and bond-level data to show that firms in
} 
influence interest rates and the allocation of capital by stabilizing its currency.

Whereas currency stabilization $([\mathrm{P} 1)$ and $(\mathrm{P} 2)$ with $\zeta<1)$ can, in principle, be achieved with a range of different nonlinear policies, such as intervening only in response to shocks smaller or larger than some critical value, we focus our discussion on the unique linear policy that entails a proportional intervention in each state. The advantage of focusing on this case is that it preserves the Gaussian structure of the problem and thus lends itself to closed-form solutions. In section 4. we discuss issues that arise when the government cannot credibly commit to stabilizing shocks larger than some critical value and show that our main conclusions do not change in that case.

The following lemma characterizes the unique linear form of state-contingent taxes that implements the exchange rate stabilization:

\section{Lemma 1}

A tax on the consumption of traded goods in the stabilizing country of the form

$$
z(\omega)=\zeta \frac{\gamma \tau+(1-\tau)}{\gamma \tau}\left(p^{t *}(\omega)-p^{m *}(\omega)\right)
$$

implements a real exchange rate stabilization of strength $\zeta$.

The cost of implementing the stabilization equals the change in the world-market cost of traded goods consumed by households in the stabilizing country,

$$
\Delta R e s=\mathbb{E}\left[\left(\frac{\Lambda_{T}(\omega)}{\Lambda_{T, 1}}\right) C_{T}^{m}(\omega)\right]-\mathbb{E}\left[\left(\frac{\Lambda_{T}^{*}(\omega)}{\Lambda_{T, 1}^{*}}\right) C_{T}^{m *}(\omega)\right]
$$

\section{Proof. See Appendix C.6.}

The intuition for both results is simple and quite general: When the target country appreciates $\left(p^{t *}\right.$ increases $)$, the stabilizing country must increase its own price level to keep pace. Because the number of nontraded goods in the country is fixed, the only way it can do so is by artificially increasing the relative price of traded goods in the stabilizing country, driving a wedge between the domestic and world-market price of traded goods $(z(\omega))$. When the target country appreciates, the stabilizing country thus reduces the domestic consumption of traded goods relative to what it would have been in the freely floating regime and exports additional of production. 
traded goods to the rest of the world 14

$$
c_{T}^{m}-c_{T}^{m *}=-\zeta \frac{\left(1-\theta^{m}\right)}{\tau \gamma}\left(p^{t *}-p^{m *}\right) .
$$

Conversely, when the target country depreciates, the stabilizing country subsidizes imports of traded goods, resulting in higher imports of traded goods than under the freely floating regime. The cost of implementing the stabilization, therefore, is simply the change in the world-market cost of traded goods consumed by households in the stabilizing country.

We start by analyzing the effect of this stabilization policy on allocations, prices, and reserves in the stabilizing country. Afterwards, we analyze its impact on the target country.

\subsubsection{Internal Effects of Currency Stabilization}

The most immediate effect of currency stabilization is that the price level in the stabilizing country becomes more correlated with the price level in the target country:

$$
p^{m}=p^{m *}+\left(1-\theta^{m}\right) \zeta\left(p^{t *}-p^{m *}\right) .
$$

Because larger countries tend to appreciate when $\lambda_{T}$ is high, a stabilization relative to a larger country $\left(\theta^{t}>\theta^{m}\right)$ naturally also makes the stabilizing country appreciate in these states; that is, stabilization increases the covariance between the stabilizing country's price level, $p^{m}$, and the shadow price of traded goods, $\lambda_{T}$, similar to the intervention considered in section 1. As a result, a risk-free asset that pays one unit of the stabilizing country's consumption bundle with certainty becomes a better hedge against consumption risk, increasing its value in the world market, and lowering the stabilizing country's risk-free interest rate.

Moreover, stabilizing relative to a larger country increases domestic capital accumulation because it raises the world-market value of domestic firms by increasing the covariance of their dividends with the larger country's price level, and thus with $\lambda_{T}$ :

$$
p_{N}^{m}+y_{N}^{m}=\left(p_{N}^{m *}+y_{N}^{m *}\right)+\zeta \frac{\left(\theta^{m}+(\gamma-1) \tau\right)}{\tau \gamma}\left(p^{t *}-p^{m *}\right)
$$

where $p_{N}^{m}=\lambda_{N}^{m}-\lambda_{T}$ is the price of nontraded goods in country $m$.

\footnotetext{
${ }^{14}$ Note the relative prices of nontraded goods are no longer a sufficient statistic for the real exchange rate, because the state-contingent tax drives a wedge between the domestic and world-market prices of traded goods.
} 


\section{Proposition 1}

If $\gamma>1$, a country that stabilizes its real exchange rate relative to a target country sufficiently larger than itself lowers its risk-free interest rate and increases the world-market value of domestic firms, domestic capital accumulation, and domestic wages relative to the target country.

Proof. The interest rate differential with respect to the target country is

$$
r^{m}+\Delta \mathbb{E} s^{m, t}-r^{t}=r^{m *}+\Delta \mathbb{E} s^{m, t *}-r^{t *}-\zeta \frac{\gamma(1-\tau)^{2}\left(\left(\theta^{t}-\theta^{m}\right)(\gamma-1) \tau+2 \theta^{m}(1-\zeta)\right)}{\tau(1+(\gamma-1) \tau)} \sigma_{N}^{2} .
$$

See Appendix C.7 for details and the corresponding proof for capital accumulation, which requires that the target country be sufficiently large.

In other words, the model predicts precisely the conditional relationships between the strength of stabilization, interest rates, currency returns, and capital intensity shown in Figure1. Plugging (18) into (23), and comparing with (19) yields exactly the specification depicted.

Aside from these effects on interest rates and capital accumulation, the stabilization policy also affects the level of currency reserves. From (20), we already know the cost of implementing the stabilization is simply the cost of altering the stabilizing country's purchases of traded goods in world markets. Moreover, we also know the stabilization induces the stabilizing country to sell additional traded goods in response to an appreciation of the target country, and to buy additional traded goods in response to a depreciation. If the target country is larger than the stabilizing country, this policy amounts to selling traded goods when they are expensive and buying them when they are cheap. In other words, stabilization induces the stabilizing country to provide insurance to the world market against the (larger) target country's shocks, so that it pockets an insurance premium.

\section{Proposition 2}

If $\gamma>1$ and the stabilizing country is small, $\theta^{m}=0$, the cost of stabilization globally decreases with the size of the target country and locally increases with the size of the stabilizing country. Additionally, the cost of stabilization ( $\Delta R e s)$ is negative if and only if

$$
\theta^{t}>\frac{\zeta+(\gamma-1) \tau}{(\gamma-1)^{2} \tau^{2}}
$$

Proof. See Appendix C.8.

If the target country is sufficiently large relative to the stabilizing country, this insurance premium can be so large that the stabilization generates positive net revenues, so that the 
stabilization increases, rather than decreases, currency reserves 15

When the stabilizing country itself is large $\left(\theta^{m}>0\right)$, its purchases and sales of traded goods also affect the equilibrium shadow price of traded goods, $\lambda_{T}$. This price impact generally increases the cost of stabilization. The reason is that stabilization effectively induces the stabilizing country to "do more" of what it would have done under freely floating exchange rates: Even under freely floating exchange rates, all countries increase their exports of traded goods when a large country appreciates. Stabilization then induces the stabilizing country to export even more than it ordinarily would have (compare equations (15) and (21)). The larger the stabilizing country is (i.e., the more price impact it has), the more costly it therefore is to maintain the stabilization. This increasing cost of stabilization will be key to our finding below that stabilization relative to the largest country in the world tends to be an optimal policy for small but not large countries.

\subsubsection{External Effects of Currency Stabilization}

If the stabilizing country is large $\left(\theta^{m}>0\right)$, its actions also have external effects on consumption and prices in the rest of the world. The shadow price of traded goods is

$$
\lambda_{T}=\lambda_{T}^{*}-\frac{(1+(\gamma-1) \tau)}{\gamma \tau} \zeta \theta^{m}\left(p^{t *}-p^{m *}\right)
$$

The second term on the right-hand side shows that stabilization by a large country reduces the covariance between the target country's price level and $\lambda_{T}$. By selling insurance against the target country's shocks, the stabilizing country dampens the effect of these shocks on the worldmarket price of traded goods. It follows immediately that becoming the target of a stabilization raises the target country's interest rate and lowers its capital accumulation.

\section{Proposition 3}

If $\gamma>1$, a country that becomes the target of a stabilization of any strength $\zeta>0$ imposed by a large country experiences an increase in its risk-free interest rate, a decrease in capital accumulation, and a decrease in average wages relative to all other countries. If the stabilizing country is smaller than the target country $\left(\theta^{m}<\theta^{t}\right)$, the stabilization also lowers the volatility of consumption in the target country.

\footnotetext{
${ }^{15}$ That is, the portfolio of stocks that pays exactly the cost of the stabilization policy in each state of the world has negative cost in the first period. See Appendix C.6 for details on the form of this portfolio.
} 
Proof. The interest rate differential between the target and outside country is

$$
r^{t}+\Delta \mathbb{E} s^{t, o}-r^{o}=\left(r^{t *}+\Delta \mathbb{E} s^{t, o *}-r^{o *}\right)+\zeta \frac{\theta^{p}(1-\tau)^{2} \gamma}{\tau(1+(\gamma-1) \tau)} \sigma_{N}^{2} .
$$

See Appendix C.9 for details and the remainder of the proof.

Currency stabilization can thus divert capital from the target country to the stabilizing country even though it has no effect on the level of the real exchange rate. This finding is particularly interesting because it sheds new light on recent public controversies, for example, between Chinese and US officials (Levy, 2011), which usually focus on the idea that an undervaluation of the Chinese real exchange rate favors Chinese workers at the expense of U.S. workers. By contrast, our model suggests that even a currency stabilization that manipulates the variance but not the level of the real exchange rate can have this effect.

On the flip side, currency stabilization by a large country decreases the volatility of consumption in the target country, because it effectively prompts the stabilizing country to provide consumption insurance to the target country. We show below that this positive effect of insurance provision can dominate, so that stabilization is associated with utility gains in both the stabilizing and the target country, at the expense of the outside country.

\subsection{Welfare and the Rationale for Stabilization}

Having characterized the positive effects of currency stabilization, we next study why a country might find it optimal to stabilize its currency. The existing literature has shown currency stabilization can be a second-best policy response in the presence of monetary and other frictions ${ }^{16}$ Perhaps surprisingly, we show that even in the absence of such frictions, stabilization relative to a larger country may increase welfare in the stabilizing country through a valuation effect that increases its share in world wealth 17

So far, we have defined a currency stabilization as reducing the variance of the log real exchange rate $(\mathrm{P} 1)$ while not distorting its level $(\mathrm{P} 2)$. Achieving both objectives simultaneously requires that the government has the ability to add and subtract resources from the economy by accumulating or depleting currency reserves. For the purposes of assessing the welfare effects of currency stabilization, we now drop objective $(\overline{\mathrm{P} 2})$ and assume that, instead, the government rebates the cost of stabilizing the exchange rate back to households using the lump-sum transfer,

\footnotetext{
${ }^{16}$ For a recent example see Fanelli and Straub (2019).

${ }^{17}$ We define the valuation effect as the $(\log )$ difference in the value of the household's traded consumption from its value under freely floating exchange rates.
} 
so that $\Delta$ Res $=0$ and $(7)$ becomes $\int_{i \in[0,1]} C_{T, 2}(i, \omega) d i=1$. That is, households in the stabilizing country directly bear the financial cost or benefit of stabilizing the exchange rate, shifting the level of their traded consumption in all states of the world, and thus also affecting the level of their real exchange rate. Closing the model in this way does not interfere with the intuition of the positive results derived above but increases the complexity of the solution, so that we relegate the mathematical details to Appendix $\mathrm{D}$.

Within this closed model, solving for the effect of an exchange rate stabilization on the utility of a household in a small stabilizing country $\left(\theta^{m}=0\right)$ yields: ${ }^{18}$

$$
\begin{aligned}
\Delta u^{m}= & \underbrace{\frac{\left(-\zeta^{2}+\zeta \Theta^{t}(\gamma-1) \tau\right)(1-\tau)^{2}}{\tau(1+(\gamma-1) \tau)^{2}} \sigma_{N}^{2}}_{\Delta K, \text { Revenues }}-\underbrace{\frac{\left(\zeta \Theta^{t}+\zeta^{2}\right)(\gamma-1)(1-\tau)^{2}}{(1+(\gamma-1) \tau)^{2}} \sigma_{N}^{2}}_{\Delta \operatorname{Var}\left[c^{m}\right]} \\
& +\underbrace{\frac{\left(\zeta \Theta^{t}+\zeta^{2}\right) \tau(\gamma-1)^{2}(1-\tau)^{2}}{(1+(\gamma-1) \tau)^{2}} \sigma_{N}^{2}}_{\text {Valuation Effect }},
\end{aligned}
$$

where $\Delta u^{m}$ is measured as the percentage increase of the household's certainty-equivalent consumption attributable to the stabilization, and $\Theta^{t}=\theta^{t}(\gamma-1) \tau-1$ is positive and monotonically increasing in $\theta^{t}$ if $\gamma>1$ and the target country is sufficiently large.

The first term on the right-hand side reflects changes in the expected level of consumption that result from changes in the level of domestic capital accumulation and the cost of implementing the stabilization. We have already seen that a stabilization relative to a larger country can increase capital accumulation and generate positive revenue, so that this term is positive if $\theta^{t}$ is sufficiently large. However, stabilization also increases the variance of consumption because the stabilizing country effectively provides insurance to the world market against shocks that affect the target country. This increase in the volatility of consumption strictly reduces expected utility, as shown in the second term.

One can show that the second term is always larger than the first term so that stabilizing would never be welfare increasing if not for the third term: the effect of the stabilization on the stabilizing country's share in world wealth.19 This term reflects the fact, already shown above, that stabilizations relative to a larger country increase the world-market value of firms in the stabilizing country. Households in the stabilizing country are the monopoly suppliers of

\footnotetext{
${ }^{18}$ In keeping with the solution method outlined above, we solve for the equilibrium valuation change in households' portfolios using a second-order approximation around the point at which the marginal utility of wealth of households in all countries is equalized.

${ }^{19}$ See Appendix $\mathrm{D}$ for a formal proof of this statement.
} 
domestic firms so that, even if the country is small and a price-taker in international markets, it is always large enough to affect the world-market price of its own firms relative to the worldmarket price of foreign firms ${ }^{20}$ Because we have assumed households and governments can only trade stocks in these firms in international markets, but cannot write insurance contracts contingent on the imposition of a stabilization itself, this valuation effect effectively enables the stabilizing government to shift wealth from the rest of the world to its own country by announcing a stabilization relative to a larger country. ${ }^{21}$

\section{Proposition 4}

If $\gamma>1$ and all households own the portfolio of stocks that decentralizes the Pareto-efficient allocation of consumption under freely floating exchange rates at the time of the announcement of the stabilization policy, then there exists a $\bar{\theta}>0$ such that a small stabilizing country $\left(\theta^{m}=0\right)$ strictly increases the welfare of its households by stabilizing relative to a target country with $\theta^{t}>\bar{\theta}$.

\section{Proof. See Appendix D,}

In other words, the positive effect of the stabilization on the valuation of domestic firms can be large enough to make stabilization relative to a larger country a welfare-increasing policy for the stabilizing country 22

Panel (a) of Figure 2 illustrates this result graphically by plotting the three terms of (25) over the size of the target country for a typical numerical example where $\theta^{m}=0, \zeta=1, \tau=1 / 3$, and $\gamma = 7 \longdiv { 2 3 }$ If the target country is small, all three terms are negative, but as the size of the target increases, both the first and the third term monotonically increase and become positive. The sum across the three lines represents the total change in the stabilizing country's welfare. This net effect is positive for all $\theta^{t}>\bar{\theta}=\left(\zeta+(1-\zeta) \tau^{2}(\gamma-1)\right) /\left(\tau^{3}(\gamma-1)^{2}\right)$. If it is optimal for

\footnotetext{
${ }^{20}$ For a similar result, where small countries benefit from deviating from policy coordination, see Chari and Kehoe (1990).

${ }^{21}$ One can show the same result holds if instead households are confined to trading international bonds, because, again, stabilizing relative to a larger country increases the world-market value of the stabilizing country's bonds. See Appendix D.1 for details.

${ }^{22}$ In this static model the number of domestic firms is fixed, so that the valuation gain appears as a one-off effect from the announcement of the stabilization. However, in reality, countries continuously create new firms and are the "monopoly producers" of domestic firms. We may thus think of the valuation effect more broadly as increasing the value of domestic entrepreneurship and generating a persistent flow of rents to the stabilization country.

${ }^{23}$ Because the consumption index (3) has a unit elasticity of substitution between traded and nontraded goods, the portfolio of stocks that decentralizes the Pareto-efficient allocation of consumption under freely floating exchange rates is naturally home biased, in the sense that a given country's households own a relatively larger share of their own country's firms. As a result, an increase in the relative valuation of the stabilizing country's firms shifts wealth from foreign to domestic agents. Appendix D gives analytical solutions.
} 
a small country to stabilize relative to any target country, that country is thus always the largest country in the world.

This increase in welfare through stabilization is, for a given set of parameters, easier to achieve for a small country than for a large country. As we have already seen above, a stabilization implemented by a large stabilizing country manipulates state-prices of traded goods in an unfavorable direction, which increases the cost of implementing the stabilization. The welfare benefits of stabilization thus tend to decrease with the size of the stabilizing country. Panel (b) of Figure 2 shows the utility gain from stabilization is smaller for larger stabilizing countries. The figure also shows the optimal stabilization need not be a hard peg: In the example shown, the largest stabilizing country $\left(\theta^{m}=0.2\right)$ maximizes its utility gains with a soft peg $(\zeta \approx 0.2)$.

Taken together, these findings provide a rich set of predictions for a stabilizing country's optimal choice of exchange rate regime $(\zeta \in(0,1])$ as a function of its own size $\left(\theta^{m}\right)$ and the size of the target country $\left(\theta^{t}\right)$. Panel (a) of Figure 3 shows a graphical representation of this optimal choice for the same numerical example as above. If the largest country in the world is sufficiently large $\left(\theta^{t}>\bar{\theta}\right)$, a small stabilizing country finds it optimal to impose a hard peg relative to that country, which endogenously emerges as the anchor currency of all stabilizations. As the size of the stabilizing country increases (moving from left to right in the figure), the optimal stabilization is still relative to that anchor currency, but becomes looser, allowing more fluctuations in the real exchange rate $(\zeta \in(0,1))$. Finally, stabilizing countries above a certain size, and the anchor country itself, find it optimal to float their exchange rates $(\zeta=0){ }^{24}$

Because the allocation under freely floating exchange rates is Pareto efficient, any utility gains from exchange rate stabilization accruing to households in a stabilizing country with positive mass $\left(\theta^{m}>0\right)$ must be causing losses to households somewhere else in the world. Interestingly, this collateral damage typically does not fall on the target country, but rather on the outside country (which, on the surface, has no relation to the stabilization). The reason is that although both the target and outside countries suffer from distortions to the state prices of traded goods, and from the relatively higher prices of firms in the stabilizing country, the target country also receives a benefit: The stabilizing country provides tailor-made insurance against shocks that are specific to the target country.

Panel (b) of Figure 3 shows the same triangular region as in Panel (a) (the area where stabilization is welfare improving for the stabilizing country), but now highlights the area where the target country also receives a net utility gain (the lower shaded area). In this subset of

\footnotetext{
${ }^{24}$ In this sense, the target country also has no incentive to "retaliate" by imposing its own stabilization.
} 
the parameter space, stabilization is thus welfare increasing for residents of both the stabilizing and the target country, and goes exclusively to the detriment of residents in the outside country (which always loses when it is optimal for the stabilizing country to stabilize) ${ }^{25}$

In the upper-left triangular region, the target country would also prefer the stabilizing country to float its exchange rate and not stabilize. However, given a stabilization, the welfare loss in the target country is less than the welfare loss of the outside country $\left(\Delta u^{t}>\Delta u^{o}\right)$. In this sense, the model generates the intuitive result that for a large country that cannot gain from stabilizing itself, being the target country of choice can be beneficial: Given that other countries stabilize, being the target of that stabilization is preferable to being the outside country. (See Appendix D.2 for a formal proof.)

In sum, our simple, near frictionless, model can simultaneously rationalize all four of the stylized facts about international exchange rate arrangements outlined in the introduction as the outcome of a non-cooperative equilibrium where each country chooses the exchange rate regime that maximises its own welfare. In equilibrium, (i) small economies find it optimal to stabilize their exchange rates, whereas only the largest economies in the world float their exchange rate, (ii) larger countries choose looser stabilizations, (iii) all stabilizations are relative to the largest economy in the world, which endogenously emerges at the world's anchor currency, and (iv) other things equal, countries that maintain stronger stabilizations to the anchor currency have lower interest rates, pay lower currency returns, and have higher capita-to-output ratios in equilibrium.

The former three insights on the optimal choice of exchange rate regime ((i)-(iii)) rely crucially on the interaction of two forces. The first is the fact that exchange rate stabilization makes domestic firms safer investments from the perspective of international investors, and thus increases their world-market value. The second is our assumption that households cannot write insurance contracts contingent on the imposition of a currency stabilization, but instead transact only in an international stock market. Because of this (we believe realistic) restriction on the asset space, changes in the value of an asset that even small countries have pricing power over (the relative value of their own firms) translate into shifts in relative wealth across countries. ${ }^{26}$

\footnotetext{
${ }^{25}$ We believe these statements hold quite generally. However we were unable to prove them formally as the analytical expressions are quite complex. See Appendix D.2.

${ }^{26}$ Maybe as relevant in practice as these welfare considerations, our model also lends itself to a political economy rationalization for the same patterns: A large literature argues that policymakers trying to win elections have an interest in raising wages (e.g., if the median voter is a worker, Persson and Tabellini (2002)) and often prefer generating revenue through central bank or currency board operations to direct taxation, even if these operations are distortionary, because they are less visible to the public and easier to control (Cukierman et al., 1992; Bates, 2005). Currency stabilizations relative to the largest economy in the world achieve both of these objectives and may thus be politically attractive. For example, a stabilization relative to the largest economy in the world may
} 
Having studied the positive and normative implications of exchange rate stabilization in this canonical environment, we now show how the insights from this analysis continue to hold in more general settings.

\section{Nominal Stabilization and Monetary Policy}

In practice, most countries stabilize their exchange rates not by levying state-contingent taxes, but instead by buying and selling currency in foreign exchange markets. An extreme example is Hong Kong, which simply exchanges US for Hong Kong dollars at a pre-determined nominal rate. Other countries instead buy and sell foreign currency in open-market operations when the real or nominal exchange rate deviates too far from a reference level (Sarno and Taylor, 2001). This section formally introduces currencies and nominal frictions into our model and shows that the insights carry over directly to the kinds of currency-based stabilizations we see in the data.

In the main text, we focus our attention on perhaps the empirically most relevant case - a standard "new open economy" framework in which money and currencies affect the allocation because the prices of traded goods are sticky. A large body of empirical work shows that price stickiness in traded goods is pervasive in the data. As a result, the pass-through of changes in exchange rates into the prices of traded goods is limited, real and nominal exchange rates are highly correlated, and the law of one price regularly fails (Mussa, 1986; Engel, 1999; Cavallo et al., 2014). We show that within this framework with sticky prices, stabilizing wedges of the same form as those shown in section 2 arise naturally from a simple nominal stabilization regime, where the central bank buys and sells currency to stabilize the nominal or real exchange rate relative to a target country. Appendix E shows similar results for variants of the model with other, widely used, frictions allowing for the transmission of monetary policy to the real economy.

To formally introduce currencies, we extend the setup of our model in section 2.1 by assuming each country has a central bank that issues and controls the supply of domestic currency through open market operations. In each country $n$, the nominal price of the traded good is fixed at $\tilde{P}_{T}^{n}$ units of domestic currency. Households face a cash-in-advance constraint — that is, they must use their domestic currency when buying stocks in period 1 and when buying consumption goods

be optimal even in the absence of valuation effects if policymakers in a stabilizing country maximize a function of the form

$$
E U^{n}+\mu_{1} K^{n}-\mu_{2} \Delta R e s,
$$

where $\mu_{1}$ and $\mu_{2}$ are constants that may reflect the political influence of workers, externalities from capital accumulation, or a motive for generating revenues in a way that avoids direct taxation of households or firms. 
in period 2. Each central bank controls its own money supply. Let $\Delta M_{1}^{n}$ and $\Delta M^{n}(\omega)$ denote the growth of money supply in the first and second period, respectively. A given household's second-period budget constraint then reads:

$$
\tilde{P}_{T}^{n} C_{T}^{n}(\omega)+\tilde{P}_{N}^{n}(\omega) C_{N}^{n}(\omega) \leq \tilde{P}_{T}^{n}\left(\sum_{l} A_{l}^{n} P_{N}^{l}(\omega) Y_{N}^{l}(\omega)+Y_{T}^{n}\right)+\Delta \tilde{M}^{n}(\omega)
$$

where $\tilde{P}_{N}^{n}$ denotes the equilibrium price of the domestic non-traded good in terms of country $n$ 's currency and $A_{l}^{n}$ is the number of shares a household in country $n$ bought in firms in country $l$ in the first period 27

Having introduced money into the model, we can write the log nominal exchange rate as:

$$
\tilde{s}^{f, h}=p^{f}-p^{h}+\tilde{p}_{T}^{f}-\tilde{p}_{T}^{h}
$$

In keeping with our convention above, we define a stabilization of the nominal exchange rate of strength $\tilde{\zeta}$ as a set of policies that decreases the variance of this log nominal exchange rate between the stabilizing and target countries, $\operatorname{var}\left(\tilde{s}^{t, m}\right)=(1-\tilde{\zeta})^{2} \operatorname{var}\left(\tilde{s}^{t, m *}\right)$, while keeping the conditional mean of the log nominal exchange rate unchanged, $\mathbb{E}\left[\tilde{s}^{t, m} \mid\left\{K^{n}\right\}\right]=\mathbb{E}\left[\tilde{s}^{t, m *} \mid\left\{K^{n}\right\}\right]$.

We assume the central banks in the target and outside countries use their control of their money supply to recover the efficient allocation of resources, taking as given the actions of the stabilizing country's central bank. By contrast, the central bank in the stabilizing country uses its control of monetary policy to stabilize the nominal exchange rate.

Although the actors and policymakers have different names in this extended version of the model, the equilibrium allocation is identical to the one already discussed above.

To see this result, note first that the term $\tilde{p}_{T}^{f}-\tilde{p}_{T}^{h}$ in 27 is fixed so that the real exchange rate is simply proportional to the nominal exchange rate. In this model, nominal and real stabilizations are isomorphic: A central bank that stabilizes the nominal exchange rate relative to some target currency automatically stabilizes the real exchange rate relative to that same target country and to the same degree $(\zeta=\tilde{\zeta})$.

This tight link between nominal and real stabilization holds quite generally in this class of models. As long as the price of traded goods is at least partially sticky in terms of the domestic currency (that is, pass-through is not perfect), any stabilization of the nominal exchange rate also implies some stabilization of the real exchange rate and vice versa. Therefore, in practice, it

\footnotetext{
${ }^{27}$ Appendix E.1 gives formal details and additional notation.
} 
may not matter much if policymakers target the real or the nominal exchange rate. Even if we allowed $\tilde{P}_{T}^{m}$ to partially adjust, any nominal stabilization would simply amount to a looser real stabilization with $\zeta<\tilde{\zeta} 28$

Second, through its control of money supply, the stabilizing country's central bank effectively has the same ability to drive a state-contingent wedge between $\lambda_{T}$ and the domestic price of traded goods in the second period (and pay a lump-sum transfer in the first period) as the stabilizing government in section 2. Instead of policy instruments $\bar{Z}$ and $Z(\omega)$ it has $\Delta M_{1}$ and $\Delta M(\omega)$ at its disposal.

Solving the extended model (formal details are in Appendix E.1) shows these monetary policy tools are just as effective. Because the nominal price of the traded good cannot adjust, expansions and contractions of the money supply artificially make traded goods relatively more and less expensive, and thus again drive a wedge between the domestic and world-market price of traded goods. In order to maintain stabilization, the stabilizing central bank must contract the domestic money supply whenever the target country appreciates:

$$
m^{m}(\omega)-m^{m *}(\omega)=-\frac{\zeta\left(1-\theta^{m}\right)}{\gamma \tau}\left(p^{t *}(\omega)-p^{m *}(\omega)\right),
$$

where $m^{m}(\omega)$ is the log size of the monetary base in period 2 .

Moreover, comparing this expression with the one in Lemma 1 shows that there is a oneto-one mapping between these monetary policy actions by the stabilizing central bank and the stabilizing wedges in Lemma 1: $m^{m}(\omega)-m^{m *}(\omega)=-\frac{1-\theta^{m}}{1+(\gamma-1) \tau} z(\omega)$. As a result, the equilibrium allocation, as well as our our positive and normative analyses of the internal and external effects of stabilizations, are identical to the ones the previous section.

The only real difference to our baseline model is that this policy is now much easier to map to the real-world nominal exchange rate stabilization policies that central banks typically follow: When the target country appreciates, the central bank in the stabilizing country decreases the domestic money supply by buying domestic currency and selling foreign currency, matching the nominal appreciation. Because the price of traded goods is sticky in domestic currency, this reduction in domestic money supply increases the real price of traded goods in the stabilizing country, prompting domestic households to consume fewer traded goods whenever the target

\footnotetext{
${ }^{28}$ In practice, monetary authorities often sterilize the effects of their interventions in currency markets on interest rates by additionally changing the money supply. Modeling the difference between these two types of interventions would require introducing additional frictions. However, there is mixed evidence on whether sterilized exchange rate interventions are effective (see for example Obstfeld (1982), Chamon et al. (2017), and Fratscher et al. (2019)).
} 
country appreciates. A conventional nominal stabilization thus automatically replicates the effect of stabilizing state-contingent taxes: The stabilizing country exports additional traded goods whenever the target country appreciates, and vice versa.

\section{Proposition 5}

If the price of the traded good is rigid in terms of the stabilizing country's currency,

1. a nominal stabilization implements a real stabilization of equal strength $\zeta=\tilde{\zeta}$, and

2. the seigniorage from stabilization is equal to $-\Delta$ Res,

$$
\text { seigniorage }=\mathbb{E}\left[\frac{\Lambda_{T}^{*}(\omega)}{\Lambda_{T, 1}^{*}} C_{T}^{m *}(\omega)\right]-\mathbb{E}\left[\frac{\Lambda_{T}(\omega)}{\Lambda_{T, 1}} C_{T}^{m}(\omega)\right]=-\Delta \text { Res }
$$

Proof. See Appendix E.1.

If households need domestic currency to buy consumption goods and prices are sufficiently sticky to give the central bank some leverage over real allocations, we thus conclude that stabilizations of the real exchange rate can be implemented with a simple and intuitive rule that commits the central bank to contract the domestic money supply whenever the target country appreciates. The role played by the country's reserves in the previous section is now taken over, one-for-one, by seigniorage accruing to the central bank. Aside from this relabeling, all the remaining insights from the positive and normative analysis of our baseline model remain unchanged and continue to apply.

Appendix E shows these same insights continue to hold in additional variations of the model that employ other, widely used, nominal frictions. Appendix E.2 shows an extension where, instead of the price of traded goods, the price of the entire domestic consumption bundle is sticky 29 Appendix E.3 studies an economy shows where prices are fully flexible and monetary policy instead affects real allocations because some households within each country hold only nominal bonds and are excluded from accessing the stock market. In each case, the stabilizing central bank must contract the domestic money supply whenever the target country appreciates to maintain the stabilization; and all positive results from our baseline model continue to apply. The normative analysis again remains unchanged in the former variant (Appendix E.2), but is naturally harder to interpret when there are different types of households within each country (Appendix E.3).

\footnotetext{
${ }^{29}$ Allowing for rigid prices of non-traded goods is more complicated because it requires additional frictions to ensure market clearing.
} 


\section{Partially Credible Stabilizations and Floating Bands}

A major issue in the study of policies that manipulate the first moment of exchange rates (underor over-valuations), is the depletion of reserves and the credibility of such manipulations in the face of potential speculative attacks (Krugman, 1979; Garber and Svensson, 1995). By contrast, we have already shown that stabilizations of the real exchange rate relative to a large target country may generate, rather than deplete, reserves, assuaging some potential concerns about the policy's credibility. (The portfolio of stocks that finances the stabilization policy in each state has a negative cost in period 1.)

Nevertheless, it is worthwhile to consider the effects of only partially credible stabilizations. Suppose the government, either by choice or necessity, abandons the stabilization in a subset of states $\Omega_{-s} \subset \Omega$ (where $\Omega$ is the set of all possible states). Assuming the government continues to stabilize state-by-state within $\Omega_{s}=\Omega \backslash \Omega_{-s}$, and that this limited stabilization continues to leave the mean of the real exchange rate undistorted (e.g., the partition of $\Omega$ into $\Omega_{s}$ and $\Omega_{-s}$ is symmetric around the mean), we can show that 30

$$
\operatorname{var}\left(s^{m, t}\right)=\left(\operatorname{Prob}\left[\omega \in \Omega_{s}\right](1-\zeta)^{2}+\operatorname{Prob}\left[\omega \in \Omega_{-s}\right]\right) \operatorname{var}\left[s^{* m, t} \mid \Omega_{-s}\right]<\operatorname{var}\left(s^{m, t *}\right)
$$

and

$$
r^{m}+\Delta \mathbb{E}\left[s^{m, t}\right]-r^{t}=-\left(\operatorname{Prob}\left[\omega \in \Omega_{s}\right](1-\zeta)-\operatorname{Prob}\left[\omega \in \Omega_{-s}\right]\right) \operatorname{cov}\left[\lambda_{T}, s^{* m, t} \mid \Omega_{s}\right] .
$$

In contrast to partially credible manipulations of the level of the real exchange rate, partially credible manipulations of its variance are thus still effective: They reduce the variance of the real exchange rate and affect interest rates and other outcomes in the same way as characterized above - only less so than a fully credible stabilization. In this sense, we may simply think of partially credible stabilizations as "weaker" credible stabilizations.

Additionally, the equations above also describe the effects of a variety of nonlinear stabilization policies, such as floating bands, that allow freely floating exchange rates within some range and intervene state by state only when the real exchange rate departs this band.

Appendix F.2 shows that our analysis extends directly to stabilizations relative to a basket of currencies, where stabilizing relative to a basket of currencies has effects akin to a stabilization relative to a (hypothetical) country with a weighted average size of the basket's constituents.

\footnotetext{
${ }^{30}$ See Appendix $\mathrm{F} .1$ for a formal derivation.
} 


\section{Segmented Markets and Preference Shocks}

So far, we have based our analysis of currency stabilization on a conventional international real business cycle model, where productivity shocks are the only drivers of variation in real exchange rates (Backus and Smith, 1993). Although an important benchmark, this framework has a number of well-known empirical shortcomings. First, it predicts a perfectly negative correlation between appreciations of the real exchange rate and aggregate consumption growth - a currency appreciates when the country's aggregate consumption decreases. Second, the model predicts consumption should be more correlated across countries than output, whereas the opposite is true in the data (Backus, Kehoe, and Kydland, 1994). Third, real exchange rates and terms of trade seem much too volatile to be rationalized by real (productivity) shocks alone (Chari, Kehoe, and McGrattan, 2002).

In this section, we argue the conclusions from our analysis of exchange rate stabilizations do not rely on any of these counterfactual features of the international real business cycle model. Instead, they depend solely on two, more general, features of conventional approaches to modeling variation in exchange rates: First, whatever shock causes a country's real exchange rate to appreciate also prompts this country to demand higher imports of traded goods. Second, shocks that raise the price of consumption in a larger country spill over more into the world-market price of traded goods. Both of these forces are common features of a broader class of models where real exchange rates may also fluctuate in response to shocks to preferences or money supply.

To illustrate this finding, we augment our baseline model in section 2.1 with two (widely cited) demand-based sources of variation in real exchange rates. First, we allow households in each country to experience preference shocks as suggested Pavlova and Rigobon (2007):

$$
U(i)=\frac{1}{1-\gamma} \mathbb{E}\left[\left(\exp \left(\chi^{n}\right) C_{2}(i)\right)^{1-\gamma}\right]
$$

where $\chi^{n}$ is a common shock to households' preference for consumption goods in country $n$,

$$
\chi^{n} \sim N\left(-\frac{1}{2} \sigma_{\chi}^{2}, \sigma_{\chi}^{2}\right) .
$$

Second, we also allow for a direct effect of inflation on real exchange rates by assuming a measure $1-\phi$ of "inactive" households within each country exclusively hold nominal bonds denominated in their own currency, as suggested by Alvarez et al. (2002) 31 The remaining

\footnotetext{
${ }^{31}$ A substantial fraction of households in the US and in other developed economies own savings accounts or
} 
measure $\phi$ of ("active") households within each country trade stocks and nominal bonds in international markets as before ${ }^{32}$ Each country's nominal bond pays off one unit of the country's nominal consumer price index, $P_{2}^{n} e^{-\mu^{n}}$, where $\mu^{n}$ is a (monetary) shock to the growth rate of the nominal price of one unit of the traded good in the currency of country $n$,

$$
\mu^{n} \sim N\left(-\frac{1}{2} \tilde{\sigma}^{2}, \tilde{\sigma}^{2}\right)
$$

A higher $\mu^{n}$ thus implies a higher inflation rate in country $n$. Active households own all stocks and are short the nominal bonds owned by inactive households, so that monetary shocks effectively shift resources from inactive households (who live hand-to-mouth and are not hedged against inflation) to active agents whose marginal utilities determine exchange rates and asset prices. (See Appendix G.1 for details on the budget constraints of both kinds of households.)

As before, the government of the stabilizing country stabilizes its exchange rate with the target country using state-contingent taxes.

The punchline is that currency stabilization in this richer model of exchange rate determination works in the same way as in our baseline model with productivity shocks. First, note that larger countries continue to have lower interest rates and a lower cost of capital under freely floating exchange rates. Solving the model yields

$$
s^{f, h *}=p^{f *}-p^{h *}=\frac{\gamma(1-\tau)}{\phi(1-\tau)+\gamma \tau}\left((1-\phi)\left(\mu^{h}-\mu^{f}\right)+\frac{\phi(\gamma-1)}{\gamma}\left(\chi^{h}-\chi^{f}\right)\right)
$$

and

$$
\lambda_{T}^{*}=-\gamma\left(\frac{1-\phi}{\phi}\right) \sum_{n} \theta^{n} \mu^{n}-(\gamma-1) \sum_{n} \theta^{n} \chi^{n} .
$$

The structure of these expressions is identical to (16) and (17): Countries import more traded goods when they appreciate, and shocks to the price of consumption in a larger country spill over more to $\lambda_{T}^{*}$, so that larger countries tend to appreciate when $\lambda_{T}^{*}$ is high. For example, a low $\chi$ in a given country increases the marginal utility of its households, appreciates its real exchange rate, and prompts it to import more traded goods. If the country is large, these higher imports also raise $\lambda_{T}^{*}$, so that a larger country's preference shocks spill over more to the rest of the world. Similarly, a low monetary shock (deflation) shifts resources away from active households (who

bonds denominated in their domestic currency, but do not own stocks or other more sophisticated financial instruments that could hedge their portfolios against inflation (Giannetti and Koskinen, 2010, Nechio, 2010).

${ }^{32}$ Because this richer model has six linearly independent shocks, we need a stock and a bond for each country so that the payoffs of the available assets span all states of the world in the log-linear solution to the competitive equilibrium, as before. 
are short the nominal bonds owned by inactive households), increases their marginal utility, and thus appreciates the country's real exchange rate - prompting it to import more traded goods. If the country is large, these higher imports again have a proportionately higher impact on $\lambda_{T}^{*}$.

As a result, larger countries again have safer currencies, lower interest rates, and more valuable firms, as they did in our baseline model. Similarly, the effects of exchange rate stabilization follow the same logic as above: A smaller country stabilizing its real exchange rate relative to a larger country increases the covariance between its exchange rate and $\lambda_{T}$ :

$$
p^{m}=p^{m *}+\zeta\left(\frac{\gamma \tau+\theta^{m}(1-\tau) \phi}{\gamma \tau}\right)\left(p^{t *}-p^{m *}\right)
$$

and by making its currency safer, the stabilizing government increases domestic capital accumulation and its households' share in world wealth. As before, the stabilizing government must artificially increase its exports of traded goods whenever the target country appreciates, in order to maintain the stabilization:

$$
c_{T}^{m}-c_{T}^{m *}=-\zeta \frac{\left(1-\theta^{m}\right)(\tau+(1-\tau) \phi)^{2}+(1-\tau)(1-\phi)(\gamma \tau+(1-\tau) \phi)}{\gamma \tau(\tau+(1-\tau) \phi)}\left(p^{t *}-p^{m *}\right) .
$$

Moreover, by effectively selling insurance against the target country's shocks, the stabilizing country again dampens the effect of the target country's shocks on the world-market price of traded goods:

$$
\lambda_{T}=\lambda_{T}^{*}-\zeta \theta^{m}\left(\frac{\gamma \tau+(1-\tau) \phi}{\gamma \tau}\right)\left(p^{t *}-p^{m *}\right) .
$$

It follows directly that all of our positive predictions about the effects of currency stabilizations carry over to this richer model. (The conclusions of our normative analysis also continue to hold as long as the traditional welfare criterion is applicable $(\phi=1)$, but are harder to interpret once we have more than one class of households per country.)

\section{Proposition 6}

In the model with market segmentation, monetary shocks, and preference shocks with $\gamma>1$, the following hold:

1. A country that stabilizes its real exchange rate relative to a target country sufficiently larger than itself lowers its risk-free interest rate and increases the world-market value of domestic firms, domestic capital accumulation, and domestic wages relative to the target country.

2. If the stabilizing country is small $\left(\theta^{m}=0\right)$, the cost of the stabilization globally decreases with the size of the target country. 
3. A country that becomes the target of a stabilization of any strength $\zeta>0$ imposed by a large country experiences an increase in its risk-free interest rate, a decrease in capital accumulation, and a decrease in average wages relative to all other countries.

\section{Proof. See Appendix G.4.}

In addition to reinforcing the main insights from our baseline model, this richer framework addresses the three major empirical shortcomings of the international real business cycle model outlined above: The combination of market segmentation, monetary shocks, and preference shocks loosens or even reverses the negative correlation between appreciations of the real exchange rate and aggregate consumption growth, lowers the correlation of aggregate consumption across countries, and increases the volatility of real and nominal exchange rates Alvarez et al. 2002 . Pavlova and Rigobon, 2007; Kollmann, 2012). All of our conclusions from section 2 thus carry over to this empirically more viable model of exchange rate determination.

Beyond this particular model, we believe that the results stated in Proposition 6 are quite general and hold in a wide range of models where currency manipulation transmits itself through a wedge on the price of traded goods. As noted in the introduction, more general models could also allow governments to stabilize exchange rates by manipulating additional wedges on allocations within countries, such as the sectoral allocation of labor or the distribution of wealth across households. Within this broader class of models, it is possible to construct examples where stabilization of the real exchange rate is achieved by reducing rather than increasing exports in response to an appreciation by the target country. In those examples, stabilizations relative to larger countries continue to lower domestic interest rates and increase capital accumulation, but some of the other implications highlighted above may not generalize. In this sense, the first statement in Proposition 6 is the most general, whereas the second and third statements rely on the - we believe plausible - assumption that interventions in currency markets affect allocations primarily through their effect on trade and the prices of traded goods.

\section{Conclusion}

The majority of countries in the world stabilize their real or nominal exchange rate relative to the US dollar. Although exchange rate stabilizations are possibly the most pervasive form of currency market interventions, existing theories give relatively little guidance on the effects of 
such stabilizations, on what might be special about the US dollar as a target currency, and on how these stabilizations might affect the target country.

Building on a growing literature that views risk premia as the main driving force behind large and persistent differences in interest rates across developed economies, we propose a novel, risk-based theory of the effects of currency manipulation: Policies that reduce the riskiness of a country's currency from the perspective of international investors reduce its risk premium in international markets, lower the country's risk-free interest rate, and increase domestic capital accumulation, domestic wages, and the world market value of domestic firms.

In particular, we show that stabilizing a country's real exchange rate relative to a larger (and safer) target economy is precisely such a policy that enables small countries to increase the worldmarket value of their capital stock, bonds, and firms. Moreover, if the prices of traded goods are at least partially sticky in terms of the domestic currency, such real stabilizations correspond directly to the kinds of simple stabilizations of nominal exchange rates relative to the US dollar we observe in the data, where central banks engage in a variety of open market operations to maintain pegs, moving bands, or managed floats.

In equilibrium, the effect of exchange rate stabilizations on risk premia gives rise to a pattern of optimal stabilizations that is remarkably similar to the one we see in the data: In the absence of coordination, small countries find it optimal to stabilize their exchange rates relative to the currency of the largest economy in the world, which endogenously emerges as the world's "anchor" currency. By contrast, larger countries optimally choose looser stabilizations or float their exchange rates. In other words, our model suggests that the dollar-centric pattern of exchange rate regimes that has arisen since the collapse of the Bretton-Woods system can be understood as an attempt to manage risk and attract investment. This interpretation is further bolstered by our empirical finding showing small and medium-sized economies that stabilize their exchange rates have lower interest rates, their currencies pay lower returns to international investors, and their firms use relatively more capital than those that do not.

Interestingly, our model also suggests that this (non-cooperative) equilibrium pattern of stabilization tends to benefit not only the stabilizers, but also the target (anchor) country, while other countries that are too large to stabilize their own exchange rates are always worse off relative to a world-wide freely-floating regime.

In sum, we believe our paper provides a novel way of thinking about the effects of currency stabilization. Along with highlighting a model-consistent rationale for stabilizing, we also give an account of the costs and benefits of important choices for the stabilization regime, such as the 
choice of target country, the effects of hard pegs versus floating bands, and stabilizations relative to a single country versus a basket of currencies.

Our work leaves open at least three avenues for future research. First, careful empirical work will be needed to identify the effect of currency manipulation in the data and disentangle the effects of altered risk premia from effects that may transmit themselves through more conventional channels, such as facilitating trade with the target country and establishing credibility for monetary policy. A prerequisite to making further progress on these questions will be to identify (and control for) stabilizations that also involve manipulating the mean of the real exchange rate - a contentious political issue that has not been satisfactorily resolved in the empirical literature. Second, although many models have argued for risk premia as the main drivers of cross-sectional differences in interest rates, all of these papers, including our own, rely on standard preferences and thus generally imply risk premia are quantitatively small. Recent work by Govillot et al. (2010), David et al. (2016), and Colacito et al. (2018) makes progress in this dimension by studying dynamic models with heterogeneous countries and recursive preferences. However, the literature is still far from rationalizing the large differences in mean returns across currencies we see in the data in a microfounded quantitative model. Finally, our analysis has focused exclusively on a simple (non-cooperative) problem in which each country optimally chooses its own exchange rate regime, taking as given the policies of other countries. Analogous to a large literature on trade agreements (Bagwell and Staiger, 1999; Ossa, 2011), our prediction that exchange rate policy alters the equilibrium allocation of factors of production may also serve as the basis of a cooperative theory of multilateral exchange rate arrangements. 


\section{References}

Alvarez, F., A. Atkeson, and P. J. Kehoe (2002). Money, interest rates, and exchange rates with endogenously segmented markets. Journal of Political Economy 110(1), 73-112.

Auclert, A. and M. Rognlie (2014). Monetary union begets fiscal union. mimeo Stanford University.

Bacchetta, P. and E. van Wincoop (2000). Does exchange-rate stability increase trade and welfare. American Economic Review 90(5), 1093-1109.

Backus, D. K., P. J. Kehoe, and F. E. Kydland (1994). Determinants of the trade balance and the terms of trade: The j curve? American Economic Review 84(1), 84-103.

Backus, D. K. and G. W. Smith (1993). Consumption and real exchange rates in dynamic economies with non-traded goods. Journal of International Economics 35, 297-316.

Bagwell, K. and R. Staiger (1999). An economic theory of gatt. American Economic Review.

Bates, R. H. (2005). Markets and States in Tropical Africa: The Political Basis of Agricultural Policies: With a New Preface. Univ of California Press.

Bergin, P. R. and G. Corsetti (2015). International competitiveness and monetary policy. Unpublished Manuscript.

Bianchi, J. (2011, December). Overborrowing and systemic externalities in the business cycle. American Economic Review 101(7), 3400-3426.

Bocola, L. and G. Lorenzoni (2020). Financial crises, dollarization, and lending of last resort in open economies. American Economic Review Forthcoming.

Boz, E., C. Casas, F. J. Diez, G. Gopinath, P.-O. Gourinchas, and M. Plagborg-Moller (2020). Dominant currency paradigm. American Economic Review 110(3), 677-719.

Calvo, G. and E. Mendoza (2000). Rational contagion and the globalization of securities markets. Journal of International Economics 51(1), 79-113.

Campbell, J. Y., K. Serfaty-De Medeiros, and L. M. Viceira (2010). Global currency hedging. The Journal of Finance 65(1), 87-121.

Cavallo, A., B. Neiman, and R. Rigobon (2014). Currency unions, product introductions, and the real exchange rate. The Quarterly Journal of Economics, qju008.

Chahrour, R. and R. Valchev (2019). The international medium of exchange. Boston College.

Chamon, M., M. Garcia, and L. Souza (2017). Fx interventions in brazil: A synthetic control approach. Journal of International Economics 108, 157-168.

Chari, V. V. and P. J. Kehoe (1990). International coordination of fiscal policy in limiting economies. Journal of Political Economy 98(3), 617-636. 
Chari, V. V., P. J. Kehoe, and E. R. McGrattan (2002). Can sticky price models generate volatile and persistent real exchange rates? The Review of Economic Studies 69(3), 533-563.

Coeurdacier, N. (2009). Do trade costs in goods market lead to home bias in equities? Journal of International Economics 77(1), 86-100.

Coeurdacier, N. and H. Rey (2013, March). Home bias in open economy financial macroeconomics. Journal of Economic Literature 51(1), 63-115.

Colacito, R., M. Croce, F. Gavazzoni, and R. Ready (2018). Currency risk factors in a recursive multi-country economy. The Journal of Finance 73(6), 2719-2756.

Corsetti, G., L. Dedola, and S. Leduc (2010). Optimal monetary policy in open economies. In B. M. Friedman and M. Woodford (Eds.), Handbook of Monetary Economics (1 ed.), Volume 3, Chapter 16, pp. 861-933. Elsevier.

Costinot, A., G. Lorenzoni, and I. Werning (2014). A theory of capital controls as dynamic terms-of-trade manipulation. Journal of Political Economy 122(1), 77-128.

Cukierman, A., S. Edwards, and G. Tabellini (1992). Seigniorage and political instability. The American Economic Review, 537-555.

David, J. M., E. Henriksen, and I. Simonovska (2016). The risky capital of emerging markets. NBER Working Paper Series 20769, National Bureau of Economic Research.

Devereux, M. B. and C. Engel (2003). Monetary policy in the open economy revisited: Price setting and exchange-rate flexibility. Review of Economic Studies.

Engel, C. (1999). Accounting for u.s. real exchange rate changes. Journal of Political Economy.

Fanelli, S. and L. Straub (2019). A theory of foreign exchange interventions.

Farhi, E. and X. Gabaix (2015). Rare disasters and exchange rates. Quarterly Journal of Economics forthcoming.

Farhi, E. and M. Maggiori (2017). A model of the international monetary system. Quarterly Journal of Economics 133(1), 295-355.

Farhi, E. and I. Werning (2013). Dilemma not trilemma? capital controls and exchange rates with volatile capital flows. mimeo, Massachusetts Institute of Technology.

Farhi, E. and I. Werning (2014). Dealing with the trilemma: Optimal capital controls with fixed exchange rates. IMF Economic Review 62(4), 569-605.

Fornaro, L. (2015). Financial crises and exchange rate policy. Journal of International Economics $95(2), 202-215$.

Frankel, J. A. and A. Rose (2002). An estimare of the effect of common currencies on trade and income. The Quarterly Journal of Economics 117(2), 437-466. 
Fratscher, M., O. Gloede, L. Menkhoff, L. Sarno, and T. Stohr (2019). When is foreign exchange intervention effective? evidence from 33 countries. American Economic Journal: Macroeconomics 11 (1), 132-156.

Gabaix, X. and M. Maggiori (2015). International liquidity and exchange rate dynamics. Quarterly Journal of Economics 130(3), 1369-1420.

Gali, J. and T. Monacelli (2005). Monetary policy and exchange rate volatility in a small open economy. Review of Economic Studies 72, 707-734.

Garber, P. M. and L. E. O. Svensson (1995). The operation and collapse of fixed exchange rate regimes, Volume 3, Chapter 36, pp. 1865-1911. Elsevier.

Giannetti, M. and Y. Koskinen (2010, February). Investor protection, equity returns, and financial globalization. Journal of Financial and Quantitative Analysis 45(01), 135-168.

Gopinath, G. and J. Stein (2019). Banking, trade and the making of a dominant currency. NBER Working Paper Series No. 24485.

Gourinchas, P.-O. and H. Rey (2007). From world banker to world venture capitalist: U.s. external adjustment and the exorbitant privilege. In G7 Current Account Imbalances: Sustainability and Adjustment, NBER Chapters, pp. 11-66. National Bureau of Economic Research, Inc.

Govillot, N., H. Rey, and P. Gourinchas (2010). Us external returns and the exorbitant duty. 2010 Meeting Papers 371, Society for Economic Dynamics.

Hassan, T. A. (2013). Country size, currency unions, and international asset returns. The Journal of Finance 68(6), 2269-2308.

Hassan, T. A. and R. Mano (2019). Forward and spot exchange rates in a multi-currency world. The Quarterly Journal of Economics 134(1), 397-450.

Hassan, T. A., T. M. Mertens, and T. Zhang (2016). Not so disconnected: Exchange rates and the captial stock. Journal of International Economics 99.

He, Z., A. Krishnamurthy, and K. Milbradt (2019). A model of safe asset determination. American Economic Review 109(4), 1230-1262.

Helpman, E. and A. Razin (1987). Exchange rate management: Intertemporal tradeoffs. American Economic Review 77(1), 107-123.

Hooper, P. and S. W. Kohlhagen $(1978$, s). The effect of exchange rate uncertainty on the prices and volume of international trade. Journal of International Economics 8(4), 483-511.

Ilzetzki, E., C. M. Reinhart, and K. S. Rogoff (2018). Exchange arrangements entering the 21st century: which anchor will hold? Quarterly Journal of Economics.

Jeanne, O. and A. Korinek (2010). Excessive volatility in capital flows: A pigouvian taxation approach. American Economic Review 100(2), 403-407.

Kenen, P. B. and D. Rodrik (1986). Measuring and analyzing the efects of short-term volatility in real exchange rates. The Review of Economics and Statistics 68(2), 311-315. 
Kollmann, R. (2002). Monetary policy rules in the open economy: effects on welfare and business cycles. Journal of Monetary Economics.

Kollmann, R. (2012). Limited asset market participation and the consumption-real exchange rate anomaly. Canadian Journal of Economics.

Korinek, A. (2013). Capital controls and currency wars. mimeo University of Maryland.

Korinek, A. and A. Simsek (2016). Liquidity trap and excessive leverage. American Economic Review 106 (3), 699-738.

Krugman, P. R. (1979, August). A model of balance of payments crises. Journal of Money, Credit and Banking (11), 311-325.

Levy, P. I. (2011). The united states and china: Macroeconomic imbalances and economic diplomacy. AEI Economic Policy Studies Working Paper.

Lustig, H., N. Roussanov, and A. Verdelhan (2011). Common risk factors in currency markets. Review of Financial Studies 24(11), 3731-3777.

Lustig, H. and A. Verdelhan (2007). The cross section of foreign currency risk premia and consumption growth risk. American Economic Review 97(1), 89-117.

Maggiori, M. (2017). Financial intermediation, international risk sharing, and reserve currencies. American Economic Review 107(10), 3038-71.

Martin, I. (2012). The forward premium puzzle in a two-country world. mimeo.

Menkhoff, L., L. Sarno, M. Schmeling, and A. Schrimpf (2012). Carry trades and global foreign exchange volatility. Journal of Finance 67(2), 681-718.

Miranda-Agrippino, S. and H. Rey (2015). World asset markets and the global financial cycle. NBER Working Paper Series 21722, National Bureau of Economic Research, Inc.

Mussa, M. (1986). Nominal exchange rate regimes and the behavior of real exchange rates: Evidence and implications. In Carnegie-Rochester Conference series on public policy, Volume 25, pp. 117-214. Elsevier.

Nechio, F. (2010). Foreign stock holdings: the role of information. Working Paper Series 2010-26, Federal Reserve Bank of San Francisco.

Obstfeld, M. (1982, May). Can we sterilize? theory and evidence. American Economic Review 72(2), 45-50.

Ossa, R. (2011). A new trade theory of gatt/wto negotiations. Journal of Political Economy $119(1), 122-152$.

Ottonello, P. (2015). Optimal exchange rate policy under collateral constraints and wage rigidity. manuscript, Columbia University.

Parrado, E. and A. Velasco (2002). Optimal interest rate policy in a small open economy. NBER Working Paper Series 8721, National Bureau of Economic Research, Inc. 
Pavlova, A. and R. Rigobon (2007). Asset prices and exchange rates. Review of Financial Studies 20(4), 1139-1180.

Persson, T. and G. E. Tabellini (2002). Political economics: explaining economic policy. MIT press.

Powers, T. Y. (2015). The commodity currency puzzle. mimeo Harvard University.

Ready, R., N. Roussanov, and C. Ward (2017). Commodity trade and the carry trade: a tale of two countries. The Journal of Finance 72(6), 2629-2684.

Richers, J. (2019). Uip violations and the cost of capital: Firm-level evidence. mimeo Boston University.

Richmond, R. (2019). Trade network centrality and the currency carry trade. The Journal of Finance 74 (3), 1315-1361.

Sarno, L. and M. P. Taylor (2001). Official intervention in the foreign exchange market: Is it effective and, if so, how does it work? Journal of Economic Literature, 839-868.

Schmitt-Grohé, S. and M. Uribe (2012). Pegs and pain. mimeo Columbia University.

Tran, N.-K. (2013). Growth risk of nontraded industries and asset pricing. mimeo Olin Business School.

Verdelhan, A. (2017). The share of systematic risk in bilateral exchange rates. The Journal of Finance 73(1), 375-418.

Zhang, T. (2019). Monetary policy spillovers through invoicing currencies. Boston University. 

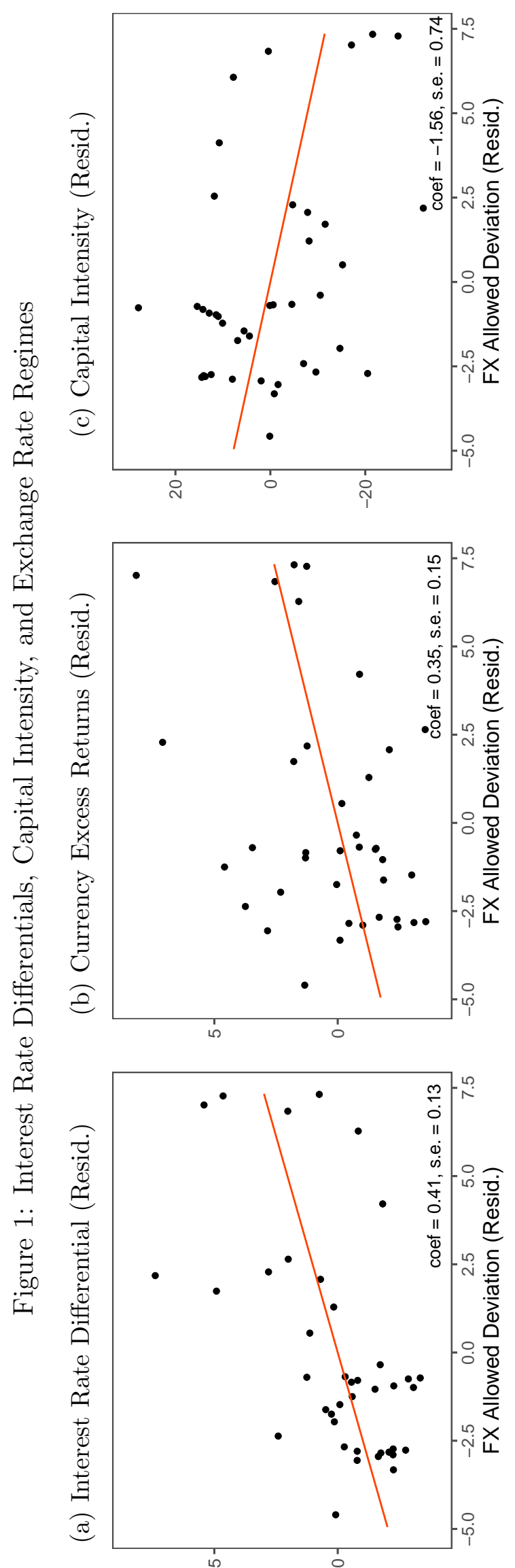

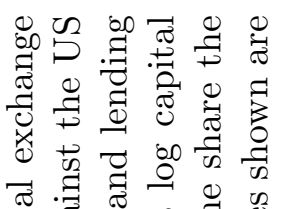

胥

สี $\frac{\sigma}{\bar{\sigma}}$ है

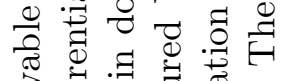

它过

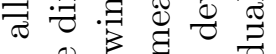

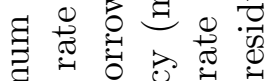

.

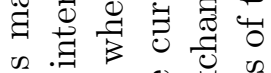

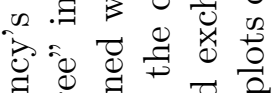

ष

嵌.

त्व

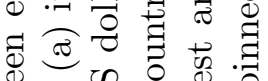

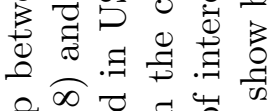

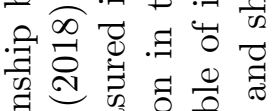

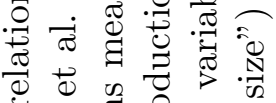

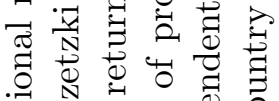

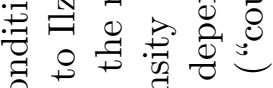

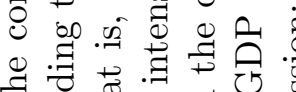

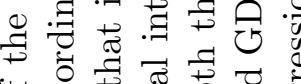

पु

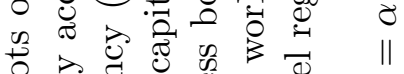

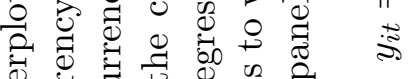

ए

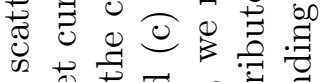

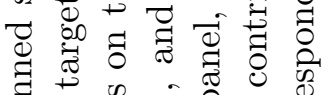

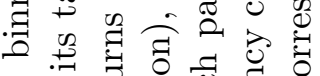

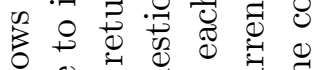

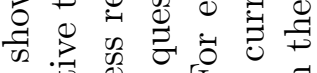

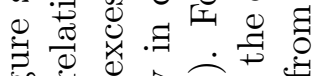

50.

. .

E.

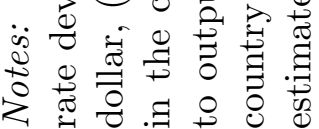

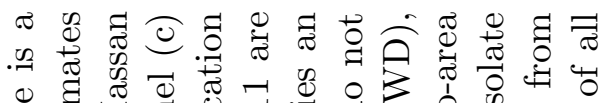

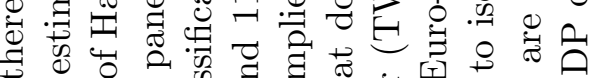

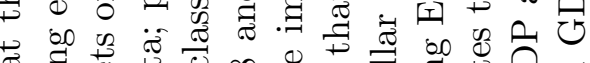

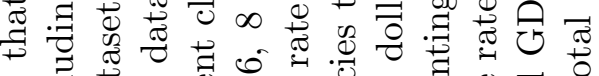

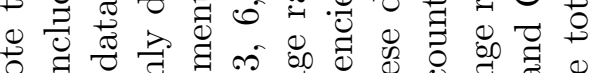

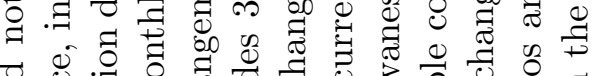

च

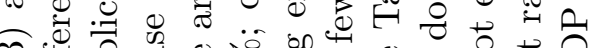

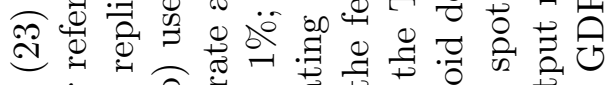

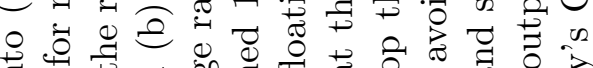

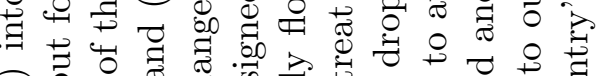

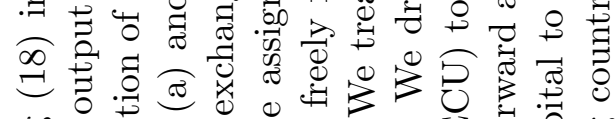

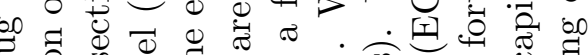

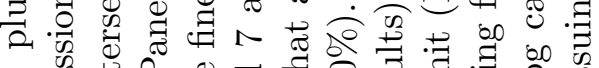

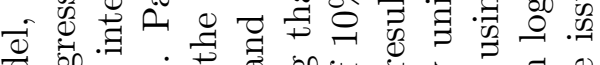

过号

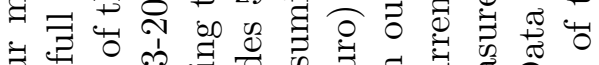

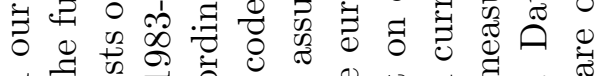

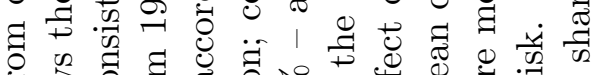

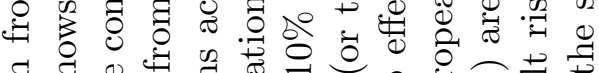

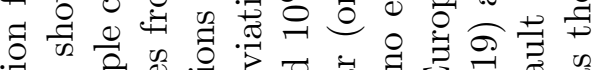

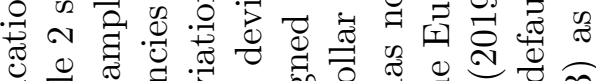

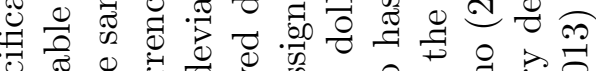

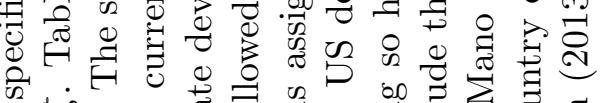
心

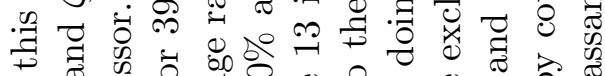
จ

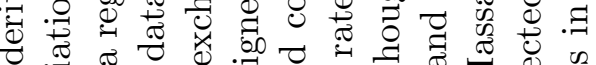
0 它

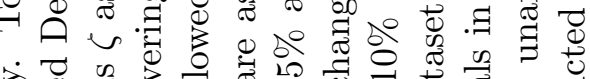

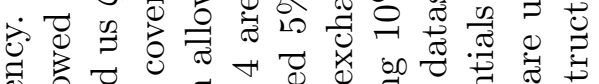

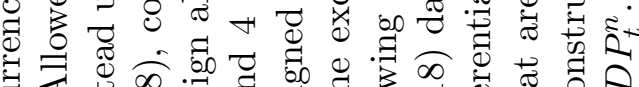

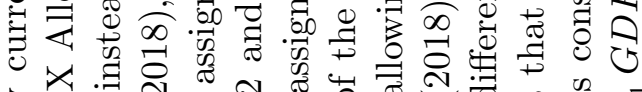
ठิ ర

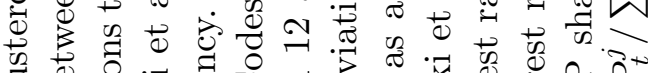

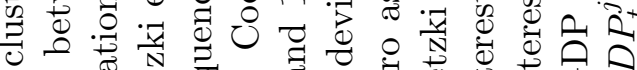
৩ की

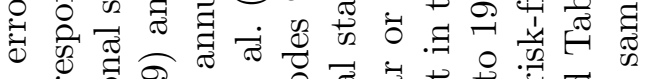
节 范 范

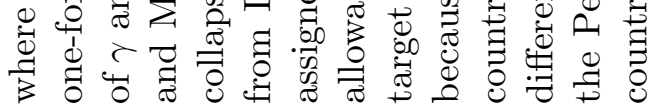


Table 1: 2010 Exchange Rate Arrangements According to Ilzetzki, Reinhart, and Rogoff (2018)

\begin{tabular}{lccc}
\hline \hline Panel A & \multicolumn{3}{c}{ Exchange rate arrangement } \\
\hline GDP Decile & $\begin{array}{c}1-5 \\
\text { (smallest) }\end{array}$ & $6-9$ & $\begin{array}{c}10 \\
\text { (largest) }\end{array}$ \\
\hline Floating & $0 \%$ & $0 \%$ & $29 \%$ \\
Stabilized & $100 \%$ & $100 \%$ & $71 \%$ \\
\multicolumn{1}{c}{ soft peg } & $40 \%$ & $60 \%$ & $65 \%$ \\
\multicolumn{1}{c}{ hard peg } & $60 \%$ & $40 \%$ & $6 \%$ \\
\hline Panel B & Target currency \\
\hline \multirow{2}{*}{ Number of Countries } & 124 & Euro & Other \\
\hline \hline
\end{tabular}

Notes: Countries are divided into deciles by GDP in 2010. Deciles 1-9 each contain 18 countries, the tenth 17 countries. The "floating" category refers to exchange rates classified as "freely floating" in Ilzetzki, Reinhart, and Rogoff (2018) (fine classification code 13), the "soft peg" category includes currencies with any form of crawling peg, crawling band, or managed float. The "hard peg" category includes currency unions, pre-announced pegs, and de facto pegs (codes 1, 2, and 4). 
Figure 2: Effect of Stabilization on Utility in the Stabilizing Country

(a) Drivers of utility gains/losses over the size of the target country

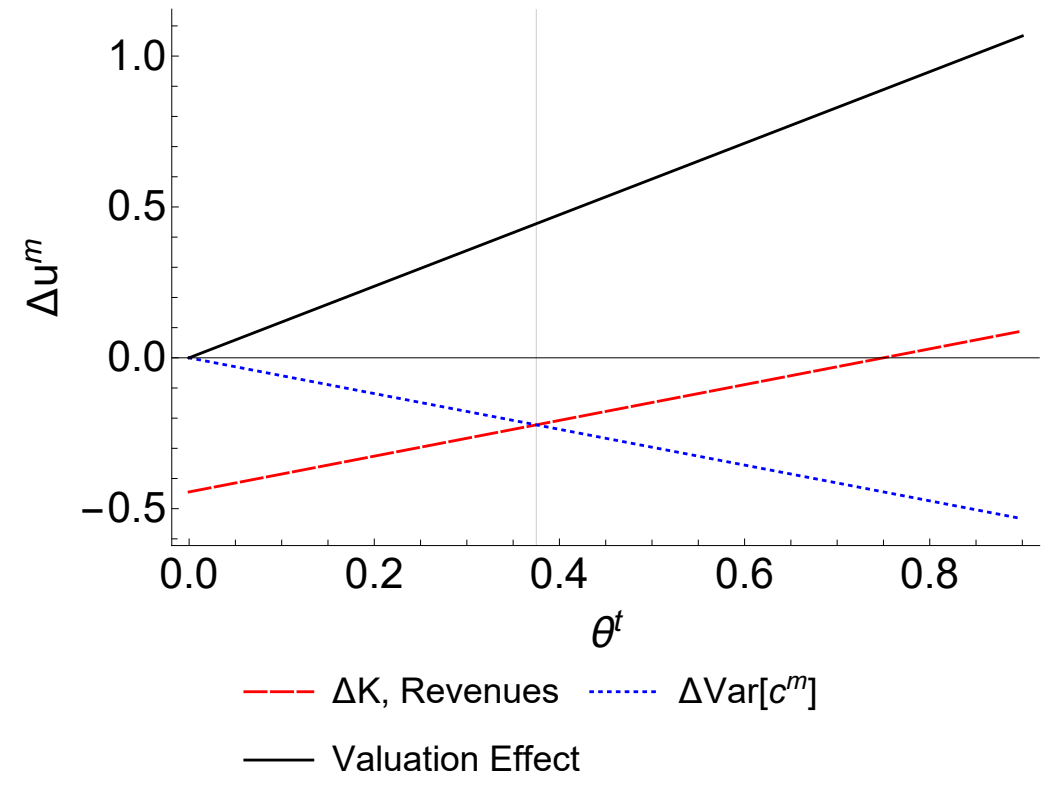

(b) Utility gains of stabilization over strength of stabilization for stabilizing countries of different sizes

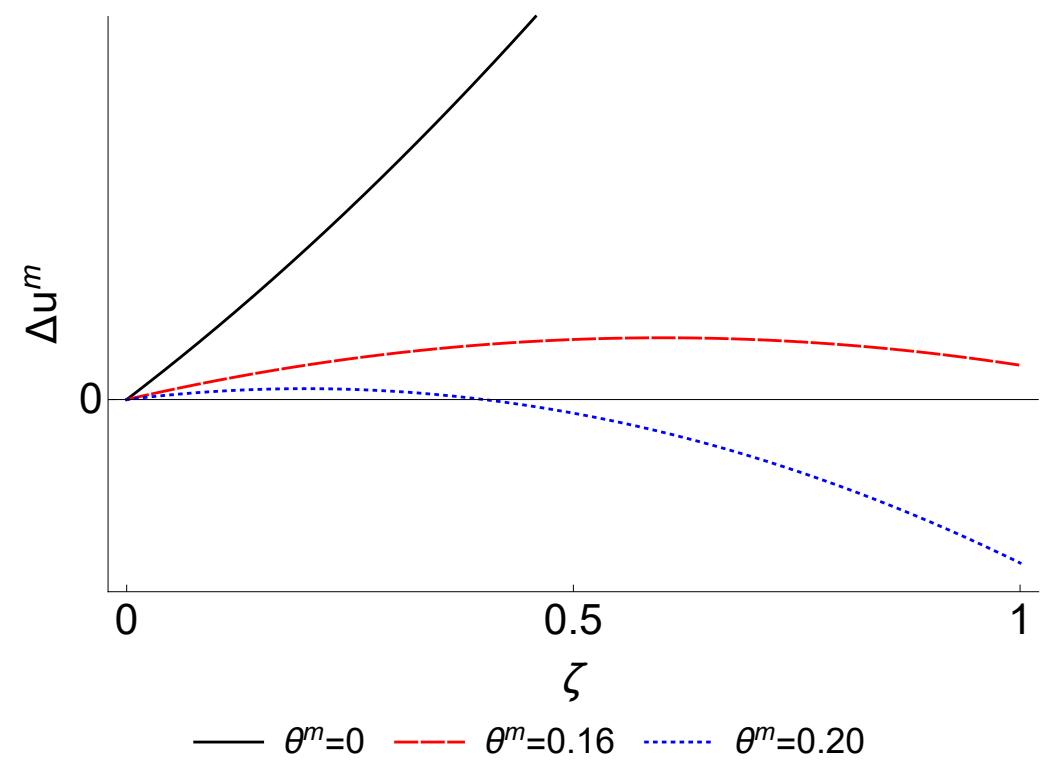

Notes: Both plots show the percentage increase in the certainty-equivalent consumption of a representative household in the stabilizing country attributable to the stabilization $\left(\Delta u^{m}\right)$ for a numerical example where $\tau=1 / 3$, and $\gamma=7$. Panel (a) shows the three components of $\Delta u^{m}$ shown on the right hand side of 25 for a small stabilizing country $\left(\theta^{m}=0\right)$ and a hard peg $(\zeta=1)$. The net utility gain is the sum of the three lines. It is positive for all $\theta^{t}>\bar{\theta}$. Panel (b) shows the net utility gain as a function of $\zeta$ for stabilizing countries of different sizes. See Appendix D for the generalization of (25) that allows for $\theta^{m}>0$. 


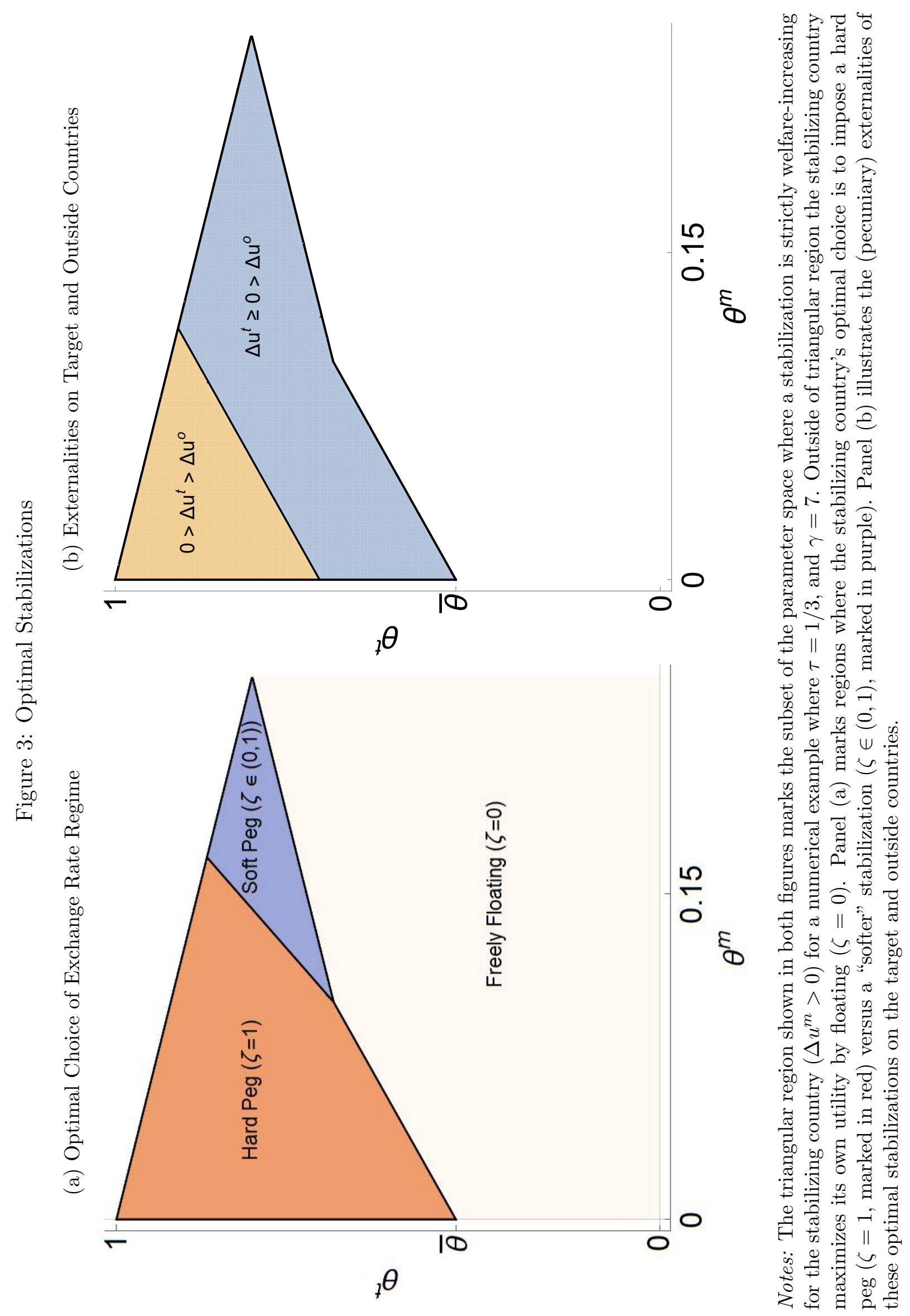




\section{Appendix \\ -For online publication only-}

\section{A Additional Empirical Results}

Table 2: Interest Rate Differentials, Capital Intensity, and Exchange Rate Regimes

\begin{tabular}{|c|c|c|c|}
\hline \multirow[t]{2}{*}{ Panel A: } & \multicolumn{3}{|c|}{ Table Corresponding to Figure 1} \\
\hline & Interest Rate Diff. & FX Excess Returns & Capital Intensity \\
\hline \multirow[t]{2}{*}{ FX Allowed Deviation } & $0.41^{* * *}$ & $0.35^{* *}$ & $-1.56^{* *}$ \\
\hline & $(0.13)$ & $(0.15)$ & $(0.74)$ \\
\hline \multirow[t]{2}{*}{ GDP Share } & $-23.36^{* * *}$ & $-12.50^{* *}$ & $86.82^{* * *}$ \\
\hline & $(7.54)$ & $(5.85)$ & $(27.83)$ \\
\hline Num. obs. & 7,515 & 7,515 & 662 \\
\hline $\mathrm{R}^{2}$ & 0.12 & 0.00 & 0.06 \\
\hline \multirow[t]{2}{*}{ Panel B: } & \multicolumn{3}{|c|}{ Table with Alternative Measure of Stabilization } \\
\hline & Interest Rate Diff. & FX Excess Returns & Capital Intensity \\
\hline \multirow[t]{2}{*}{$\zeta$} & $-4.08^{* * *}$ & $-3.51^{* *}$ & $15.58^{* *}$ \\
\hline & $(1.28)$ & $(1.49)$ & $(7.41)$ \\
\hline \multirow[t]{2}{*}{ GDP Share } & $-23.36^{* * *}$ & $-12.50^{* *}$ & $86.82^{* * *}$ \\
\hline & $(7.54)$ & $(5.85)$ & $(27.83)$ \\
\hline Num. obs. & 7,515 & 7,515 & 662 \\
\hline $\mathrm{R}^{2}$ & 0.12 & 0.00 & 0.06 \\
\hline \multirow[t]{2}{*}{ Panel C: } & \multicolumn{3}{|c|}{ Summary Statistics } \\
\hline & & Mean & Std. Dev \\
\hline Interest Rate Diff. (\%) & & 1.95 & 4.56 \\
\hline FX Excess Returns (\%) & & 2.29 & 36.44 \\
\hline Capital Intensity (\%) & & 118.86 & 24.12 \\
\hline FX Allowed Deviation (\%) & & 3.54 & 3.65 \\
\hline$\zeta$ & & 0.65 & 0.37 \\
\hline GDP Share & & 0.04 & 0.07 \\
\hline
\end{tabular}

Notes: This table shows panel regressions of interest rate differentials, currency excess returns, and capital intensity on the allowed annual standard deviation under the issuing country's exchange rate regime and country size (the share the issuing country contributes to World GDP). The sample and data construction correspond to Figure 1. Panel A shows the full regression output corresponding to the conditional scatter plots in Figure 1. Panel B shows an alternative specification that follows more closely the model by using $\zeta=1-(F X$ Allowed Deviation $) / 10$ as a regressor, where we again assume that a freely floating exchange rate amounts to an allowed annual standard deviation of $10 \%$. Standard errors are clustered by currency. Panel C displays summary statistics. Capital intensity is the log capital to output ratio. Interest Rate Diff., FX Excess Returns, Capital Intensity, and FX Allowed Deviation are all given in percent. See the caption of Figure 1 for details. 


\section{B Appendix to Section 1}

The country $n$ risk-free bond pays off $P^{n}$ units of the traded good at maturity. We derive the value of the risk-free bond, $V_{P}^{n}$, by applying the asset pricing equation to the bond payoff:

$$
V_{P}^{n}=\mathbb{E}\left[\Lambda_{T} P^{n}\right]
$$

where $\Lambda_{T}$ denotes the stochastic discount factor. The country $n$ risk-free rate (in levels), $R^{n}$, is the inverse of the price of the risk-free bond:

$$
R^{n}=\frac{1}{V_{P}^{n}}
$$

Putting the previous two equations together yields the following relationship:

$$
\mathbb{E}\left[\Lambda_{T} P^{n}\right] R^{n}=1
$$

As a result, the risk-free rates of countries $f$ and $h$ are related as follows:

$$
\mathbb{E}\left[\Lambda_{T} P^{f}\right] R^{f}=\mathbb{E}\left[\Lambda_{T} P^{h}\right] R^{h}=1
$$

If the stochastic discount factor and prices are log-normal, we can perform the following calculations:

$$
\begin{aligned}
& \mathbb{E}\left[\Lambda_{T} P^{f}\right] R^{f}=\mathbb{E}\left[\Lambda_{T} P^{h}\right] R^{h} \\
\Leftrightarrow & \mathbb{E}\left[\exp \left[\lambda_{T}+p^{f}+r^{f}\right]\right]=\mathbb{E}\left[\exp \left[\lambda_{T}+p^{h}+r^{h}\right]\right] \\
\Leftrightarrow & \mathbb{E}\left[\lambda_{T}+p^{f}\right]+\frac{1}{2} \operatorname{var}\left(\lambda_{T}\right)+\frac{1}{2} \operatorname{var}\left(p^{f}\right)+\operatorname{cov}\left(\lambda_{T}, p^{f}\right)+r^{f} \\
& =\mathbb{E}\left[\lambda_{T}+p^{h}\right]+\frac{1}{2} \operatorname{var}\left(\lambda_{T}\right)+\frac{1}{2} \operatorname{var}\left(p^{h}\right)+\operatorname{cov}\left(\lambda_{T}, p^{h}\right)+r^{h},
\end{aligned}
$$

We cancel out $\operatorname{var}\left(\lambda_{T}\right)$ from both sides of the previous equation.

$$
\begin{aligned}
& \mathbb{E}\left[p^{f}\right]+\frac{1}{2} \operatorname{var}\left(p^{f}\right)+\operatorname{cov}\left(\lambda_{T}, p^{f}\right)+r^{f}=\mathbb{E}\left[p^{h}\right]+\frac{1}{2} \operatorname{var}\left(p^{h}\right)+\operatorname{cov}\left(\lambda_{T}, p^{h}\right)+r^{h} \\
\Leftrightarrow & r^{f}+\mathbb{E}\left[p^{f}-p^{h}\right]+\frac{1}{2} \operatorname{var}\left(p^{f}\right)-\frac{1}{2} \operatorname{var}\left(p^{h}\right)-r^{h}=-\operatorname{cov}\left(\lambda_{T}, p^{f}-p^{h}\right) \\
\Leftrightarrow & r^{f}+\log \left(\mathbb{E}\left[P^{f}\right] / \mathbb{E}\left[P^{h}\right]\right)-r^{h}=-\operatorname{cov}\left(\lambda_{T}, p^{f}-p^{h}\right)
\end{aligned}
$$


We define $\Delta \mathbb{E}\left[s^{f, h}\right]=\log \left(\mathbb{E}\left[P^{f}\right] / \mathbb{E}\left[P^{h}\right]\right)$. With this definition:

$$
r^{f}+\Delta \mathbb{E}\left[s^{f, h}\right]-r^{h}=-\operatorname{cov}\left(\lambda_{T}, p^{f}-p^{h}\right)
$$

\section{Appendix to Sections 2.1 - 2.4}

\section{C.1 Equilibrium Conditions}

In this appendix, we provide additional details for our baseline model in Section 2.1 and formally derive its equilibrium conditions. To avoid solving the optimization problem separately for households in the stabilizing country and households in the rest of the world, we generalize the notation to allow all countries to impose state-contingent taxes, $Z^{n}(\omega)$, and provide lump sum transfers, $\bar{Z}^{n}$. The governments in the target and outside countries do not use these instruments, such that $Z^{t}(\omega)=Z^{o}(\omega)=1$ and $\bar{Z}^{t}=\bar{Z}^{o}=0$.

In the second period, all households maximize their utility (4) subject to their budget constraint:

$$
Z^{n}(\omega) C_{T}^{n}(\omega)+P_{N}^{n}(\omega) C_{N}^{n}(\omega) \leq \sum_{l} A_{l}^{n} P_{N}^{l}(\omega) Y_{N}^{l}(\omega)+Y_{T}
$$

where $P_{N}^{n}(\omega)$ is the price of the nontraded good in the stabilizing country in state $\omega, A_{l}^{n}$ is number the stocks a country $n$ household owns in the firm in country $l$, and $Y_{T}=1$ is the unit endowment of the traded good.

In the first period, households choose their portfolio of stocks to maximize expected utility in the second period. The first-period budget constraint reads:

$$
\sum_{l} A_{l}^{n} Q_{N}^{l}+Q_{K} K_{N}^{n} \leq W_{0}^{n}
$$

where $W_{0}^{n}$ represents initial household wealth in terms of traded goods in the first period.

$\Lambda_{T}^{n}(\omega)$ denotes the Lagrange multiplier on the budget constraint for the country $n$ household in state $\omega$ in the second period. The first-order conditions are:

$$
\begin{gathered}
\frac{\tau\left(C^{n}(\omega)^{1-\gamma}\right)\left(C_{T}^{n}(\omega)\right)^{-1}}{Z^{n}(\omega)}=\Lambda_{T}^{n}(\omega) \\
(1-\tau)\left(C^{n}(\omega)^{1-\gamma}\right)\left(C_{N}^{n}(\omega)\right)^{-1}=\Lambda_{T}^{n}(\omega) P_{N}^{n}(\omega) .
\end{gathered}
$$

The consumption tax drives a wedge between the marginal utility of consumption of traded 
goods and its shadow price, as equation (31) shows. Equations (12) and (32) jointly imply $P_{N}^{n}(\omega)=\Lambda_{N}^{n}(\omega) / \Lambda_{T}^{n}(\omega)$.

Next, we derive equilibrium conditions that determine first-period investment in stocks and capital. Since the final consumption bundle is a Cobb-Douglas aggregate of traded and nontraded goods, households spend a fraction $\tau$ of their second-period wealth on traded consumption and a fraction $1-\tau$ on nontraded consumption:

$$
C_{T}^{n}(\omega)=\tau\left(\frac{\sum_{l} A_{l}^{n} P_{N}^{l}(\omega) Y_{N}^{l}(\omega)+Y_{T}}{Z^{n}(\omega)}\right) \text { and } C_{N}^{n}(\omega)=(1-\tau)\left(\frac{\sum_{l} A_{l}^{n} P_{N}^{l}(\omega) Y_{N}^{l}(\omega)+Y_{T}}{P_{N}^{n}(\omega)}\right)
$$

In the first period, households choose their portfolio of stocks and firms decide on their capital investment, $K_{N}^{n}$. We plug the consumption of traded and nontraded goods into equations (3) and (4) and take first-order conditions to obtain:

$$
Q_{N}^{l}=\mathbb{E}\left[\left(\frac{\tau^{\tau}(1-\tau)^{1-\tau}}{\Lambda_{T, 1}^{n}\left(Z^{n}(\omega)\right)^{\tau}\left(P_{N}^{n}(\omega)\right)^{1-\tau}}\right)\left(C^{n}(\omega)\right)^{-\gamma} P_{N}^{l}(\omega) Y_{N}^{l}(\omega)\right]
$$

where $\Lambda_{T, 1}^{n}$ denotes the Lagrange multiplier on the first-period budget constraint for a household in country $n$.

Divide through by $Q_{N}^{l}$ and apply the definition of the price index $P^{n}(\omega)$ given by equation (38) in Appendix C.2 to obtain

$$
\mathbb{E}\left[\frac{\Lambda_{T}^{n}(\omega)}{\Lambda_{T, 1}^{n}} \frac{P_{N}^{l}(\omega) Y_{N}^{l}(\omega)}{Q_{N}^{l}}\right]=1
$$

Firms invest in capital to maximize the expected discounted value of profits:

$$
\max _{K^{n}} \mathbb{E}\left[\left(\frac{\Lambda_{T}^{n}(\omega)}{\Lambda_{T, 1}^{n}}\right) P_{N}^{n}(\omega) \exp \left(\eta^{n}\right)\left(K^{n}\right)^{\nu}\right]-Q_{K}\left(K^{n}-1\right)
$$

Their first-order condition with respect to $K^{n}$ yields

$$
Q_{K}=\nu \mathbb{E}\left[\frac{\Lambda_{T}^{n}(\omega)}{\Lambda_{T, 1}^{n}} P_{N}^{n}(\omega) \exp \left(\eta^{n}\right)\left(K^{n}\right)^{\nu-1}\right]
$$

Multiply both sides of the previous equation by $K^{n}$, divide by $Q_{K}$, substitute $Y_{N}^{n}=\exp \left(\eta^{n}\right)\left(K^{n}\right)^{\nu}$, and apply the definition of $P_{N}^{n}(\omega)$ to get 13 .

Equations (33) and (13) show $\Lambda_{T}^{n}(\omega) / \Lambda_{T, 1}^{n}$ are the stochastic discount factors used to price 
assets that pay off in traded goods in the second period. Since stocks and capital are freely traded in international markets, all households must be marginal to investing in all stocks and all firms must be marginal to purchasing an additional unit of capital. As a result, the stochastic discount factors are equal in equilibrium across countries,

$$
\frac{\Lambda_{T}^{n}(\omega)}{\Lambda_{T, 1}^{n}}=\frac{\Lambda_{T}^{m}(\omega)}{\Lambda_{T, 1}^{m}} \quad \forall n, m,
$$

even though the government's intervention drives a wedge between $\Lambda_{T}(\omega)$ and the marginal utility of traded consumption in the stabilizing country, as equation (31) shows.

As a final step, we derive the equations that pin down the first and second-period Lagrange multipliers. Household wealth in the first period is:

$$
W_{0}^{n}=Q_{N}^{n}+Q_{K}+\kappa^{n}+\bar{Z}^{n}
$$

Recall that households are endowed with a unit of stock and a unit of capital. $\kappa^{n}$ is the transfer that equalizes the marginal utility of wealth across households when countries do not manipulate the exchange rate, and the transfer $\bar{Z}^{m}$ ensures the same is true under a stabilization, so that

$$
\Lambda_{T, 1}^{n}=\Lambda_{T, 1} \quad \forall n
$$

As a result, 34 implies

$$
\Lambda_{T}^{n}(\omega)=\Lambda_{T}(\omega) \quad \forall n, \omega
$$

Hence, we drop the country index on the Lagrange multipliers, and interpret $\Lambda_{T}(\omega)$ as the shadow price of traded consumption in the target and outside countries in the second period. This result implies equations (10), (12) and (13).

Equation (35) shows the first-period Lagrange multipliers are equal to each other, but it does not determine the level of the Lagrange multipliers. Without loss of generality, we normalize the first period Lagrange multiplier:

$$
\Lambda_{T, 1}=\mathbb{E}\left[\Lambda_{T}^{n}(\omega)\right]
$$




\section{C.2 Deriving the Price Index}

The cost of one unit of consumption in country $n$ is given by the price index

$$
P^{n}=\arg \min C_{T}^{n}+P_{N}^{n} C_{N}^{n} \text { s.t. }\left(C_{T}^{n}\right)^{\tau}\left(C_{N}^{n}\right)^{1-\tau}=1
$$

First-order conditions imply $C_{N}^{n}=(1-\tau) /\left(P_{N}^{n} \tau\right) C_{T}^{n}$. We plug this expression for $C_{N}^{n}$ into the constraint $\left(C_{T}^{n}\right)^{\tau}\left(C_{N}^{n}\right)^{1-\tau}=1$, and solve for $C_{T}^{n}$ :

$$
C_{T}^{n}=\left(\frac{\tau}{1-\tau} P_{N}^{n}\right)^{1-\tau}
$$

We plug the expressions for $C_{T}^{n}$ and $C_{N}^{n}$ back into equation 37 to derive the optimal price index:

$$
P^{n}=\frac{\left(P_{N}^{n}\right)^{1-\tau}}{\tau^{\tau}(1-\tau)^{1-\tau}}
$$

The total value of consumption for households in country $n$ is

$$
P^{n} C^{n}=\left(\frac{\left(P_{N}^{n}\right)^{1-\tau}}{\tau^{\tau}(1-\tau)^{1-\tau}}\right)\left(\left(C_{T}^{n}\right)^{\tau}\left(C_{N}^{n}\right)^{1-\tau}\right)=\frac{C_{T}^{n}}{\tau}
$$

Similarly, we use the expression $P_{N}^{n}=\frac{1-\tau}{\tau} \frac{C_{T}^{n}}{C_{N}^{n}}$ to show that

$$
C_{T}^{n}+P_{N}^{n} C_{N}^{n}=\frac{C_{T}^{n}}{\tau}=P^{n} C^{n}
$$

\section{C.3 Log-linearized System of Equations}

This appendix derives the log-linearized first-order conditions. To reiterate, we log-linearize around the deterministic solution - the point at which the variances of shocks are zero $\left(\sigma_{N, n}=0\right)$ and all firms have a capital stock fixed at the deterministic steady-state level.

We have shown in Appendix C.1 that the stochastic discount factor $\Lambda_{T}^{n}(\omega) / \Lambda_{T, 1}^{n}$ is equalized across all households in all states. It is convenient to write the logarithm of this stochastic discount factor as:

$$
q=\lambda_{T}^{n}-\lambda_{T, 1}^{n}
$$


We can then write the log-linear first-order conditions for the second period as

$$
\begin{gathered}
(1-\gamma)\left(\tau c_{T}^{n}+(1-\tau) c_{N}^{n}\right)-c_{T}^{n}+\log \tau=z^{n}+q+\lambda_{T, 1}^{n} \\
(1-\gamma)\left(\tau c_{T}^{n}+(1-\tau) c_{N}^{n}\right)-c_{N}^{n}+\log (1-\tau)=p_{N}^{n}+q+\lambda_{T, 1}^{n},
\end{gathered}
$$

and the log-linear resource constraints are:

$$
\begin{aligned}
c_{N}^{n} & =y_{N}^{n} \\
\sum_{n=m, t, o} \theta^{n} c_{T}^{n} & =0
\end{aligned}
$$

where $z^{m}=\log \left(Z^{m}(\omega)\right)$ and $z^{t}=z^{o}=0$. Note that $\Delta$ Res is a second-order term (linear in $\left.\sigma^{n}\right)$ and consequently does not show up in the log-linear resource constraint. This set of ten linear equations (two first order conditions for each country and four resource constraints) allows us to solve for the endogenous variables $\left\{c_{N}^{n}, c_{T}^{n}, p_{N}^{n}\right\}_{n=m, t, o}$ and $q$. Keeping in mind the loglinear relationship between each country's output and its respective productivity shock (5), it is convenient to solve for these endogenous variables in terms of each country's output $\left\{y_{N}^{m}, y_{N}^{t}, y_{N}^{o}\right\}$, and the Lagrange multipliers $\left\{\lambda_{T, 1}^{m}, \lambda_{T, 1}^{t}, \lambda_{T, 1}^{o}\right\}$.

Solving the system yields:

$$
\begin{aligned}
& c_{T}^{m}=\frac{(\gamma-1)(1-\tau)}{1+(\gamma-1) \tau}\left(\bar{y}_{N}-y_{N}^{m}\right)-\frac{1-\theta^{m}}{1+(\gamma-1) \tau} z^{m}+\frac{\bar{\lambda}_{T, 1}-\lambda_{T, 1}^{m}}{1+(\gamma-1) \tau} \\
& c_{T}^{t}=\frac{(\gamma-1)(1-\tau)}{1+(\gamma-1) \tau}\left(\bar{y}_{N}-y_{N}^{t}\right)+\frac{\theta^{m}}{1+(\gamma-1) \tau} z^{m}+\frac{\bar{\lambda}_{T, 1}-\lambda_{T, 1}^{t}}{1+(\gamma-1) \tau} \\
& c_{T}^{o}=\frac{(\gamma-1)(1-\tau)}{1+(\gamma-1) \tau}\left(\bar{y}_{N}-y_{N}^{o}\right)+\frac{\theta^{m}}{1+(\gamma-1) \tau} z^{m}+\frac{\bar{\lambda}_{T, 1}-\lambda_{T, 1}^{o}}{1+(\gamma-1) \tau} \\
& c_{N}^{n}=y_{N}^{n} \quad \forall n
\end{aligned}
$$


where $\bar{\lambda}_{T, 1}=\sum_{n} \theta^{n} \lambda_{T, 1}^{n}$. In addition, we have the equilibrium prices:

$$
\begin{aligned}
q & =-(1-\tau)(\gamma-1) \bar{y}_{N}-\theta^{m} z-\bar{\lambda}_{T, 1} \\
p_{N}^{m} & =\frac{(\gamma-1)(1-\tau)}{1+(\gamma-1) \tau} \bar{y}_{N}-\frac{\gamma}{1+(\gamma-1) \tau} y_{N}^{m}+\frac{\theta^{m}+(\gamma-1) \tau}{1+(\gamma-1) \tau} z^{m}+\frac{\bar{\lambda}_{T, 1}-\lambda_{T, 1}^{m}}{1+(\gamma-1) \tau}+\log \left[\frac{1-\tau}{\tau}\right] \\
p_{N}^{t} & =\frac{(\gamma-1)(1-\tau)}{1+(\gamma-1) \tau} \bar{y}_{N}-\frac{\gamma}{1+(\gamma-1) \tau} y_{N}^{t}+\frac{\theta^{m}}{1+(\gamma-1) \tau} z^{m}+\frac{\bar{\lambda}_{T, 1}-\lambda_{T, 1}^{t}}{1+(\gamma-1) \tau}+\log \left[\frac{1-\tau}{\tau}\right] \\
p_{N}^{o} & =\frac{(\gamma-1)(1-\tau)}{1+(\gamma-1) \tau} \bar{y}_{N}-\frac{\gamma}{1+(\gamma-1) \tau} y_{N}^{o}+\frac{\theta^{m}}{1+(\gamma-1) \tau} z^{m}+\frac{\bar{\lambda}_{T, 1}-\lambda_{T, 1}^{o}}{1+(\gamma-1) \tau}+\log \left[\frac{1-\tau}{\tau}\right]
\end{aligned}
$$

It is also useful to keep track of the shadow prices of total consumption in each country. To this end, we also use the log-linear expression $\lambda^{n}=-\gamma\left(\tau c_{T}^{n}+(1-\tau) c_{N}^{n}\right)$ along with the solutions for traded and nontraded consumption above to obtain:

$$
\begin{aligned}
\lambda^{m} & =-\frac{(\gamma-1)(1-\tau) \gamma \tau}{1+(\gamma-1) \tau} \bar{y}_{N}-\frac{\gamma(1-\tau)}{1+(\gamma-1) \tau} y_{N}^{m}+\frac{\left(1-\theta^{m}\right) \gamma \tau}{1+(\gamma-1) \tau} z^{m}-\frac{\gamma \tau\left(\bar{\lambda}_{T, 1}-\lambda_{T, 1}^{m}\right)}{1+(\gamma-1) \tau} \\
\lambda^{t} & =-\frac{(\gamma-1)(1-\tau) \gamma \tau}{1+(\gamma-1) \tau} \bar{y}_{N}-\frac{\gamma(1-\tau)}{1+(\gamma-1) \tau} y_{N}^{t}+\frac{\theta^{m} \gamma \tau}{1+(\gamma-1) \tau} z^{m}-\frac{\gamma \tau\left(\bar{\lambda}_{T, 1}-\lambda_{T, 1}^{t}\right)}{1+(\gamma-1) \tau} \\
\lambda^{o} & =-\frac{(\gamma-1)(1-\tau) \gamma \tau}{1+(\gamma-1) \tau} \bar{y}_{N}-\frac{\gamma(1-\tau)}{1+(\gamma-1) \tau} y_{N}^{o}+\frac{\theta^{m} \gamma \tau}{1+(\gamma-1) \tau} z^{m}-\frac{\gamma \tau\left(\bar{\lambda}_{T, 1}-\lambda_{T, 1}^{o}\right)}{1+(\gamma-1) \tau}
\end{aligned}
$$

Finally, the following log-linear equations determine the first-period Lagrange multipliers. Again, recall the stabilizing country's government uses $\bar{Z}^{m}$ to add and subtract resources from the economy to achieve (P2), which equalizes the marginal utility of initial wealth across households. As a result:

$$
\lambda_{T, 1}^{m}=\lambda_{T, 1}^{t}=\lambda_{T, 1}^{o}=\lambda_{T, 1}
$$

so that the remaining endogenous term drop out of the solutions above, $\bar{\lambda}_{T, 1}-\lambda_{T, 1}^{m}=0$. Next, we normalize $\lambda_{T, 1}$ using the second-order approximation of equation (36):

$$
\lambda_{T, 1}=\mathbb{E}\left[\lambda_{T}\right]+\frac{1}{2} \operatorname{var}\left[\lambda_{T}\right]
$$

\section{C.4 Equilibrium Asset Portfolio}

In the log-linear solution, all prices and quantities are a linear combination of $\left\{y_{N}^{m}, y_{N}^{t}, y_{N}^{o}\right\}$. In particular, household expenditure, $p^{n}+c^{n}$, in each state of the world is a linear combination of $\left\{y_{N}^{m}, y_{N}^{t}, y_{N}^{o}\right\}$. All asset payoffs are also linear combinations of $\left\{y_{N}^{m}, y_{N}^{t}, y_{N}^{o}\right\}$. Any set of assets with the same rank as the set of household expenditures will thus be able to span the space of 
household expenditure. Therefore, given the appropriate set of assets, we can write household expenditure in each state of the world as a linear combination of these assets.

It is straightforward to verify that the set of log-linear stock payoffs spans the space of loglinear household wealth.

\section{Lemma 2}

Households in the freely floating exchange rate equilibrium hold levered positions in their own country's stocks and hold short positions in other countries' stocks,

$$
A_{n}^{n}=\frac{1-\theta^{n} \tau}{1-\tau} \text { and } A_{l}^{n}=-\frac{\theta^{n} \tau}{1-\tau} \text { for } l \neq n
$$

Proof. The household budget constraint (29) can be re-written as:

$$
P^{n}(\omega) C^{n}(\omega)=\sum_{l=m, t, o} A_{l}^{n} P_{N}^{n}(\omega) Y_{N}^{n}(\omega)+Y_{T}^{n}
$$

The log-linear approximation of household expenditure of the left-hand side is:

$$
\frac{1}{\tau}\left(p^{n}+c^{n}+\log [\tau]\right)=\frac{(\gamma-1)(1-\tau)}{\tau(1-(\gamma-1) \tau)}\left(\bar{y}_{N}-y_{N}^{n}\right)
$$

The log-linear approximation the stock portfolio payoff (right-hand side) is:

$$
\sum_{l=m, t, o} A_{l}^{n} \frac{1-\tau}{\tau}\left(p_{N}^{l *}+y_{N}^{l}-\log \left[\frac{1-\tau}{\tau}\right]\right)
$$

where:

$$
p_{N}^{l *}+y_{N}^{l}=\frac{(\gamma-1)(1-\tau)}{1+(\gamma-1) \tau}\left(\bar{y}_{N}-y_{N}^{l}\right)+\log \left[\frac{1-\tau}{\tau}\right] .
$$

We equate household expenditures in each state of the world with the portfolio payoff:

$$
\frac{(\gamma-1)(1-\tau)}{(1-(\gamma-1) \tau)}\left(\bar{y}_{N}-y_{N}^{n}\right)=\sum_{l=m, t, o} A_{l}^{n} \frac{1-\tau}{\tau}\left(p_{N}^{l *}+y_{N}^{l}-\log \left[\frac{1-\tau}{\tau}\right]\right)
$$

Since this equation holds state-by-state, we solve for the shares, $A_{l}^{n}$, by matching the coefficients on $y_{N}^{l}$ in the portfolio payoff with the coefficients on $y_{N}^{l}$ in household expenditure. 


\section{C.5 Derivation of Equation (19)}

To derive (19), we use the following second-order approximation of equation (13):

$$
\lambda_{T, 1}+q_{K}+k^{n}=\log [\nu]+\mathbb{E}\left[\lambda_{N}^{n}+y_{N}^{n}\right]+\frac{1}{2} \operatorname{var}\left(\lambda_{N}^{n}+y_{N}^{n}\right)
$$

Next, we substitute $\lambda_{N}^{n}=p_{N}^{n}+\lambda_{T}$, and take differences across two arbitrary countries $f$ and $h$ to obtain:

$$
k^{f}-k^{h}=\frac{1}{2} \operatorname{var}\left(p_{N}^{f}+y_{N}^{f}\right)-\frac{1}{2} \operatorname{var}\left(p_{N}^{h}+y_{N}^{h}\right)+\operatorname{cov}\left(p_{N}^{f}+y_{N}^{f}-p_{N}^{h}-y_{N}^{h}, \lambda_{T}\right) .
$$

For any country $n$ :

$$
p_{N}^{n *}+y_{N}^{n *}=\frac{(1-\tau)(\gamma-1)}{1+(\gamma-1) \tau}\left(\bar{y}_{N}-y_{N}^{n}\right) .
$$

Plugging this expression for $p_{N}^{n *}+y_{N}^{n *}$ into the right-hand side of equation (39) shows:

$$
k^{f *}-k^{h *}=\frac{(\gamma-1)^{3}(1-\tau)^{2} \tau}{1+(\gamma-1) \tau}\left(\theta^{f}-\theta^{h}\right) \sigma_{N}^{2} .
$$

Combine this equation with equation 18 to derive (19),

\section{C.6 Proof of Lemma 1}

First, we solve for the state-contingent taxes that implement the real exchange rate stabilization. Afterwards, we derive an expression for the cost of stabilizing the exchange rate. We guess a tax of the form $Z(\omega)=\left(Y_{N}^{m}(\omega) / Y_{N}^{t}(\omega)\right)^{a}$ stabilizes the exchange rate for a constant $a$ and solve for the coefficient $a$ that stabilizes the real exchange rate. In logs, this tax is: $z=a\left(y_{N}^{t}-y_{N}^{m}\right)$. We plug this expression into the solution of the model derived in Appendix C.3 and solve for the log real exchange rate:

$$
s^{m, t}=\frac{\gamma(1-\tau)}{1+(\gamma-1) \tau}\left(y_{N}^{t}-y_{N}^{m}\right)+a \frac{\gamma \tau}{1+(\gamma-1) \tau}\left(y_{N}^{m}-y_{N}^{t}\right)
$$

Choose $a$ such that $s^{m, t}=(1-\zeta) s^{m, t *}$. This yields $a=\zeta(1-\tau) / \tau$. Finally, we use the expression for $s^{f, h *}$ given by equation (17) to write $z$ as a function of $p^{m *}$ and $p^{t *}$.

$\Delta R e s$ is defined by equation (6). First, we solve for $\bar{Z}$ by plugging in the equilibrium con- 
sumption of nontraded goods and $K^{m}=1$ into the budget constraint 30 :

$$
\bar{Z}=\left(A_{m}^{m}-1\right) Q_{N}^{m}+\sum_{l \neq m} A_{l}^{m} Q_{N}^{l}-\kappa^{m}
$$

Next, multiply equation (29) by the stochastic discount factor, $\Lambda_{T}(\omega) / \Lambda_{T, 1}$, and take expectations to derive the present value of tax revenues:

$$
\begin{aligned}
& \mathbb{E}\left[\left(\frac{\Lambda_{T}(\omega)}{\Lambda_{T, 1}}\right)(Z(\omega)-1) C_{T}^{m}(\omega)\right] \\
= & \mathbb{E}\left[\left(\frac{\Lambda_{T}(\omega)}{\Lambda_{T, 1}}\right)\left(\left(A_{m}^{m}-1\right) P_{N}^{m}(\omega) Y_{N}^{m}(\omega)+\sum_{l \neq m} A_{l}^{m} P_{N}^{m}(\omega) Y_{N}^{m}(\omega)+Y_{T}^{n}-C_{T}^{m}(\omega)\right)\right] \\
= & \left(A_{m}^{m}-1\right) Q_{N}^{m}+\sum_{l \neq m} A_{l}^{m} Q_{N}^{l}+Y_{T}^{m} \mathbb{E}\left[\left(\frac{\Lambda_{T}(\omega)}{\Lambda_{T, 1}}\right)\right]-\mathbb{E}\left[\left(\frac{\Lambda_{T}(\omega)}{\Lambda_{T, 1}}\right) C_{T}^{m}(\omega)\right]
\end{aligned}
$$

Finally, we derive $\kappa^{m}$. In the freely floating exchange rate economy, $\bar{Z}=0$ and $Z(\omega)=1$. Plug these values into equations $(29)$ and (30). Finally, we substitute equation (36) and use the fact that $Y_{T}^{m}$ is a constant to show:

$$
\kappa^{m}=\mathbb{E}\left[\left(\frac{\Lambda_{T}^{*}(\omega)}{\Lambda_{T, 1}^{*}}\right) C_{T}^{m *}(\omega)\right]-Y_{T}^{m}
$$

We plug the expressions for $\bar{Z}$, the present value of tax revenues, and $\kappa^{m}$ in equation (6), and simplify to arrive at equation 20 .

We also derive the portfolio of stocks that exactly finances the stabilization policy. This is the portfolio that pays the difference between traded consumption when stabilizing and traded consumption in the freely floating regime given by equation (21). For convenience, this equation is repeated here where $p^{t *}-p^{m *}$ is written in terms differences in nontraded output:

$$
c_{T}^{m}-c_{T}^{m *}=\zeta \frac{\left(1-\theta^{m}\right)(1-\tau)}{\tau(1+(\gamma-1) \tau)}\left(y_{N}^{t}-y_{N}^{m}\right) .
$$

We use the same log-linear approximation of the stock portfolio as in Appendix C.4. Letting $A_{l}^{m}$ denote the number of shares of country $l$ stock the stabilizing country's central bank holds, we get

$$
A_{m}^{m}=\zeta \frac{1-\theta^{m}}{\gamma-\zeta(\gamma-1)(1-\tau)}, A_{t}^{m}=-A_{m}^{m}, A_{o}^{m}=0
$$




\section{C.7 Proof of Proposition 1}

We use the expressions from Appendix C.3 to calculate $p^{t}-p^{m}=\lambda^{t}-\lambda^{m}$ and we plug the resulting expression into equation (2):

$$
\begin{aligned}
r^{m}+\Delta \mathbb{E} s^{m, t}-r^{t} & =\operatorname{cov}\left(\lambda_{T}, p^{t}-p^{m}\right) \\
& =\left(r^{m *}+\Delta \mathbb{E} s^{m, t *}-r^{t *}\right)-\zeta \frac{(1-\tau)^{2} \gamma\left(2 \theta^{m}(1-\zeta)+\left(\theta^{t}-\theta^{m}\right)(\gamma-1) \tau\right)}{\tau(1+(\gamma-1) \tau)} \sigma_{N}^{2} .
\end{aligned}
$$

When the stabilizing country is smaller than the target country, $\theta^{m}<\theta^{t}$, the right-hand side of this expression implies the stabilization decreases the risk-free rate in the stabilizing country relative to the risk-free rate in the target country.

We use equation (39) to calculate the differential incentives to accumulate capital:

$$
k^{m}-k^{t}=k^{m *}-k^{t *}+\zeta\left(\frac{(\gamma-1)^{2}(1-\tau)^{2}\left(\left(1-2 \theta^{m}\right)(1-\zeta)+\left(\theta^{t}-\theta^{m}\right)(\gamma-1) \tau\right)}{(1+(\gamma-1) \tau)^{2}}\right) \sigma_{N}^{2} .
$$

The last term of the right-hand side of this expression shows that incentives to accumulate capital in the stabilizing country increase relative to the target country as long as

$$
\theta^{t}>\theta^{m}+\frac{\left(1-2 \theta^{m}\right)(1-\zeta)}{\tau(\gamma-1)}
$$

Because firms are competitive, wages are given by the marginal product of labor. $w^{n}=(1-$ $\nu) \exp \left(\eta^{n}\right)\left(K^{n}\right)^{\nu}$. Since the marginal product of labor rises with the level of capital accumulation, the exchange rate stabilization increases wages in the stabilizing country relative to all other countries.

Recall, the world-market value of the country $m$ domestic firm given by equation (33) is:

$$
Q_{N}^{m}=\mathbb{E}\left[\frac{\Lambda_{T}(\omega)}{\Lambda_{T, 1}} P_{N}^{m} Y_{N}^{m}\right]
$$

The second-order log-linear approximation of the world-market value of the country $m$ domestic firm is:

$$
q_{N}^{m}=\mathbb{E}\left[\lambda_{T}-\lambda_{T, 1}+p_{N}^{m}+y_{N}^{m}\right]+\frac{1}{2} \operatorname{var}\left[\lambda_{T}-\lambda_{T, 1}+p_{N}^{m}+y_{N}^{m}\right] .
$$

The spread between the value of the firm in the stabilizing and target countries yields the same expression as the right-hand side of equation (39). Hence, we have already shown the value of the firm in the stabilizing country increases relative to the target country if $\theta^{t}$ is large enough. 


\section{C.8 Proof of Proposition 2}

Equation (20) shows the cost of the stabilization is the difference in the value of traded consumption between the freely floating regime and stabilized regime. We derive a second-order log-linear approximation of the value of traded consumption:

$$
v_{T}^{m}=\mathbb{E}\left[\lambda_{T}-\lambda_{T, 1}+c_{T}^{m}\right]+\frac{1}{2} \operatorname{var}\left[\lambda_{T}-\lambda_{T, 1}+c_{T}^{m}\right]
$$

We plug the expressions for $\lambda_{T}, \lambda_{T, 1}$, and $c_{T}^{m}$ into the previous equation in order to derive the change in the log value of traded consumption

$$
v_{T}^{m}-v_{T}^{m *}=\frac{\left((\zeta+(\gamma-1) \tau)-\tau^{2}(1-\gamma)^{2} \theta^{t}\right)(1-\tau)^{2} \zeta \sigma_{N}^{2}}{\tau^{2}(1+(\gamma-1) \tau)^{2}}
$$

This expression is decreasing in the size of the target country, and becomes negative if and only if the target country is large enough: $\theta^{t}>(\zeta+(\gamma-1) \tau) /(\tau(\gamma-1))^{2}$.

Next, we evaluate the derivative of $v_{T}^{m}-v_{T}^{m *}$ with respect to $\theta^{m}$ at the point where $\theta^{m}=0$ :

$$
\left.\frac{\partial\left(v_{T}^{m}-v_{T}^{m *}\right)}{\partial \theta^{m}}\right|_{\theta^{m}=0}=\zeta \frac{(\gamma-1)(1-\tau)^{2}\left(\theta^{t}+2 \zeta+2\left(1+\theta^{t}\right)(\gamma-1) \tau\right)}{\tau(1+(\gamma-1) \tau)^{2}} \sigma_{N}^{2}>0
$$

Hence, the cost of the stabilization increases locally with the size of the stabilizing country.

\section{C.9 Proof of Proposition 3}

We use the expressions from Appendix C.3 to calculate $p^{o}-p^{t}=\lambda^{o}-\lambda^{t}$ and we plug the resulting expression into equation (2):

$$
r^{t}+\Delta \mathbb{E} s^{t, o}-r^{o}=\operatorname{cov}\left(\lambda_{T}, p^{o}-p^{t}\right)=\left(r^{t *}+\Delta \mathbb{E} s^{t, o *}-r^{o *}\right)+\zeta \frac{\theta^{m}(1-\tau)^{2} \gamma}{\tau(1+(\gamma-1) \tau)} \sigma_{N}^{2}
$$

which implies the exchange rate stabilization increases the risk-free rate in the target country relative to the risk-free rate in the outside country.

We use equation 39 to calculate the differential incentives to accumulate capital,

$$
k^{t}-k^{o}=k^{t *}-k^{o *}-\frac{\theta^{m}(\gamma-1)^{2}(1-\tau)^{2}}{(1+(\gamma-1) \tau)^{2}} \zeta \sigma_{N}^{2}
$$

The last term on the right-hand side shows that incentives to accumulate capital in the target 
country decrease relative to the outside country.

Because firms are competitive, wages are given by the marginal product of labor. Since the marginal product of labor rises with the level of capital accumulation, the exchange rate stabilization decreases wages in the target country relative to all other countries.

Finally, we show that if the stabilizing country is smaller than the target country, $\theta^{m}<\theta^{t}$, then the stabilization lowers the volatility of consumption in the target country. The log-linear approximation of household consumption in the target country is, $c^{t}=\tau c_{T}^{t}+(1-\tau) c_{N}^{t}$. We use the expression for traded consumption derived in Appendix C.3 and the expression for the state-contingent tax derived in Appendix C.6 to derive the volatility of aggregate consumption in the target country:

$$
\operatorname{var}\left(c^{t}\right)=\operatorname{var}\left(c^{t *}\right)-\zeta \frac{2 \theta^{m}(1-\tau)^{2}\left(1-\theta^{m} \zeta+\left(\theta^{t}-\theta^{m}\right)(\gamma-1) \tau\right)}{(1+(\gamma-1) \tau)^{2}} \sigma_{N}^{2} .
$$

Therefore, $\operatorname{var}\left(c^{t}\right)$ decreases when a country stabilizes its exchange rate relative to the target country as long as the stabilizing country is smaller, $\theta^{t}>\theta^{m}$.

\section{Appendix to Section 2.5}

Households continue to maximize utility subject to their budget constraints (29) and (30). However, when $\Delta$ Res $=0$ and households hold the portfolio of assets derived in Appendix C.4, their initial wealth is:

$$
W_{0}^{n}=\sum_{l \in\{m, t, o\}} A_{l}^{n *} Q_{N}^{l}+Q_{K} K_{N}^{n *}+\bar{Z} .
$$

Because $\Delta$ Res $=0$,

$$
\bar{Z}=\mathbb{E}\left[\frac{\Lambda_{T}^{n}(\omega)}{\Lambda_{T, 1}^{n}}\left(Z^{n}(\omega)-1\right) C_{T}^{n}(\omega)\right]
$$

is just the present value of tax-revenues. To re-iterate, $A_{l}^{n *}$ denotes the country $n$ households holding of the country $l$ stock in the freely floating exchange rate regime. We plug this value of $W_{0}^{n}$ into the budget constraint 30 :

$$
\sum_{l \in\{m, t, o\}} A_{l}^{n} Q_{N}^{l}+Q_{K} K_{N}^{n *}=\sum_{l \in\{m, t, o\}} A_{l}^{n *} Q_{N}^{l}+Q_{K} K_{N}^{n *}+\bar{Z}
$$


Next, we multiply equation (29) by the stochastic discount factor and take expectations:

$$
\begin{aligned}
\mathbb{E}\left[\frac{\Lambda_{T}^{n}(\omega)}{\Lambda_{T, 1}^{n}}\left(Z^{n}(\omega) C_{T}^{n}(\omega)+P_{N}^{n}(\omega) C_{N}^{n}(\omega)\right)\right] & =\sum_{l} \mathbb{E}\left[\frac{\Lambda_{T}^{n}(\omega)}{\Lambda_{T, 1}^{n}}\left(A_{l}^{n} P_{N}^{l}(\omega) Y_{N}^{l}(\omega)+Y_{T}\right)\right] \\
& =\sum_{l \in\{m, t, o\}} A_{l}^{n} Q_{N}^{l}+\mathbb{E}\left[\frac{\Lambda_{T}^{n}(\omega)}{\Lambda_{T, 1}^{n}} Y_{T}\right]
\end{aligned}
$$

We subtract the two equations from each other and re-arrange:

$$
\mathbb{E}\left[\frac{\Lambda_{T}^{n}(\omega)}{\Lambda_{T, 1}^{n}}\left(Z^{n}(\omega) C_{T}^{n}(\omega)+P_{N}^{n}(\omega) C_{N}^{n}(\omega)\right)\right]=\sum_{l \in\{m, t, o\}} A_{l}^{n *} Q_{N}^{l}+\bar{Z}+\mathbb{E}\left[\frac{\Lambda_{T}^{n}(\omega)}{\Lambda_{T, 1}^{n}} Y_{T}\right]
$$

Because households must consume their endowment of non-traded goods, we subtract the value of nontraded consumption from both sides. We cancel out the present value of tax revenues with the lump sum transfer $\bar{Z}$. Finally, we apply equation 36 to arrive at the following expression for the value of traded consumption in country $n$ :

$$
\mathbb{E}\left[\frac{\Lambda_{T}^{n}(\omega)}{\Lambda_{T, 1}^{n}} C_{T}^{n}(\omega)\right]=\left(A_{n}^{n *}-1\right) Q_{N}^{n}+\sum_{l \neq n} A_{l}^{n *} Q_{N}^{l}+Y_{T}^{n}
$$

The left-hand side represents the value of traded consumption when stabilizing. The righthand side represents the household's wealth from its portfolio of stocks after subtracting out expenditure on nontraded consumption and capital investment.

Next, we derive a second-order approximation for equation 41):

$$
\mathbb{E}\left[\lambda_{T}-\lambda_{T, 1}+c_{T}^{n}\right]+\frac{1}{2} \operatorname{var}\left[\lambda_{T}-\lambda_{T, 1}+c_{T}^{n}\right]=\frac{1-\tau}{\tau}\left(\left(A_{n}^{n *}-1\right) q_{N}^{n}+\sum_{l \neq n} A_{t}^{l *} q_{N}^{t}\right)+q_{T}
$$

where:

$$
q_{N}^{n}=\mathbb{E}\left[\lambda_{T}-\lambda_{T, 1}+p_{N}^{n}+y_{N}^{n}\right]+\frac{1}{2} \operatorname{var}\left[\lambda_{T}-\lambda_{T, 1}+p_{N}^{n}+y_{N}^{n}\right]
$$

and

$$
q_{T}^{n}=0
$$

In keeping with the solution method in Section 2, we solve for the equilibrium valuation change in households' portfolios using a second-order approximation around the point at which the marginal utility of wealth of households in all countries is equalized. Hence, we plug in the 
expressions for $p_{N}^{n}, y_{N}^{n}, \lambda_{T}$ and , $\lambda_{T, 1}$ from Section 2 into the expressions for $q_{N}^{n}$, which appear on the right-hand side of equation (42). These expressions are given by equations (22), (24) and (36).

We solve for the Lagrange multiplier $\lambda_{T, 1}^{n}$ (from the left-hand side of equation (42) that satisfies equation (42). We let $\lambda_{T, 1, S t o c k}^{n}$ denote the set of Lagrange multipliers derived from solving equation (42). After solving the Lagrange multipliers, we obtain solutions for traded consumption by plugging the Lagrange multipliers, $\lambda_{T, 1, S t o c k}^{n}$, into the log-linear expressions for $c_{T}^{n}$ derived in Appendix C.3. These new expressions for traded consumption reflect the level shifts in traded consumption due to changes in the value of the household's stock portfolio.

We calculate changes in welfare using a second-order approximation of household utility:

$$
u^{n}=\frac{1}{1-\gamma} \log \left[(1-\gamma) U^{n}\right]=\mathbb{E}\left[c^{n}\right]-\frac{\gamma-1}{2} \operatorname{var}\left[c^{n}\right]
$$

where $c^{n}=\tau c_{T}^{n}+(1-\tau) c_{N}^{n}$. We plug in the solutions for $c_{T}^{n}$, with the Lagrange multipliers derived above, into the welfare function. Define the welfare change $\Delta u^{n}=u^{n}-u^{n *}$, where $u^{n *}$ is the value of $u^{n}$ when $\zeta=0$. The welfare change in the stabilizing country is:

$$
\begin{aligned}
\Delta u^{m} & =\frac{\zeta(\gamma-1)^{2}\left(\theta^{m}-1\right)(\tau-1)^{2} \tau\left((\gamma-1) \tau\left(\theta^{m}-\theta^{t}\right)+1\right)}{(1+(\gamma-1) \tau)^{2}} \sigma_{N}^{2} \\
& +\frac{\zeta^{2}(1-\tau)^{2}\left((\gamma-1)\left(\left(\theta^{m}\right)^{2}-1\right) \tau+(\gamma-1)^{2}\left(\theta^{m}-1\right)\left(2 \theta^{m}-1\right) \tau^{2}+\theta^{m}-1\right)}{\tau(1+(\gamma-1) \tau)^{2}} \sigma_{N}^{2}
\end{aligned}
$$

Equation 25) displays the welfare consequences for a small stabilizing country $\left(\theta^{m}=0\right)$.

In order to decompose changes in welfare, we also compute traded consumption under the assumption there is no valuation effect. In this calculation, the household's value of traded consumption post exchange rate stabilization exactly equals the value of traded consumption prior to the stabilization:

$$
\mathbb{E}\left[\lambda_{T}-\lambda_{T, 1}+c_{T}^{n}\right]+\frac{1}{2} \operatorname{var}\left[\lambda_{T}-\lambda_{T, 1}+c_{T}^{n}\right]=\mathbb{E}\left[\lambda_{T}^{*}-\lambda_{T, 1}^{*}+c_{T}^{n *}\right]+\frac{1}{2} \operatorname{var}\left[\lambda_{T}^{*}-\lambda_{T, 1}^{*}+c_{T}^{n *}\right] .
$$

Denote the Lagrange multipliers derived from solving equation (44) by $\lambda_{T, 1, A D}^{n}$. Again, we plug these the Lagrange multipliers $\lambda_{T, 1, A D}^{n}$ into the expressions from Appendix C.3 to derive expressions for traded consumption with stabilization, but without any change in the total value of traded consumption.

The first term of 25 is calculated by plugging the expression for $c_{T}^{n}$ with the Lagrange 
multipliers $\Lambda_{T, 1, A D}^{n}$ into $c^{n}$ and deriving the change in $\mathbb{E}\left[c^{n}\right]$ when $\zeta$ deviates from zero. The $\Delta \operatorname{var}\left[c^{m}\right]$ term reflects the change captured by $\frac{\gamma-1}{2} \operatorname{var}\left[c^{m}\right]$. The "Valuation Effect" is calculated by plugging the expression for $c_{T}^{n}$ with the Lagrange multipliers $\Lambda_{T, 1, S t o c k}^{n}$ into $c^{n}$, deriving the change in $\mathbb{E}\left[c^{n}\right]$ when $\zeta$ deviates from zero, and then subtracting out the first term of (25).

When the first term of (25) is combined with the "Valuation Effect":

$$
\Delta u^{m}=-\frac{\zeta^{2}(1-\tau)^{2}}{\tau(1+(\gamma-1) \tau)} \sigma_{N}^{2}+\frac{\left(\zeta \Theta^{t}+\zeta^{2}\right) \theta^{t} \tau(\gamma-1)^{2}(1-\tau)^{2}}{(1+(\gamma-1) \tau)^{2}} \sigma_{N}^{2}
$$

The first term on the right-hand side is clearly negative, which indicates the welfare losses from the increase in consumption volatility are larger than any gains from accumulating reserves.

Finally, equation 25 can be condensed to:

$$
\Delta u^{m}=\zeta \frac{(1-\tau)^{2}\left(-\zeta(1+(\gamma-1) \tau)+\left(\theta^{t}(\gamma-1) \tau-1+\zeta\right)(\gamma-1)^{2} \tau^{2}\right)}{\tau(1+(\gamma-1) \tau)^{2}} \sigma_{N}^{2}
$$

The right-hand side of this equation is positive if:

$$
\theta^{t}>\bar{\theta}=\frac{1-\zeta}{(\gamma-1) \tau}+\frac{\zeta(1+(\gamma-1) \tau)}{(\gamma-1)^{3} \tau^{3}}
$$

\section{D.1 Equilibrium Bond Portfolio}

Suppose households are confined to trading international risk-free bonds rather than stocks. The country $n$ risk-free bond pays $P^{n}(\omega)$ units of the traded good in state $\omega$ of period 2. Similar to the exercise in Appendix C.4. these asset payoffs are linear combinations of the nontraded output in each country. Likewise, it is straightforward to verify the set of log-linear bond payoffs spans the space of log-linear household wealth. As a result, equilibrium outcomes in the economy are unaffected by the change in the asset space. We just need to solve for the household bond portfolios that pay the appropriate payoff in each state in the second period.

Let $B_{l}^{n}$ denote the number of country $l$ bonds purchased by households in country $n$. Hence, the log-linear approximation of the payoff received from the portfolio held by country $n$ households is:

$$
\sum_{l=m, t, o} B_{l}^{n} \frac{1}{\tau} p^{l}
$$

Again, we solve for the portfolio weights, $B_{l}^{n}$, by matching the coefficients on $y_{N}^{l}$ in the portfolio payoff with the coefficients on $y_{N}^{l}$ in household expenditure. This procedure yields the following 
result:

$$
B_{n}^{n}=\frac{\left(1-\theta^{n}\right)(\gamma-1)}{\gamma} \text { and } B_{l}^{n}=-\frac{\theta^{l}(\gamma-1)}{\gamma} \text { for } l \neq n .
$$

Households thus hold levered positions in their domestic risk-free bond. Proposition 1 shows the stabilizing country's risk-free rate decreases when the target country is larger than the stabilizing country, increasing the relative value of its bonds. As a result, the same intuition from Proposition 4 shows that announcing a stabilization relative to a larger country increases the stabilizing country's share of world wealth and thus, by the same logic, can increase the welfare of its households.

\section{D.2 Welfare Consequences in Target and Outside Countries}

In this appendix, we provide expressions for the welfare consequences of stabilization on households in the target and outside countries. Analogous to the calculation of $\Delta u^{m}$, we plug the Lagrange multipliers derived in Appendix $\mathrm{D}$ into the expression of $c_{T}^{t}$ and $c_{T}^{o}$ derived in Appendix C.3. We again plug the value of $c_{T}^{t}$ into the second-order approximation of household welfare given by equation 43):

$$
\begin{aligned}
\Delta u^{t} & =\frac{\zeta^{2} \theta^{m}(1-\tau)^{2}\left((\gamma-1) \tau\left((\gamma-1)\left(2 \theta^{m}-1\right) \tau+\theta^{m}\right)+1\right)}{\tau(1+(\gamma-1) \tau)^{2}} \sigma_{N}^{2} \\
& +\frac{(\gamma-1) \zeta \theta^{m}(1-\tau)^{2}\left((\gamma-1) \tau\left((\gamma-1) \tau\left(\theta^{m}-\theta^{t}\right)+1\right)+2\right)}{((\gamma-1) \tau+1)^{2}} \sigma_{N}^{2} .
\end{aligned}
$$

The analogous calculation for the outside country yields:

$$
\Delta u^{o}=\Delta u^{t}-\frac{\zeta \theta^{m}(\gamma-1)(1-\tau)^{2}}{(1+(\gamma-1) \tau)^{2}} \sigma_{N}^{2} .
$$

Households in the outside country are weakly worse off than households in the target country as a result of the stabilization.

\section{E Appendix to Section 3}

\section{E.1 Sticky Prices of Traded Goods}

In this appendix, we provide additional details about the model setup, derive the monetary policy rule that implements an exchange rate stabilization, and afterwards, relate the seigniorage from 
stabilization to $-\Delta R e s$.

Households enter each period with a fixed quantity of domestic currency, and all goods consumed in a given country must be purchased using this domestic currency. In the first period, households use their currency to purchase stocks. The first period cash-in-advance constraint reads:

$$
\tilde{P}_{T}^{n}\left(\sum_{l} A_{l}^{n} Q_{N}^{l}+Q_{K} K_{N}^{n}\right) \leq \tilde{M}_{1}^{n}
$$

where $\tilde{M}_{1}^{n}$ is the quantity of currency available to country $n$ households in period 1 .

Households enter the first period with the monetary value of the claim to their firm, $Q_{N}$, their endowment of capital, $Q_{k}$, and their transfer, $\kappa^{n}$, as well as any additional money balances the central bank injects through open market operations, $\Delta M_{1}^{n}$. The household's first-period budget constraint can thus be expressed as:

$$
\tilde{P}_{T}^{n}\left(\sum_{l} A_{l}^{n} Q_{N}^{l}+Q_{K} K_{N}^{n}\right) \leq \tilde{P}_{T}^{n}\left(Q_{N}^{n}+Q_{K}+\kappa^{n}\right)+\Delta M_{1}^{n}
$$

Hence, $\tilde{M}_{1}^{n}=\tilde{P}_{T}^{n}\left(Q_{N}^{n}+Q_{K}+\kappa^{n}\right)+\Delta M_{1}^{n}$.

In the second period, households face the cash-in-advance constraint:

$$
\tilde{P}_{T}^{n} C_{T}^{n}(\omega)+\tilde{P}_{N}^{n}(\omega) C_{N}^{n}(\omega) \leq \tilde{M}_{2}^{n}(\omega)
$$

where $\tilde{M}_{2}^{n}(\omega)$ is the total quantity of currency available to country $n$ households in period 2 to purchase consumption. Households again enter the second period with the monetary payoff from their stock portfolio and any additional money balances the central bank injects through open market operations:

$$
\Delta \tilde{M}^{n}(\omega)=\tilde{M}_{2}^{n}(\omega)-\tilde{P}_{T}^{n}\left(\sum_{l} A_{l}^{n} P_{N}^{l}(\omega) Y_{N}^{l}(\omega)+Y_{T}^{n}\right)
$$

As a result, the household's budget constraint in the second period can be expressed as:

$$
\tilde{P}_{T}^{n} C_{T}^{n}(\omega)+\tilde{P}_{N}^{n}(\omega) C_{N}^{n}(\omega) \leq \tilde{P}_{T}^{n}\left(\sum_{l} A_{l}^{n} P_{N}^{l}(\omega) Y_{N}^{l}(\omega)+Y_{T}^{n}\right)+\Delta \tilde{M}^{n}(\omega)
$$

In the second period, households maximize utility (4) subject to 46 . Letting $\tilde{\Lambda}_{T}^{n}(\omega)$ denote the Lagrange multiplier on the household's budget constraint, the first-order conditions with 
respect to traded and nontraded consumption are:

$$
\begin{gathered}
\tau\left(C^{n}(\omega)\right)^{1-\gamma}\left(C_{T}^{n}(\omega)\right)^{-1}=\tilde{P}_{T}^{n} \tilde{\Lambda}^{n}(\omega) \\
(1-\tau)\left(C^{n}(\omega)\right)^{1-\gamma}\left(C_{N}^{n}(\omega)\right)^{-1}=\tilde{P}_{N}^{n}(\omega) \tilde{\Lambda}^{n}(\omega)
\end{gathered}
$$

Because households exhibit Cobb-Douglas utility, they spend a fraction $\tau$ of their wealth on the traded good, and a fraction $1-\tau$ of their wealth on the nontraded good:

$$
\begin{aligned}
C_{T}^{n}(\omega) & =\tau \frac{\tilde{M}_{2}^{n}(\omega)}{\tilde{P}_{T}^{n}} \\
C_{N}^{n}(\omega) & =(1-\tau) \frac{\tilde{M}_{2}^{n}(\omega)}{\tilde{P}_{N}^{n}(\omega)} .
\end{aligned}
$$

Since the price of the traded good is fixed, equation (49) immediately shows that monetary policy determines the consumption of traded goods in each country. With the consumption of the nontraded goods being determined by the capital stock and the exogenous productivity shock, central banks are able to neutralize the monetary friction and can therefore replicate the freely floating allocation in the baseline model.

Next, we derive the monetary policy that stabilizes exchange rates. In equilibrium, households must consume their country's endowment of nontraded goods. Hence, equation (50) shows the nominal price of the nontraded good can be written as a function of the money supply and the nontraded endowment:

$$
\tilde{P}_{N}^{n}(\omega)=(1-\tau) \tilde{M}_{2}^{n}(\omega) / Y_{N}^{n}(\omega)
$$

We plug equation (51) into (48) to derive traded consumption as a function of $\tilde{M}_{2}^{n}(\omega), Y_{N}^{n}(\omega)$ and $\tilde{\Lambda}^{n}(\omega)$ :

$$
C_{T}^{n}(\omega)=\tau^{\frac{1}{\tau(1-\gamma)}}(1-\tau)^{\frac{1}{\tau(\gamma-1)}} Y_{N}^{n}(\omega)^{\frac{1-\tau}{\tau}} \tilde{M}_{2}^{n}(\omega)^{\frac{1}{\tau(1-\gamma)}} \tilde{\Lambda}^{n}(\omega)^{\frac{1}{\tau(1-\gamma)}}
$$

Next, we plug (52) into 47) to derive a relationship between $\tilde{P}_{T}^{n}, \tilde{M}_{2}^{n}(\omega)$ and $\tilde{\Lambda}^{n}(\omega)$ :

$$
\tilde{P}_{T}^{n}=\tau^{2+\frac{1}{\tau(\gamma-1)}}(1-\tau)^{-1-\frac{1}{\tau(\gamma-1)}} Y_{N}^{n}(\omega)^{-\frac{(1-\tau)(1+2 \tau(\gamma-1))}{\tau}} \tilde{M}_{2}^{n}(\omega)^{1+\frac{1}{\tau(\gamma-1)}} \tilde{\Lambda}^{n}(\omega)^{\frac{1}{\tau(\gamma-1)}}
$$

\section{Proposition 7}

The central banks of the target and outside countries float their exchange rates by choosing $M_{2}^{n}(\omega)$ to neutralize the monetary friction in their countries

$$
\left.M_{2}^{n}(\omega)=(1-\tau) \tau^{-2+\frac{1}{1+\tau(\gamma-1)}} Y_{N}^{n}(\omega)^{-1+2 \tau+\gamma\left(2(1-\tau)-\frac{1}{1+\tau(\gamma-1)}\right.}\right)\left(\Lambda_{T}(\omega)\right)^{-\frac{1}{1+\tau(\gamma-1)}}
$$


The central bank of the stabilizing country stabilizes its real and nominal exchange rate by setting monetary policy according to:

$$
\left.M_{2}^{m}(\omega)=(1-\tau) \tau^{-2+\frac{1}{1+\tau(\gamma-1)}} Y_{N}^{m}(\omega)^{-1+2 \tau+\gamma\left(2(1-\tau)-\frac{1}{1+\tau(\gamma-1)}\right.}\right)\left(Z(\omega) \Lambda_{T}(\omega)\right)^{-\frac{1}{1+\tau(\gamma-1)}}
$$

where $Z(\omega)$ is the state-contigent tax and $\Lambda_{T}(\omega)$ is the shadow price of traded consumption from baseline model in section 2. The equilibrium allocation then coincides exactly with the equilibrium allocation under stabilized exchange rates in the baseline model in section 2. If the central bank in the stabilizing country instead also behaves according to (54), the equilibrium allocation coincides with the equilibrum under freely floating exchange rates in section 2.

Proof. Plugging (55) into (53) and solving for $Z(\omega) \Lambda_{T}(\omega)$ yields:

$$
Z(\omega) \Lambda_{T}(\omega)=\tilde{\Lambda}^{m}(\omega) \tilde{P}_{T}^{m}
$$

Moreover, plugging (54) into (53) and solving for $\Lambda_{T}(\omega)$ yields:

$$
\Lambda_{T}(\omega)=\tilde{\Lambda}^{n}(\omega) \tilde{P}_{T}^{n} \text { for } n=t, o
$$

Hence, the first-order conditions (47) and (48) coincide with the shadow prices of traded and nontraded consumption from Appendix C.1. As a result, the allocation of goods must also be the same.

Equation (55) shows that when the target country appreciates (i.e. states of the world in which $Z(\omega) \Lambda_{T}(\omega)$ is high), the stabilizing country's central bank contracts its money supply to match the appreciation. Another way to show this policy is to take the log difference in the stabilizing country's monetary policy between the stabilizing regime, $M_{2}^{m}(\omega)$ and the freely floating regime (when we replace $Z(\omega) \Lambda_{T}(\omega)$ with $\Lambda_{T}^{*}(\omega)$ ):

$$
m_{2}^{m}-m_{2}^{m *}=-\frac{1}{1+\tau(\gamma-1)}\left(z+\lambda_{T}-\lambda_{T}^{*}\right)
$$

We plug in the expressions for $z$ and $\lambda_{T}-\lambda_{T}^{*}$ given by Lemma 1 and equation (24) to show:

$$
m_{2}^{m}-m_{2}^{m *}=-\frac{\zeta\left(1-\theta^{m}\right)}{\gamma \tau}\left(p^{t *}-p^{m *}\right)
$$

Next, we derive an expression for seigniorage and show the value of seigniorage accruing to 
the central bank is equal to $-\Delta R e s$, which is given by equation (20). The net present value of seigniorage is:

$$
\text { seigniorage }=-\left(\frac{\Delta \tilde{M}_{1}^{n}}{\tilde{P}_{T}^{n}}\right)-\mathbb{E}\left[\frac{\Lambda_{T}(\omega)}{\Lambda_{T, 1}}\left(\frac{\Delta \tilde{M}^{n}(\omega)}{\tilde{P}_{T}^{n}}\right)\right],
$$

where $\Delta \tilde{M}_{1}^{n}$ and $\Delta \tilde{M}^{n}(\omega)$ are given by the budget constraints (45) and 46). Equation 46. shows:

$$
\begin{aligned}
\frac{\Delta \tilde{M}^{n}(\omega)}{\tilde{P}_{T}^{n}} & =C_{T}^{n}(\omega)+P_{N}^{l}(\omega) C_{N}^{n}(\omega)-\sum_{l} A_{l}^{n} P_{N}^{l}(\omega) Y_{N}^{l}(\omega)-Y_{T}^{n} \\
& =C_{T}^{n}(\omega)-\left(A_{n}^{n}-1\right) P_{N}^{l}(\omega) Y_{N}^{n}(\omega)-\sum_{l \neq n} A_{l}^{n} P_{N}^{l}(\omega) Y_{N}^{l}(\omega)-Y_{T}^{n}
\end{aligned}
$$

The second equality comes from plugging in the equilibrium condition $C_{N}^{n}=Y_{N}^{n}$. We multiply this result with the stochastic discount factor, $\Lambda_{T}(\omega) / \Lambda_{T, 1}$, and take expectations:

$$
\mathbb{E}\left[\frac{\Lambda_{T}(\omega)}{\Lambda_{T, 1}}\left(\frac{\Delta \tilde{M}^{n}(\omega)}{\tilde{P}_{T}^{n}}\right)\right]=\mathbb{E}\left[\frac{\Lambda_{T}(\omega)}{\Lambda_{T, 1}} C_{T}^{n}(\omega)\right]-\left(A_{n}^{n}-1\right) Q_{N}^{n}-\sum_{l \neq n} A_{l}^{n} Q_{N}^{l}-Y_{T}^{n} \mathbb{E}\left[\frac{\Lambda_{T}(\omega)}{\Lambda_{T, 1}}\right]
$$

Equation (45) shows:

$$
\begin{aligned}
\frac{\Delta \tilde{M}_{1}^{n}}{\tilde{P}_{T}^{n}} & =\sum_{l} A_{l}^{n} Q_{N}^{l}+Q_{K}-Q_{N}^{n}-Q_{K}-\kappa^{n} \\
& =\left(A_{n}^{n}-1\right) Q_{N}^{n}+\sum_{l \neq n} A_{l}^{n} Q_{N}^{l}-\kappa^{n} .
\end{aligned}
$$

Combining the two previous expressions yields:

$$
\left(\frac{\Delta \tilde{M}_{1}^{n}}{\tilde{P}_{T}^{n}}\right)+\mathbb{E}\left[\frac{\Lambda_{T}(\omega)}{\Lambda_{T, 1}}\left(\frac{\Delta \tilde{M}^{n}(\omega)}{\tilde{P}_{T}^{n}}\right)\right]=\mathbb{E}\left[\frac{\Lambda_{T}(\omega)}{\Lambda_{T, 1}} C_{T}^{n}(\omega)\right]-Y_{T}^{n} \mathbb{E}\left[\frac{\Lambda_{T}(\omega)}{\Lambda_{T, 1}}\right]-\kappa^{n}
$$

We plug in the definition of $\kappa^{m}$ given by equation (40) to show:

$$
\begin{aligned}
\text { seigniorage } & =-\left(\frac{\Delta \tilde{M}_{1}^{n}}{\tilde{P}_{T}^{n}}\right)-\mathbb{E}\left[\frac{\Lambda_{T}(\omega)}{\Lambda_{T, 1}}\left(\frac{\Delta \tilde{M}^{n}(\omega)}{\tilde{P}_{T}^{n}}\right)\right] \\
& =\mathbb{E}\left[\frac{\Lambda_{T}^{*}(\omega)}{\Lambda_{T, 1}^{*}} C_{T}^{n *}(\omega)\right]-\mathbb{E}\left[\frac{\Lambda_{T}(\omega)}{\Lambda_{T, 1}} C_{T}^{n}(\omega)\right] \\
& =-\Delta \text { Res. }
\end{aligned}
$$




\section{E.2 Extension: Sticky Prices of the Final Consumption Good}

This appendix analyzes an extension of the baseline model in section 2 in which the price of the final consumption bundle is sticky, rather than the price of the traded good. Similar to appendix E.1, central bank policies can exactly replicate the equilibrium allocation in the baseline model.

We assume there now exists a firm in each country that produces the final consumption good according to a Cobb-Douglas production technology:

$$
Y^{n}(\omega)=\left(C_{T}^{n}(\omega)\right)^{\tau}\left(C_{N}^{n}(\omega)\right)^{1-\tau}
$$

We assume this price of the final consumption good is sticky, $\tilde{P}^{n}(\omega)=1$. Hence, the final good firm takes the demand for the final consumption good and solves the following cost-minimization problem:

$$
\min \tilde{P}_{T}^{n}(\omega) C_{T}^{n}(\omega)+\tilde{P}_{N}^{n}(\omega) C_{N}^{n}(\omega) \text { s.t. }\left(C_{T}^{n}(\omega)\right)^{\tau}\left(C_{N}^{n}(\omega)\right)^{1-\tau}=Y^{n}(\omega)
$$

The solution of this cost minimization problem determines the quantity of traded and non-traded goods the firm purchases to produce final consumption goods:

$$
C_{T}^{n}(\omega)=\left(\frac{\tau}{1-\tau} \frac{\tilde{P}_{N}^{n}(\omega)}{\tilde{P}_{T}^{n}(\omega)}\right)^{1-\tau} Y^{n}(\omega), \quad C_{N}^{n}=\left(\frac{1-\tau}{\tau} \frac{\tilde{P}_{T}^{n}(\omega)}{\tilde{P}_{N}^{n}(\omega)}\right)^{\tau} Y^{n}(\omega)
$$

which also relates the price of the traded and nontraded goods to the price of the final consumption good:

$$
\tilde{P}^{n}(\omega)=\tilde{P}_{T}^{n}(\omega) C_{T}^{n}(\omega)+\tilde{P}_{N}^{n}(\omega) C_{N}^{n}(\omega)=\frac{\left(\tilde{P}_{T}^{n}(\omega)\right)^{\tau}\left(\tilde{P}_{N}^{n}(\omega)\right)^{1-\tau}}{\tau^{\tau}(1-\tau)^{1-\tau}} .
$$

As a result, we can write the nominal price of the traded good as a function of the nominal price of the nontraded good:

$$
\tilde{P}_{T}^{n}(\omega)=\tau(1-\tau)^{\frac{1-\tau}{\tau}} \tilde{P}_{N}^{n}(\omega)^{-\frac{1-\tau}{\tau}}
$$

Households continue to exhibit utility (4) over consumption of the final consumption good, $C^{n}(\omega)$. Just as in Appendix E.1, households enter each period with a fixed quantity of the domestic currency, and all goods consumed in a given country must be purchased using the domestic currency. In the first period, households use their currency to purchase stocks. They continue to face the budget constraint given by equation 45 . In the second period, households 
face the cash-in-advance constraint:

$$
\tilde{P}^{n} C^{n}(\omega) \leq \tilde{M}^{n}(\omega)
$$

where $\tilde{M}^{n}(\omega)=\tilde{P}_{T}^{n}\left(\sum_{l} A_{l}^{n} P_{N}^{l}(\omega) Y_{N}^{l}(\omega)+Y_{T}^{n}\right)+\Delta \tilde{M}^{n}(\omega)$ is the total quantity of domestic currency each country $n$ household can use in the second period to purchase consumption goods.

Since the price of the final consumption good is fixed, equation (58) and market clearing of the final consumption good implies:

$$
Y^{n}(\omega)=\tilde{M}^{n}(\omega)
$$

Hence, equations (61), (56), (59) and market clearing in nontraded goods allow us to write $\tilde{P}_{N}^{n}(\omega)$ as a function of monetary policy:

$$
\tilde{P}_{N}^{n}(\omega)=(1-\tau) \tilde{M}^{n}(\omega) / Y_{N}^{n}(\omega)
$$

Plugging (60) into the expression for $C_{T}^{n}(\omega)$ in $(56)$ shows:

$$
C_{T}^{n}(\omega)=\left(Y_{N}^{n}(\omega)\right)^{-\frac{1-\tau}{\tau}} \tilde{M}^{n}(\omega)^{\frac{1}{\tau}}
$$

Equation (61) shows changes in the money supply directly determine the purchases of traded goods in each of the countries. Hence, the central banks in each of the countries can engage in monetary policies that directly replicate the equilibrium in the baseline model in section 2 .

When the target country appreciates, equation (61) shows that the stabilizing country's central bank would decrease $\tilde{M}^{n}(\omega)$ to decrease domestic consumption of traded goods and match the appreciation in the target country. Hence, in this extension where the price of the entire domestic consumption bundle is sticky, the central bank implements a stabilizion by following the same rule of contracting the domestic money supply whenever the target country appreciates.

Moreover, the budget constraints in this appendix are exactly the same as those in Appendix E.1. Only the location of the nominal rigidity has changed. As a result, the derivation of seigniorage accruing to the central bank is exactly the same as in Appendix E.1. Hence, the present value of the seigniorage from stabilization is still equal to $-\Delta R e s$. 


\section{E.3 Extension: Segmented Markets and Cash-In-Advance Constraint}

This appendix analyzes an alternative monetary friction where prices are flexible and monetary policy affects real allocations because financial markets are segmented (Alvarez et al., 2002). Again, the key takeaway from this exercise is that, even with this alternate type of monetary friction, a simple nominal stabilization can implement a real stabilization of the type discussed in Section 2 of the main text. We will show that when the target country appreciates, the stabilizing country's central bank matches the appreciation by contracting the domestic money supply. Finally, we show the seigniorage from stabilization remains equal to $-\Delta$ Res under this alternative monetary friction.

Each country has a central bank that issues a national currency. All goods must be paid for in the domestic currency of the country from which they originate. All households face a cash-in-advance constraint, and all prices are flexible. Within each country, only a fraction $\phi$ of households can trade in the international stock market, label these households 'active.' The remaining $1-\phi$ of households do not have access to financial markets. The central banks in the target and outside countries use their control of the money supply to recover the efficient allocation of resources, taking as given the actions of the stabilizing country's central bank. By contrast, the central bank in the stabilizing country uses its control of monetary policy to stabilize the nominal exchange rate.

In the second period, the cash-in-advance constraint for active households is:

$$
\tilde{P}_{T}^{n}(\omega) C_{T}^{n}(\omega)+\tilde{P}_{N}^{n}(\omega) C_{N}^{n}(\omega) \leq \tilde{M}_{1}^{n}+\tilde{P}_{T}^{n}(\omega)\left(\sum_{l} A_{l}^{n} P_{N}^{l}(\omega) Y_{N}^{l}(\omega)+Y_{T}^{n}\right) .
$$

where $\tilde{P}_{T}^{n}$ is the nominal price of the traded good in country $n$ and $\tilde{M}_{1}^{n}$ is the nominal money holding of the active household in terms of the national currency of its home country $n$ that is carried over from the first period. Since inactive households do not have access to financial markets, their cash in advance constraint in period 2 is:

$$
\tilde{P}_{T}^{n}(\omega) \hat{C}_{T}^{n}(\omega)+\tilde{P}_{N}^{n}(\omega) \hat{C}_{N}^{n}(\omega) \leq \hat{M}_{1}^{n}
$$

where $\hat{M}_{1}^{n}$ is the cash holding of an inactive households carried over from the first period. All households within a given country start the first period with identical cash holdings, $\tilde{M}_{0}^{n}$. The 
first-period constraint for active households is

$$
\tilde{M}_{1}^{n}+\tilde{P}_{T, 1}^{n}\left(\sum_{l} A_{l}^{n} Q_{N}^{l}+Q_{K} K_{N}^{n}\right) \leq \tilde{P}_{T, 1}^{n}\left(Q_{N}^{n}+Q_{K}+\kappa^{n}\right)+\tilde{M}_{0}^{n}
$$

and the first-period constraint for inactive households is

$$
\hat{M}_{1}^{n} \leq \tilde{P}_{T, 1}^{n}\left(Q_{N}^{n}+Q_{K}+\hat{\kappa}^{n}\right)+\hat{M}_{0}^{n}
$$

The assumption that all goods must be paid for in the domestic currency from which they originate implies the money market clearing condition:

$$
\tilde{P}_{T}^{n}(\omega) Y_{T}^{n}+\tilde{P}_{N}^{n}(\omega) Y_{N}^{n}=\bar{M}^{n}(\omega)
$$

where $\bar{M}^{n}=\phi \tilde{M}^{n}+(1-\phi) \hat{M}^{n}$ is the aggregate money supply in country $n$. The central bank changes the monetary base in the second period through open market operations in the stock market:

$$
\phi \tilde{P}_{T}^{n}(\omega)\left(\sum_{l} A_{l}^{n} P_{N}^{l}(\omega) Y_{N}^{l}(\omega)+Y_{T}^{n}\right)=\bar{M}_{2}^{n}-\bar{M}_{1}^{n}=\phi\left(\tilde{M}_{2}^{n}-\tilde{M}_{1}^{n}\right) .
$$

Inactive households split their supply of money between traded and nontraded goods. Their consumption is:

$$
\hat{C}_{T}^{n}(\omega)=\tau \frac{\hat{M}_{1}^{n}}{\tilde{P}_{T}^{n}(\omega)}, \text { and } \hat{C}_{N}^{n}(\omega)=(1-\tau) \frac{\hat{M}_{1}^{n}}{\tilde{P}_{N}^{n}(\omega)} .
$$

Because prices are flexible, changes in the money supply affect the equilibrium allocation in this economy only because it affects the real purchasing power of these inactive households. That is, the central bank can affect the allocation by increasing or decreasing the purchasing power of these households. Define the shock to the real purchasing power of inactive households in country $n$, controlled by country $n$ 's central bank as

$$
\exp \left(-\mu^{n}\right)=\frac{1}{P^{n}(\omega)} \frac{\hat{M}_{1}^{n}}{\tilde{P}_{T}^{n}(\omega)}
$$

so that a high $\mu$ corresponds to an expansionary monetary policy, higher inflation, and lower purchasing power of inactive households. 
Given this definition, the consumption of inactive households can be re-written as:

$$
\hat{C}_{T}^{n}(\omega)=\tau \exp \left(-\mu^{n}\right) P^{n}(\omega), \text { and } \hat{C}_{N}^{n}(\omega)=(1-\tau) \exp \left(-\mu^{n}\right) P^{n}(\omega) \frac{\tilde{P}_{T}^{n}(\omega)}{\tilde{P}_{N}^{n}(\omega)}
$$

Active households maximize their expected utility subject to their budget constraints (62) and (63), as well as the consumption of inactive households. We derive first-order conditions and log-linearize around the deterministic equilibrium. The real exchange rate between the stabilizing country and target country is:

$$
s^{p, t}=\frac{\gamma(1-\tau)}{\gamma \tau+\phi(1-\tau)}\left(y_{N}^{t}-y_{N}^{p}\right)+\frac{\gamma(1-\tau)(1-\phi)}{\gamma \tau+\phi(1-\tau)}\left(\mu^{t}-\mu^{p}\right)
$$

A positive $\mu^{n}$ (high inflation) shifts resources to the active households in country $n$ and depreciates the stabilizing country's real exchange rate.

The real exchange rate under the freely floating regime is:

$$
s^{m, t *}=\frac{\gamma(1-\tau)}{\gamma \tau+\phi(1-\tau)}\left(y_{N}^{t}-y_{N}^{m}\right)
$$

and the variance of this exchange rate is:

$$
\operatorname{var}\left[s^{m, t *}\right]=\frac{2 \gamma^{2}(1-\tau)^{2}}{(\gamma \tau+\phi(1-\tau))^{2}} \sigma_{N}^{2}
$$

The stabilizing country imposes a real exchange rate stabilization of strength $\zeta$ by choosing:

$$
\begin{aligned}
\mu^{m} & =\zeta \frac{1}{1-\phi}\left(y_{N}^{t}-y_{N}^{m}\right) \\
& =\zeta \frac{\gamma \tau+\phi(1-\tau)}{\gamma(1-\tau)(1-\phi)}\left(p^{m *}-p^{t *}\right)
\end{aligned}
$$

The previous equation shows that when the target country appreciates, the stabilizing country lowers its own inflation rate (i.e. contracts) to match the appreciation in the target country. Under this alternative form of monetary friction, lower inflation shifts resources from the active household towards the inactive household, which increases the marginal utility of active households and thus appreciates the real price level in the stabilizing country.

We show this result formally by explicitly solving for the monetary policy that enforces a nominal exchange rate stabilization. The nominal exchange rate in this economy is equal to the 
real exchange rate plus inflation:

$$
\tilde{s}^{m, t}=p^{m}+\mu^{m}-p^{t}-\mu^{t}
$$

$\mu^{t}=\mu^{o}=0$ by assumption. However, the nominal exchange rate is affected by monetary policy through $\mu^{m}$. We solve for the monetary policy that implements a nominal exchange rate stabilization of strength $\tilde{\zeta}$ :

$$
\begin{aligned}
\mu^{m} & =\frac{\tilde{\zeta} \gamma(1-\tau)}{\gamma(1-\phi)(1-\tau)-(\gamma \tau+(1-\tau) \phi)}\left(y_{N}^{t}-y_{N}^{m}\right) \\
& =\frac{\tilde{\zeta}(\gamma \tau+\phi(1-\tau))}{\gamma(1-\phi)(1-\tau)-(\gamma \tau+(1-\tau) \phi)}\left(p^{m *}-p^{t *}\right)
\end{aligned}
$$

Under this policy, the stabilizing country's real exchange rate is:

$$
s^{m, t}=\left(1-\frac{\tilde{\zeta} \gamma(1-\tau)(1-\phi)}{\gamma(1-\phi)(1-\tau)-(\gamma \tau+(1-\tau) \phi)}\right) s^{m, t *}
$$

Hence, a policy that implements a nominal stabilization of strength of $\tilde{\zeta}$ will implement a real stabilization of strength:

$$
\zeta=\tilde{\zeta} \frac{\gamma(1-\tau)(1-\phi)}{\gamma(1-\phi)(1-\tau)-(\gamma \tau+(1-\tau) \phi)}
$$

If $\gamma(1-\phi)(1-\tau)>(\gamma \tau+(1-\tau) \phi)$, then a nominal stabilization implements a stronger real stabilization.

Seigniorage is a function of the present discounted value of the change in the money supply in both periods:

$$
\text { seigniorage }=-\frac{\bar{M}_{1}^{n}-\bar{M}_{0}^{n}}{\tilde{P}_{T, 1}^{n}}-\mathbb{E}\left[\frac{\Lambda_{T}(\omega)}{\Lambda_{T, 1}}\left(\frac{\bar{M}_{2}^{n}(\omega)-\bar{M}_{1}^{n}}{\tilde{P}_{T}^{n}(\omega)}\right)\right]
$$

Following the same calculations as in Appendix E.1, we can show:

$$
\begin{aligned}
\text { seigniorage }=\mathbb{E} & {\left[\left(\frac{\Lambda_{T}^{*}(\omega)}{\Lambda_{T, 1}^{*}}\right)\left(\phi C_{T}^{m *}(\omega)+(1-\phi) \hat{C}_{T}^{m *}(\omega)\right)\right] } \\
& -\mathbb{E}\left[\left(\frac{\Lambda_{T}(\omega)}{\Lambda_{T, 1}}\right)\left(\phi C_{T}^{m}(\omega)+(1-\phi) \hat{C}_{T}^{m}(\omega)\right)\right]
\end{aligned}
$$

where asterisks denote an equilibrium in which the stabilizing country does not actively manipu- 
late the variance of the exchange rate. In the segmented markets model, seigniorage is still equal to change in the value of traded consumption $(-\Delta R e s)$. However, seigniorage in the segmented markets model takes into account the consumption of both active and inactive households.

\section{F Model Extensions}

\section{F.1 Partial exchange rate stabilization}

This appendix formalizes the effects of partial exchange rate stabilization. In a first step, we use the partition defined in the main text to write the variance of exchange rates in the freely floating regime as

$$
\begin{aligned}
\operatorname{var}\left[s^{* m, t}\right] & =\int_{\Omega}\left(s^{* m, t}-\mathbb{E}\left[s^{* m, t} \mid\left\{K_{n}\right\}\right]\right)^{2} g(\omega) d \omega \\
& =\int_{\Omega_{s}}\left(s^{* m, t}-\mathbb{E}\left[s^{* m, t} \mid\left\{K_{n}\right\}\right]\right)^{2} g(\omega) d \omega+\int_{\Omega_{-s}}\left(s^{* m, t}-\mathbb{E}\left[s^{* m, t} \mid\left\{K_{n}\right\}\right]\right)^{2} g(\omega) d \omega \\
& =\operatorname{Prob}\left[\omega \in \Omega_{s}\right] \operatorname{var}\left[s^{* m, t} \mid \Omega_{s}\right]+\operatorname{Prob}\left[\omega \in \Omega_{-s}\right] \operatorname{var}\left[s^{* m, t} \mid \Omega_{-s}\right]
\end{aligned}
$$

since the conditional means in the two subregions of the state space are identical. By the same token, partial stabilization delivers a variance of the exchange rate of

$$
\begin{aligned}
\operatorname{var}\left[s^{m, t}\right] & =\operatorname{Prob}\left[\omega \in \Omega_{s}\right] \operatorname{var}\left[s^{m, t} \mid \Omega_{s}\right]+\operatorname{Prob}\left[\omega \in \Omega_{-s}\right] \operatorname{var}\left[s^{m, t} \mid \Omega_{-s}\right] \\
& =\operatorname{Prob}\left[\omega \in \Omega_{s}\right] \operatorname{var}\left[(1-\zeta)\left(s^{* m, t}-\mathbb{E}\left[s^{* m, t} \mid\left\{K_{n}\right\}\right]\right) \mid \Omega_{s}\right]+\operatorname{Prob}\left[\omega \in \Omega_{-s}\right] \operatorname{var}\left[s^{* m, t} \mid \Omega_{-s}\right] \\
& =\operatorname{Prob}\left[\omega \in \Omega_{s}\right](1-\zeta)^{2} \operatorname{var}\left[s^{* m, t} \mid \Omega_{s}\right]+\operatorname{Prob}\left[\omega \in \Omega_{-s}\right] \operatorname{var}\left[s^{* m, t} \mid \Omega_{-s}\right] \\
& <\operatorname{var}\left[s^{* m, t}\right] .
\end{aligned}
$$

With exchange rate stabilization of strength $\zeta$, the interest rate differential given by equation (2) becomes

$$
\begin{aligned}
r^{m}+\Delta \mathbb{E}\left[s^{m, t}\right]-r^{t} & =-\operatorname{cov}\left[\lambda_{T}, s^{m, t}\right] \\
& =-\operatorname{cov}\left[\lambda_{T},(1-\zeta) s^{* m, t}\right] \\
& =-(1-\zeta) \operatorname{cov}\left[\lambda_{T}, s^{* m, t}\right] .
\end{aligned}
$$

The effects of partial stabilization for interest rate differentials work in the same direction. Again using the fact that the conditional means are identical in the two subregions, we decompose the 
covariance into the following terms:

$$
\begin{aligned}
r^{m}+\Delta \mathbb{E}\left[s^{m, t}\right]-r^{t}= & -\operatorname{cov}\left[\lambda_{T}, s^{m, t}\right]=-\int_{\Omega}\left(\lambda_{T}-\mathbb{E}\left[\lambda_{T} \mid\left\{K_{n}\right\}\right]\right)\left(s^{m, t}-\mathbb{E}\left[s^{m, t} \mid\left\{K_{n}\right\}\right]\right) g(\omega) d \omega \\
= & -\operatorname{Prob}\left[\omega \in \Omega_{s}\right] \int_{\Omega_{s}}\left(\lambda_{T}-\mathbb{E}\left[\lambda_{T} \mid\left\{K_{n}\right\}\right]\right)\left(s^{m, t}-\mathbb{E}\left[s^{m, t} \mid\left\{K_{n}\right\}\right]\right) g_{s}(\omega) d \omega \\
& -\operatorname{Prob}\left[\omega \in \Omega_{-s}\right] \int_{\Omega_{-s}}\left(\lambda_{T}-\mathbb{E}\left[\lambda_{T} \mid\left\{K_{n}\right\}\right]\right)\left(s^{m, t}-\mathbb{E}\left[s^{m, t} \mid\left\{K_{n}\right\}\right]\right) g_{-s}(\omega) d \omega \\
= & -\operatorname{Prob}\left[\omega \in \Omega_{s}\right] \int_{\Omega_{s}}\left(\lambda_{T}-\mathbb{E}\left[\lambda_{T} \mid \Omega_{s},\left\{K_{n}\right\}\right]\right)\left(s^{m, t}-\mathbb{E}\left[s^{m, t} \mid\left\{K_{n}\right\}\right]\right) g_{s}(\omega) d \omega \\
& -\operatorname{Prob}\left[\omega \in \Omega_{s}\right]\left(\mathbb{E}\left[\lambda_{T} \mid \Omega_{s},\left\{K_{n}\right\}\right]-\mathbb{E}\left[\lambda_{T} \mid\left\{K_{n}\right\}\right]\right) \int_{\Omega_{s}}\left(s^{m, t}-\mathbb{E}\left[s^{m, t} \mid\left\{K_{n}\right\}\right]\right) g_{s}(\omega) d \omega \\
& -\operatorname{Prob}\left[\omega \in \Omega_{-s}\right] \int_{\Omega_{-s}}\left(\lambda_{T}-\mathbb{E}\left[\lambda_{T} \mid \Omega_{-s},\left\{K_{n}\right\}\right]\right)\left(s^{m, t}-\mathbb{E}\left[s^{m, t} \mid\left\{K_{n}\right\}\right]\right) g_{-s}(\omega) d \omega \\
& -\operatorname{Prob}\left[\omega \in \Omega_{-s}\right]\left(\mathbb{E}\left[\lambda_{T} \mid \Omega_{-s},\left\{K_{n}\right\}\right]-\mathbb{E}\left[\lambda_{T} \mid\left\{K_{n}\right\}\right]\right) \int_{\Omega_{-s}}\left(s^{m, t}-\mathbb{E}\left[s^{m, t} \mid\left\{K_{n}\right\}\right]\right) g_{-s}(\omega) d \omega \\
= & -\operatorname{Prob}\left[\omega \in \Omega_{s}\right] \int_{\Omega_{s}}\left(\lambda_{T}-\mathbb{E}\left[\lambda_{T} \mid \Omega_{s},\left\{K_{n}\right\}\right]\right)\left(s^{m, t}-\mathbb{E}\left[s^{m, t} \mid\left\{K_{n}\right\}\right]\right) g_{s}(\omega) d \omega \\
& -\operatorname{Prob}\left[\omega \in \Omega_{-s}\right] \int_{\Omega_{-s}}\left(\lambda_{T}-\mathbb{E}\left[\lambda_{T} \mid \Omega_{-s},\left\{K_{n}\right\}\right]\right)\left(s^{m, t}-\mathbb{E}\left[s^{m, t} \mid\left\{K_{n}\right\}\right]\right) g_{-s}(\omega) d \omega \\
= & -\operatorname{Prob}\left[\omega \in \Omega_{s}\right] \operatorname{cov}\left[\lambda_{T}, s^{m, t} \mid \Omega_{s}\right]-\operatorname{Prob}\left[\omega \in \Omega_{-s}\right] \operatorname{cov}\left[\lambda_{T}, s^{m, t} \mid \Omega_{-s}\right],
\end{aligned}
$$

where $g_{s}(\omega)=\frac{g(\omega)}{\operatorname{Prob}\left[\omega \in \Omega_{s}\right]}$ and $g_{-s}(\omega)=\frac{g(\omega)}{\operatorname{Prob}\left[\omega \in \Omega_{-s}\right]}$. The second-to-last step follows from the fact that the conditional means are identical and thus $\mathbb{E}\left[s^{m, t}-\mathbb{E}\left[s^{m, t} \mid\left\{K_{n}\right\}\right] \mid \Omega_{s}\right]=0$.

With partial exchange rate stabilization, we get

$$
\begin{aligned}
r^{m}+\Delta \mathbb{E}\left[s^{m, t}\right]-r^{t} & =-\operatorname{cov}\left[\lambda_{T}, s^{m, t}\right] \\
& =-\operatorname{Prob}\left[\omega \in \Omega_{s}\right] \operatorname{cov}\left[\lambda_{T}, s^{m, t} \mid \Omega_{s}\right]-\operatorname{Prob}\left[\omega \in \Omega_{-s}\right] \operatorname{cov}\left[\lambda_{T}, s^{m, t} \mid \Omega_{-s}\right] \\
& =-\operatorname{Prob}\left[\omega \in \Omega_{s}\right](1-\zeta) \operatorname{cov}\left[\lambda_{T}, s^{* m, t} \mid \Omega_{s}\right]-\operatorname{Prob}\left[\omega \in \Omega_{-s}\right] \operatorname{cov}\left[\lambda_{T}, s^{* m, t} \mid \Omega_{-s}\right] .
\end{aligned}
$$

Rearranging the last equation to

$$
r^{m}+\Delta \mathbb{E}\left[s^{m, t}\right]-r^{t}=-\operatorname{cov}\left[\lambda_{T}, s^{m, t}\right]=-\operatorname{cov}\left[\lambda_{T}, s^{* m, t}\right]+\zeta \operatorname{Prob}\left[\omega \in \Omega_{s}\right] \operatorname{cov}\left[\lambda_{T}, s^{* m, t} \mid \Omega_{s}\right],
$$

we see that the effects of partial stabilization are a milder version of currency stabilization discussed previously. In fact, partial stabilization of strength $\zeta$ in a subset of the state space corresponds to currency stabilization of strength $\zeta \operatorname{Prob}\left[\omega \in \Omega_{s}\right] \operatorname{cov}\left[\lambda_{T}, s^{* m, t} \mid \Omega_{s}\right]$. 


\section{F.2 Stabilization Relative to a Basket of Currencies}

Our analysis above also extends directly to stabilizations relative to a basket of currencies. Consider a country that wishes to stabilize its real exchange rate with the basket

$$
p^{b}=(1-w) p^{t}+w p^{o}
$$

where $w$ is the basket's weight on the outside country and $1-w$ the weight on the target country. Using (2), it is then easy to show that stabilizing relative to a basket of currencies has effects akin to a stabilization relative to a (hypothetical) country with a weighted average size of the basket's constituents:

$r^{m}+\Delta \mathbb{E} s^{m, o}-r^{o}=\left(r^{t *}+\Delta \mathbb{E} s^{t, o *}-r^{o *}\right)-\zeta \frac{\gamma(1-\tau)^{2}\left(\left(\bar{\theta}-\theta^{m}\right)(\gamma-1) \tau+\theta^{m}(2-w-2 \bar{w} \zeta)\right)}{\tau(1+(\gamma-1) \tau)} \sigma_{N}^{2}$

where $\bar{\theta}=w \theta^{t}+(1-w) \theta^{o}$ is the weighted average size of the basket's constituents and $\bar{w}=$ $1-(1-w) w$ is a positive constant less than one.

Although clearly a less effective means of lowering domestic interest rates than stabilizations relative to the largest economy in the world, stabilizing relative to a basket may be appealing for some countries, because it reduces price impact. When stabilizing relative to a basket, the stabilizing country's exports are less sensitive to shocks affecting only one of the two other countries, decreasing the volatility of its exports and thus lowering the stabilization's impact on world-market prices. For a large country, stabilizing relative to a basket may thus be cheaper to implement than stabilizing relative to the largest economy in the world.

\section{F.3 Feedback between Risk Premia and Capital Accumulation}

In this appendix, we show Propositions 1 through 3 continue to hold when we solve explicitly for the feedback between risk premia and capital accumulation. First, note that changes in the level of capital accumulation affect the expected level of consumption, but not the conditional covariance of consumption across countries in our log-linear solution. It follows immediately that all statements in Propositions 1 through 3 that depend on the covariances between asset payoffs and the shadow price of traded goods are unchanged. That is, all statements regarding interest differentials, expected currency returns, and the world-market value of domestic firms continue to hold.

Second, to show that all statements in Propositions 1 through 3 pertaining to the capital 
stock itself continue to hold when we solve explicitly for the feedback between risk premia and capital accumulation. To this end, we use the second-order approximation of the Euler equation for capital accumulation $(13)$ :

$$
\lambda_{T, 1}+q_{K}+k^{n}=\log [\nu]+\mathbb{E}\left[\lambda_{N}^{n}+y_{N}^{n}\right]+\frac{1}{2} \operatorname{var}\left[\lambda_{N}^{n}+y_{N}^{n}\right] \quad \forall n,
$$

and the log-linear resource constraint for capital:

$$
0=\sum_{n} \theta^{n} k^{n}
$$

We plug in the expression for $\lambda_{N}^{n}=p_{N}^{n}+q+\lambda_{T, 1}^{n}$ from Appendix C.3 to write $\lambda_{N}^{n}$ as a function of $y_{N}^{n}$, and then we plug in $y_{N}^{n}=\eta+\nu k^{n}$ to write the $y_{N}^{n}$ as a function of the capital stock and the productivity shock. We solve this system of four equations for $k^{m}, k^{t}, k^{o}$ and $q_{K}$.

In a freely floating exchange rate economy $(\zeta=0)$, we find

$$
k^{m *}-k^{t *}=\frac{(\gamma-1)^{3}(1-\tau)^{2} \tau}{(1+(\gamma-1) \tau)(1+(\gamma-1)(1-\tau) \nu+(\gamma-1) \tau)}\left(\theta^{m}-\theta^{t}\right) \sigma_{N}^{2} .
$$

Comparing this expression with $k^{m}-k^{t}$ derived from solving the system of four equations above shows that allowing for feedback between risk premia and capital accumulation merely reduces the size of the difference in capital accumulation by a constant factor smaller than one, leaving the economic insights of our analysis unaffected.

The same is true for the equivalent expression under stabilized exchange rates, though this factor is too large to reproduce in print. For the special case of $\zeta=1$, we can show

$$
\left(k^{m}-\left.k^{t}\right|_{\zeta=1}\right)=k^{m *}-k^{t *}+\frac{(\gamma-1)^{3}(1-\tau)^{2} \tau\left(\theta^{t}-\theta^{m}\right) \sigma_{N}^{2}}{(1+(\gamma-1) \tau)(1+(\gamma-1)(1-\tau) \nu+(\gamma-1) \tau)}=0 .
$$

\section{G Appendix to Section 5}

In this appendix, we provide additional details about the model in section 5 and formally derive its equilibrium conditions. To avoid solving the optimization problem separately for households in the stabilizing country and households in the rest of the world, we generalize the notation to allow all countries to impose state-contingent taxes, $Z^{n}(\omega)$, and provide lump sum transfers, $\bar{Z}^{n}$. The governments in the target and outside countries do not use these instruments, such that $Z^{t}(\omega)=Z^{o}(\omega)=1$ and $\bar{Z}^{t}=\bar{Z}^{o}=0$. 


\section{G.1 Equilibrium Consumption}

Inactive households in country $n$ maximize utility, defined in equation (28), in each state of the world by splitting their wealth $\exp \left(-\mu^{n}\right) P^{n}(\omega)$ optimally between traded and nontraded consumption,

$$
\begin{aligned}
\max _{\hat{C}_{T}^{n}(\omega), \hat{C}_{N}^{n}(\omega)} & \frac{1}{1-\gamma}\left(\exp \left(\chi^{n}\right)\left(\hat{C}_{T}^{n}(\omega)\right)^{\tau}\left(\hat{C}_{N}^{n}(\omega)\right)^{1-\tau}\right)^{1-\gamma} \\
\text { s.t. } & \hat{C}_{T}^{n}(\omega)+P_{N}^{n}(\omega) \hat{C}_{N}^{n}(\omega) \leq \exp \left(-\mu^{n}\right) P^{n}(\omega)
\end{aligned}
$$

where hats indicate consumption by inactive households. We solve this problem by setting up a Lagrangian and taking first-order conditions with respect to $\hat{C}_{T}^{n}(\omega)$ and $\hat{C}_{N}^{n}(\omega)$. Inactive households then optimally consume the following bundle of traded and nontraded goods,

$$
\hat{C}_{T}^{n}(\omega)=\exp \left(-\mu^{n}\right) \tau P^{n}(\omega), \quad \hat{C}_{N}^{n}(\omega)=\exp \left(-\mu^{n}\right) \frac{(1-\tau) P^{n}(\omega)}{P_{N}^{n}(\omega)}
$$

Active households own all the productive assets within the country and are short the nominal bonds owned by inactive households. They maximize their utility (28) subject to their intertemporal budget constraint:

$$
\begin{aligned}
& \mathbb{E}\left[\frac{\Lambda_{T}(\omega)}{\Lambda_{T, 1}}\left(Z^{n}(\omega) C_{T}^{n}(\omega)+P_{N}^{n}(\omega) C_{N}^{n}(\omega)+\frac{1-\phi}{\phi} P^{n}(\omega) e^{-\mu^{n}}\right)\right] \\
& \leq \frac{1}{\phi}\left(Q_{K}-Q_{K} K^{n}+\mathbb{E}\left[\frac{\Lambda_{T}(\omega)}{\Lambda_{T, 1}}\left(P_{N}^{n}(\omega) Y_{N}^{n}+Y_{T}^{n}\right)\right]+\kappa^{n}+\bar{Z}^{n}\right)
\end{aligned}
$$

where $(1-\phi) / \phi$ is the number of inactive households per active household in each country and endowments are adjusted by a factor $1 / \phi$ because active households now own proportionally more productive assets per capita; $\kappa^{n}$ again denotes the transfer that decentralizes the allocation corresponding to the social planner's problem with unit Pareto weights under freely floating exchange rates. In the stabilizing country, the government use the lump-sum transfer, $\bar{Z}^{m}$, to equalize the marginal utility of wealth between the stabilizing country and the rest of the world (P2).

The first-order conditions of the active households' problem are:

$$
\begin{gathered}
\frac{\tau \exp \left((1-\gamma) \chi^{n}\right)\left(C^{n}\right)^{1-\gamma}\left(C_{T}^{n}\right)^{-1}}{Z^{n}(\omega)}=\Lambda_{T, 1} Q(\omega) \\
(1-\tau) \exp \left((1-\gamma) \chi^{n}\right)\left(C^{n}\right)^{1-\gamma}\left(C_{N}^{n}\right)^{-1}=\Lambda_{T, 1} Q(\omega) P_{N}^{n}(\omega) .
\end{gathered}
$$


Analogous to Appendix C.3), we find it convenient to denote the stochastic discout factor with $Q(\omega)=\Lambda_{T}(\omega) / \Lambda_{T, 1}$. The first-order condition with respect to capital accumulation is

$$
Q_{K}=\mathbb{E}\left[\frac{\Lambda_{T}(\omega)}{\Lambda_{T, 1}} P_{N}^{n}(\omega) e^{\eta^{n}} \nu\left(K^{n}\right)^{\nu-1}\right]
$$

\section{G.2 Log-linearized System of Equations}

We next derive log-linearized first-order conditions. Equation (7) defines the resource constraint for traded goods. Equation (8) defines the (three) resource constraints for nontraded goods in each country, and equation (9) defines the resource constraint for capital goods. Equations (73) and 74 define the three first-order conditions with respect to traded consumption and the three first-order conditions with respect to nontraded consumption. Equation (75) defines the three Euler equations for capital investment in each country. In total, we derive a system of 14 equations. To study the model in closed form, we again log-linearize around the deterministic solution - the point at which the variances of shocks are zero $\left(\sigma_{N, n}=0\right)$ and all firms have a capital stock fixed at the deterministic steady-state level. To simplify the exposition, we thus again ignore the feedback effect of differential capital accumulation on the size of risk premia, studying the incentives to accumulate different levels of capital across countries, while holding the capital stock fixed. The log-linear first-order conditions are:

$$
\begin{gathered}
(1-\gamma) \chi^{n}+(1-\gamma)\left(\tau c_{T}^{n}+(1-\tau) c_{N}^{n}\right)-c_{T}^{n}+\log \tau=z^{n}+q+\lambda_{T, 1} \\
(1-\gamma) \chi^{n}+(1-\gamma)\left(\tau c_{T}^{n}+(1-\tau) c_{N}^{n}\right)-c_{N}^{n}+\log (1-\tau)=p_{N}^{n}+q+\lambda_{T, 1}
\end{gathered}
$$

Similar to Appendix C.1, let $q=\lambda_{T}-\lambda_{T, 1}$ denote the stochastic discount factor. Also recall that the transfes $\left\{\kappa^{n}\right\}, \bar{Z}^{m}$ equalize the first-period Lagrange multiplier $\lambda_{T, 1}$ across active households in all countries. The log-linear approximation of equation 75 is:

$$
\lambda_{T, 1}+q_{K}+k^{n}=\log [\nu]+\mathbb{E}\left[\lambda_{N}^{n}+y_{N}^{n}\right]+\frac{1}{2} \operatorname{var}\left(\lambda_{N}^{n}+y_{N}^{n}\right)
$$


The log-linear resource constraints are:

$$
\begin{aligned}
\phi c_{N}^{n}+(1-\phi)\left(-\mu^{n}-\tau\left(\lambda_{N}^{n}-\lambda_{T}-\log \left(\frac{1-\tau}{\tau}\right)\right)\right) & =\eta^{n}+\nu k^{n}=y_{N}^{n}, \\
\sum_{n=m, t, o} \theta^{n}\left[\phi c_{T}^{n}+(1-\phi)\left(-\mu^{n}-(1-\tau)\left(\lambda_{N}^{n}-\lambda_{T}-\log \left(\frac{1-\tau}{\tau}\right)\right)\right)\right] & =\sum_{n=m, t, o} \theta^{n} y_{T, 1}^{n}=1, \\
\sum_{n=m, t, o} \theta^{n} k^{n} & =1 .
\end{aligned}
$$

This set of fourteen equations allows us to solve for the following fourteen unknowns $\left\{k^{n}, c_{N}^{n}, c_{T}^{n}, \lambda_{N}^{n}\right\}_{n=m, t, o}$, $\lambda_{T, 1}$ and $q$.

\section{G.3 Cost of Stabilization}

First, we solve for the state-contingent taxes that implement the real exchange rate stabilization in the model in section 5, and then we derive an expression for the cost of the peg. Throughout, we can recover the results in Appendix C.6 by removing the market segmentation $(\phi=1)$, by setting the monetary shocks to zero $\left(\mu^{n}=0\right)$ and by setting the preference shocks to zero $\left(\chi^{n}=0\right)$.

Analogous to Appendix C.6, we search for a state-contingent tax of the form

$$
Z(\omega)=\left(\frac{Y_{N}^{m}}{Y_{N}^{t}}\right)^{a_{1}}\left(\frac{\exp \left(-\mu^{t}\right)}{\exp \left(-\mu^{m}\right)}\right)^{a_{2}}\left(\frac{\exp \left(\chi^{m}\right)}{\exp \left(\chi^{t}\right)}\right)^{a_{3}}
$$

In logs, this state-contingent tax is

$$
z=a_{1}\left(y_{N}^{t}-y_{N}^{m}\right)+a_{2}\left(-\mu^{t}+\mu^{m}\right)+a_{3}\left(\chi^{t}-\chi^{m}\right)
$$

We follow the procedure from Appendix C.6 to derive the coefficients $a_{1}, a_{2}$ and $a_{3}$ that stabilize the exchange rate. The following lemma summarizes these results.

\section{Lemma 3}

In the model in section 5, where real exchange rates fluctuate in response to monetary shocks, preference shocks, and productivity shocks, a tax on the consumption of traded goods in the stabilizing country of the form

$$
z(\omega)=\frac{\zeta(1-\tau)}{\tau(\tau+\phi(1-\tau))}\left(y_{N}^{m}-y_{N}^{t}\right)+\frac{(1-\tau)(1-\phi)}{\tau(\tau+\phi(1-\tau))}\left(\mu^{m}-\mu^{t}\right)+\frac{(\gamma-1)(1-\tau) \phi}{\gamma \tau(\tau+\phi(1-\tau))}\left(\chi^{m}-\chi^{t}\right)
$$


implements a real exchange rate stabilization of strength $\zeta$.

Next, we derive the cost of the stabilization. We start with the budget constraint of the active household in the stabilizing country given by equation (72), and we identify the components of the lump-sum transfer, $\bar{Z}$. Following the same calculations as in Appendix C.6, we show:

$$
\begin{aligned}
\Delta R e s=\mathbb{E} & {\left[\frac{\Lambda_{T}(\omega)}{\Lambda_{T, 1}}\left(\phi C_{T}^{m}(\omega)+(1-\phi) \hat{C}_{T}^{m}(\omega)\right)\right] } \\
& -\mathbb{E}\left[\frac{\Lambda_{T}(\omega)}{\Lambda_{T, 1}}\left(\phi C_{T}^{m *}(\omega)+(1-\phi) \hat{C}_{T}^{m *}(\omega)\right)\right]
\end{aligned}
$$

In the model in section 5 , the cost of stabilization is thus the change in the value of the stabilizing country's total consumption of traded goods by active and inactive households.

\section{G.4 Proof of Proposition 6}

We first prove results for the internal effects of a real exchange rate stabilization. We plug the log-linear expressions derived from solving the system of equations in Appendix G.2 into equation (2). We can then write the interest rate differential between the stabilizing country and the target as

$$
\begin{aligned}
r^{m}+\Delta \mathbb{E} s^{m, t}-r^{t}= & \left(r^{m *}+\Delta \mathbb{E} s^{m, t *}-r^{t *}\right)-\zeta \frac{\gamma(1-\tau)^{2}\left(\left(\theta^{t}-\theta^{m}\right) \tau(\gamma-\phi)+2 \phi \theta^{m}(1-\zeta)\right)}{\tau \phi(\gamma \tau+(1-\tau) \phi)} \sigma_{N}^{2} \\
& -\zeta \frac{\gamma(1-\tau)(1-\phi)^{2}\left(\left(\theta^{t}-\theta^{m}\right) \gamma \tau+2 \phi \theta^{m}(1-\zeta)(1-\tau)\right)}{\tau \phi(\gamma \tau+(1-\tau) \phi)} \tilde{\sigma}^{2} \\
& -\zeta \frac{\phi(1-\tau)(1-\gamma)^{2}\left(\left(\theta^{t}-\theta^{m}\right) \gamma \tau+2 \phi \theta^{m}(1-\zeta)(1-\tau)\right)}{\tau \gamma(\gamma \tau+(1-\tau) \phi)} \sigma_{\chi}^{2},
\end{aligned}
$$

which implies the exchange rate stabilization decreases the risk-free rate in the stabilizing country relative to the risk-free rate in the target country if the target country is larger than the stabilizing country, $\theta^{t}>\theta^{m}$.

Plugging in the log-linear expressions for $p_{N}^{m}, p_{N}^{t}$, and $\lambda_{T}$ into equation (39), we again find that the relative incentives to accumulate capital in the stabilizing country increase with the size of the target country. Because the closed-form solution equivalent to the one above is too large to print, it is easier to prove this statement by showing that relative incentives to accumulate 
capital increase linearly in $\theta^{t}$ :

$$
\begin{aligned}
& \frac{d}{d \theta^{t}}\left[\left(k^{m}-k^{t}\right)-\left(k^{m *}-k^{t *}\right)\right]=\frac{\zeta(\gamma-1)(1-\tau)^{2} \tau(\gamma-\phi)^{2}}{(\phi+(1-\phi) \tau)(\gamma \tau+(1-\tau) \phi)} \sigma_{N}^{2} \\
& \quad+\frac{\zeta(\gamma-1) \gamma(1-\tau) \tau(\gamma-\phi)(1-\phi)^{2}}{(\phi+(1-\phi) \tau)(\gamma \tau+(1-\tau) \phi)} \tilde{\sigma}^{2}+\frac{\zeta(\gamma-1)^{3}(1-\tau) \tau(\gamma-\phi) \phi^{2}}{\gamma(\phi+(1-\phi) \tau)(\gamma \tau+(1-\tau) \phi)} \sigma_{\chi}^{2}>0 .
\end{aligned}
$$

It follows immediately that there exists some $\theta_{\min }>0$ such that stabilizing the real exchange rate relative to any country larger than $\theta_{\min }$ will increase the incentives to accumulate capital in the stabilizing country. Analogous to Appendix C.7, the spread between the value of the firm in the stabilizing and target countries yields the same expression as the right-hand side of equation (39). Hence, we have already shown the value of the firm in the stabilizing country increases relative to the target country if $\theta^{t}$ is large enough.

Because firms are competitive, wages are given by the marginal product of labor. Hence, an exchange rate stabilization relative to a sufficiently large target country increases wages in the stabilizing country relative to all other countries, concluding the proof of the first statement in Proposition 6.

Next, we derive the cost of stabilization. We calculate changes in the log value of traded consumption in the stabilizing country given by (76). The log-linear approximation of the total traded consumption in the stabilizing country from active and inactive households is: $\phi c_{T}^{m}+(1-$ $\phi) \hat{c}_{T}^{m}$. We calculate:

$$
\log \Delta R e s=v_{T}-v_{T}^{*}
$$

where we use the following second-order approximation of the log value of total traded consumption:

$$
v_{T}=\mathbb{E}\left[\lambda_{T}-\psi_{T}+\phi c_{T}^{m}+(1-\phi) \hat{c}_{T}^{m}\right]+\frac{1}{2} \operatorname{var}\left[\lambda_{T}-\psi_{T}+\phi c_{T}^{m}+(1-\phi) \hat{c}_{T}^{m}\right]
$$

When the stabilizing country is small $\left(\theta^{m}=0\right)$, the cost of the stabilization decreases as the target country gets larger:

$$
\begin{aligned}
\frac{d}{d \theta^{t}}\left(v_{T}-v_{T}^{*}\right)=- & \zeta \frac{(1-\tau)(1-\phi)^{2}(\gamma-\phi)}{(\phi+(\gamma-\phi) \tau)^{2}} \tilde{\sigma}^{2}-\zeta \frac{(1-\tau)^{2}(\gamma-\phi)^{2}}{(\phi+(\gamma-\phi) \tau)^{2}} \sigma_{N}^{2} \\
& -\zeta \frac{(\gamma-1)^{2}(1-\tau)(\gamma-\phi) \phi^{2}}{\gamma(\phi+(\gamma-\phi) \tau)^{2}} \sigma_{\chi}^{2}<0
\end{aligned}
$$

Hence, it is cheaper to stabilize relative to a larger country.

Finally, we prove results for the external effects of a real exchange rate stabilization. Us- 
ing equation (2) and the solution of the model from Appendix G.2, we can write interest rate differential between the target country and the outside country as

$$
\begin{aligned}
r^{t}+\Delta \mathbb{E} s^{t, o}-r^{o}= & \left(r^{t *}+\Delta \mathbb{E} s^{t, o *}-r^{o *}\right)+\frac{\zeta \theta^{m} \gamma(1-\tau)^{2}}{\tau(\gamma \tau+\phi(1-\tau))} \sigma_{N}^{2}+\frac{\zeta \theta^{m} \gamma(1-\tau)^{2}(1-\phi)^{2}}{\tau(\gamma \tau+\phi(1-\tau))} \tilde{\sigma}^{2} \\
& +\frac{\theta^{m} \zeta(\gamma-1)^{2}(1-\tau)^{2} \phi^{2}}{\gamma \tau(\gamma \tau+(1-\tau) \phi)} \sigma_{\chi}^{2},
\end{aligned}
$$

which implies the exchange rate stabilization increases the risk-free rate in the target country relative to the risk-free rate in the outside country.

We plug the log-linear expressions for $p_{N}^{t}, p_{N}^{o}$ and $\lambda_{T}$ into (39) to derive the differential incentive to accumulate capital in the target country relative to the outside countries:

$$
\begin{aligned}
k^{t}-k^{o}= & k^{t *}-k^{o *}-\frac{\theta^{m} \zeta(1-\tau)^{2}(\gamma-\phi)^{2}}{(\gamma \tau+(1-\tau) \phi)^{2}} \sigma_{N}^{2}-\frac{\theta^{m} \gamma \zeta(1-\tau)(\gamma-\phi)(1-\phi)^{2}}{(\gamma \tau+(1-\tau) \phi)^{2}} \tilde{\sigma}^{2}- \\
& \frac{\theta^{m}(\gamma-1)^{2} \zeta(1-\tau)(\gamma-\phi) \phi^{2}}{\gamma(\gamma \tau+(1-\tau) \phi)^{2}} \sigma_{\chi}^{2} .
\end{aligned}
$$

Incentives to accumulate capital in the target country thus decrease relative to the outside country. Since the marginal product of labor rises with the level of capital accumulation, the exchange rate stabilization decreases wages in the target country relative to all other countries. 